\title{
THE FOUNDATIONS FOR A GENERAL \\ THEORY OF GENERAL PURPOSE \\ FINANCIAL REPORTING FOR BUSINESS
}

\section{By}

David Sutton

\begin{abstract}
A thesis submitted to the Victoria University of Wellington in fulfillment of the requirements for the degree of Master of Commerce and Administration in Accounting
\end{abstract}

Victoria University of Wellington

2009 


\begin{abstract}
Accounting standards setters have progressively moved towards decision-useful, investor-focused fair value accounting standards for general purpose financial reporting (GPFR). With some qualification, the case is made that this development is positive for accounting as a discipline. This paper develops a referent theory of accounting to contextualize standards setters' implicit direction, derived from existing research and literature. A central element in the development of this theory is the case made for 'investor-as-GPFR user'. Against this, stakeholder theory and positive accounting theory will be identified as confounding influences on the development of a general theory of accounting. The argument is for the investor, both current and potential, as the sole legitimate user of GPFR. The practical implications of the theory are considered against the prevailing debate over optimal accounting valuation method; the debate between fair value measurement and historical cost. The case is made that a number of ostensible dichotomies in accounting thought, such as between relevance and accountability, are substantially reconcilable. The mutual exclusivity often implied of accounting information relevance and accountability-cum-reliability is rejected. The development of a general theory of accounting is timely as such a referent theory is necessary to legitimize standards setting and secure accounting's place in an increasingly diverse financial information market. Inferentially, trends in the evolution of fair value standards reflect the dominant concern to meet threats to the discipline as a whole; this standard setting trend qualified in speed and degree by the narrow interests of 'constituents'.
\end{abstract}




\section{Acknowledgements}

I would like to acknowledge the assistance and suggestions of my supervisors Professor Tony van Zijl and Dr. Carolyn Cordery. I would also like to acknowledge the contributions of Emeritus Professor Roger Hopkins and Kevin Simpkins, both of the School of Accounting and Commercial Law, Victoria University of Wellington. To them, and the members of the School's Financial Accounting Interest Group, your feedback is appreciated. 


\section{Table of Contents}

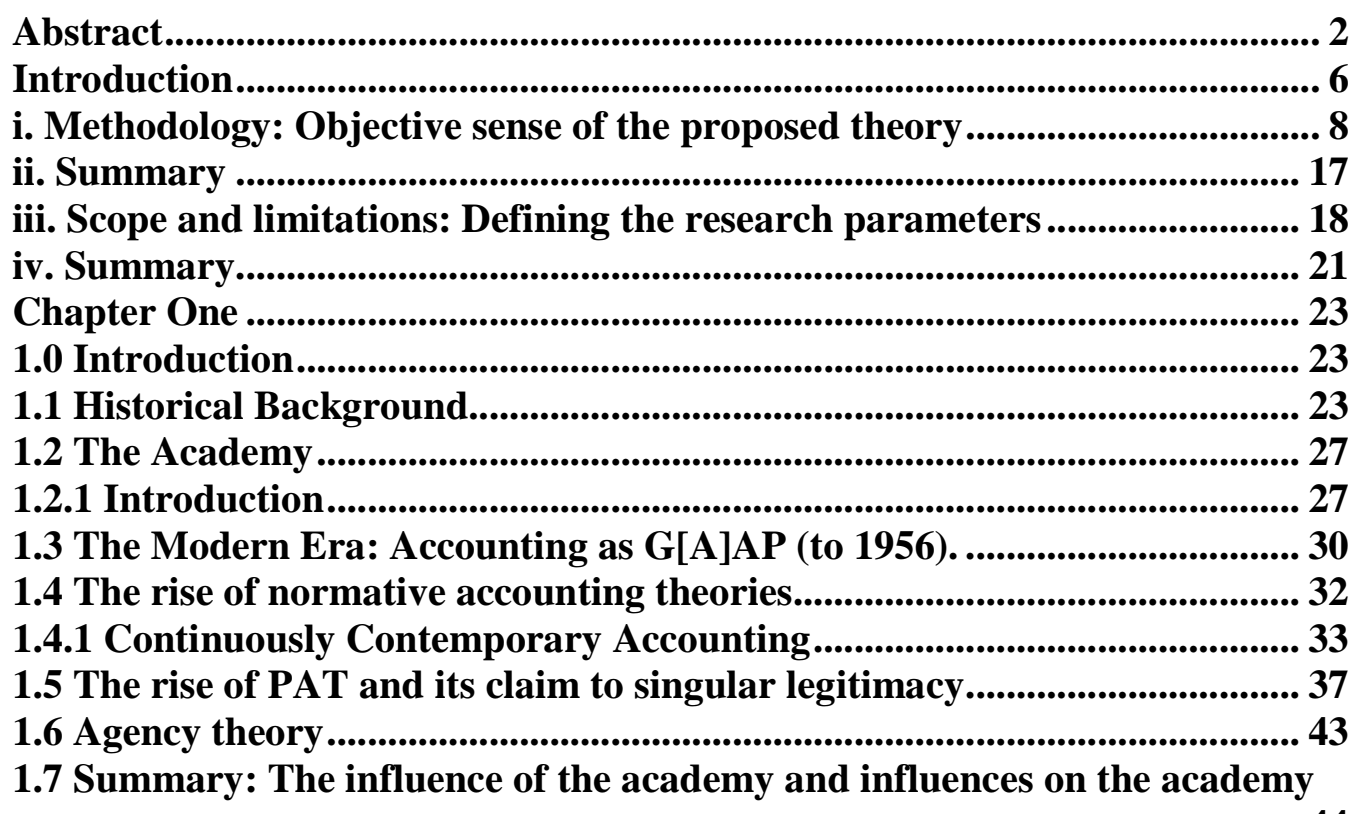

44

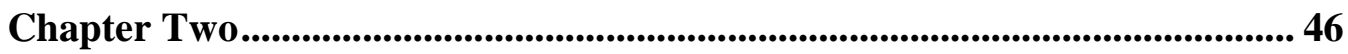

The Development of the Accounting Conceptual Frameworks......................... 46

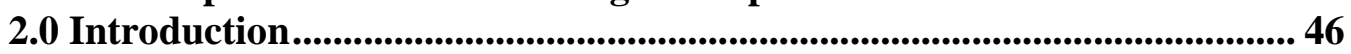

2.1 A brief history of developments in regulation and its theoretical base

(Conceptual frameworks)........................................................................................ 46

2.2 Broad trends in the development of conceptual frameworks ..................... 54

2.3 Summary of broad trends in regulation development............................... 60

2.4 Political influences on regulation.................................................................. 60

2.5 Summary ................................................................................................................ 70

Chapter Three ............................................................................................................................. 72

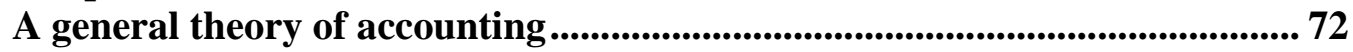

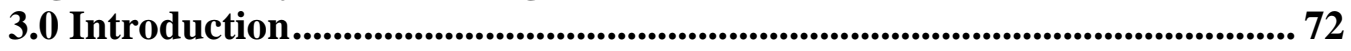

3.1 The current state of accounting theory ..................................................... 72

3.2 Foundations for a general theory of accounting ...................................... 74

3.2.1 The socio-economic environment ............................................................. 76

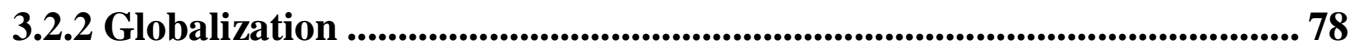

3.2.3 Summary .............................................................................................................................. 80

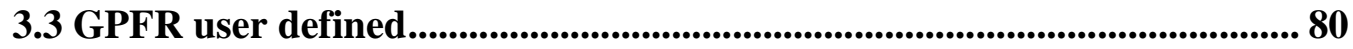

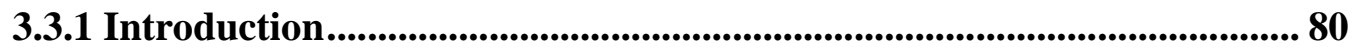

3.3.2 The Determinative Characteristics of a GPFR User ............................. 82

3.3.3 Investors as GPFR users: Current and Potential? ................................... 83

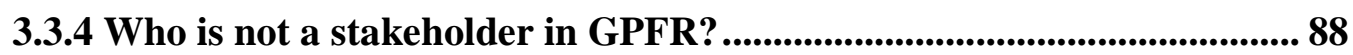

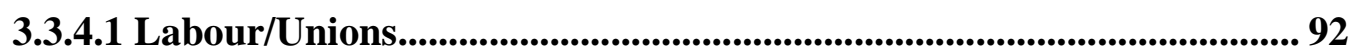

3.3.4.2 Auditor, Management, Preparer interests in GPFR ............................. 94

3.3.4.4 Lobbyists/Government/Regulators ..................................................... 97

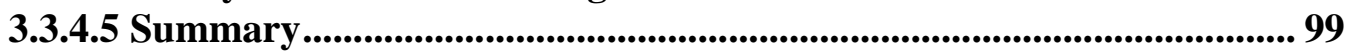

3.4.1 What is Stewardship? ......................................................................................... 100 
3.4.2 Decision-Usefulness........................................................................................ 104

3.4.3 Summary of the debate.................................................................................. 107

Chapter Four.............................................................................................................. 109

Fair value: An Implication of the Proposed Theory?....................................... 109

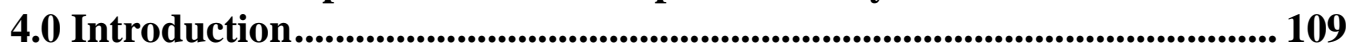

4.1 Historical cost .................................................................................................. 110

4.1.1 The case for historical cost .............................................................................. 111

4.1.2 Structural advantages of historical cost................................................... 113

4.1.3 Bases to question historical cost .................................................................. 114

4.1.4 Summary................................................................................................................ 118

4.2.1 Fair Value ....................................................................................................... 118

What is Fair Value Accounting? .......................................................................... 118

4.2.2 The case for Fair Value accounting............................................................. 120

4.2.3 The purposive approach.................................................................................. 122

4.2.4 Industry support for fair value.................................................................. 123

4.2.5 Academic/empirical support for fair value............................................... 125

4.2.6 A response to the manipulation risks of fair value ................................. 129

4.26 The misspecification of reliability: Accounting for intangibles.............. 131

4.2.7 Problems for fair value accounting ......................................................... 132

4.3.0 The counter-argument: the conceptual case for fair value ..................... 147

4.3.1 Summary ............................................................................................................ 155

Chapter Five ................................................................................................................ 156

5.0 Discussion and Conclusion ............................................................................... 156

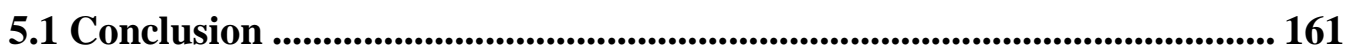

Glossary ........................................................................................................................ 162

References............................................................................................................. 163

Appendix One................................................................................................................. 195

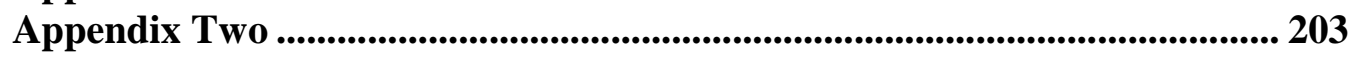

Appendix Three.......................................................................................................... 206 


\section{Introduction}

Accounting as an academic discipline is in its infancy, a fact reflected in the absence of a general theory of accounting (Higson, 2003). This lack of a referent theory has occasioned considerable sub-optimal theorizing (Inanga and Schneider, 2005; Walker, 2003; Watts and Zimmerman, 1979; Newman and Mellan, 1967; Samuels, Rickwood and Piper, 1989; Lewis and Pendrill, 2004; Zeff, 1971; Cannon, 1962; Flegm, 2000). Some part of the problem is that accounting as a discrete field of academic enquiry is nascent, where it is no more than a modern attachment to a technical specialization that is concerned with simply 'doing' without inquiry into the basis for that activity (Stamp, 1984; Cannon, 1962). We might view positivist accounting theory, in particular, as an entailment of technical, mechanistic self-perception of accounting (Whittington, 1987; Sterling, 1979; Henderson and Pierson, 1983; Mattessich, 1995). Against this view, accounting standards setters have progressively worked towards a general theory of financial accounting for GPFR. These initiatives are most clearly identifiable in their operational form, the conceptual framework (Barth, 2000; Gjesdal and Liang, 2007).

The case will be made that, notwithstanding the considerable resources committed to the research and development of a conceptually coherent framework for general purpose financial reporting, the efforts of standard setters to date have been sub-optimal, substantially due to political constraints (Horngren, 1973; Solomons, 1979; Peasnell, 1982; Miller and Redding, 1988). This has left extant concepts' statements incoherent and underspecified (Levitt, 2007). Beyond the political constraints imposed on the development of a coherent theory of accounting by partisan 'constituent' interests, this confounding influence has been compounded by the seasonal nature of the theoretical predilections of the academy, and of the conflicts between these predilections (Arai, 1970).

I make the case that, where positive accounting theory obstructs a coherent theory of accounting by its purported objectivity, it is stakeholder theory that has been, and remains, most profoundly disruptive of progress towards a general 
theory of accounting. In its purely positivist mode stakeholder theory seems to tell us no more than that numerous groups are interested in financial reports and what their interest is (Whittred, Zimmer, Taylor and Wells, 2004). In this sense it provides a simple description of an all too obvious reality. However, stakeholder theory, if it is to be considered a theory at all, must add to this literally unremarkable observation, that each interested party should have their interest satisfied by GPFR (Staunton, 1982). This normative proposition lies, variously, between underspecification, in versions of the theory advanced by Freeman (1984), Freeman, Hicks and Parner (2004), Benston (1982), Stamp (1980), Owen, Swift and Hunt (2001), Tricker (1996), Renman (1968) and Steadman and Green (1997) and the pursuit of an ulterior agenda by Tinker (1980) and Gray, Owens and Maunder (1987). ${ }^{1}$ In the first instance we are provided no means to weigh the competing interests and their information demands. Moreover, no mechanism is offered to arbitrate between conflicting information needs (Jensen, 2001; Stittle, 2003). Higson (2003, p.28) observes that:

"If standards are produced on the basis of compromise between contending views, it should be remembered that advances in knowledge seldom come about on the basis of democracy."

Notwithstanding the unsuitability of stakeholder theory as applied to GPFR the theory remains influential on standard setters and their operative conceptual frameworks.

\footnotetext{
${ }^{1}$ The distinction I draw here between stakeholder theorists is essentially a matter of degree. General or tacit allowances of diverse users are vague in the described sense of under-specification of responsibilities to particular stakeholders. Extremist stakeholder theory proponents make active attempts to obfuscate the particular claims of primary stakeholders. This is in evidence in Tinker's (1980) thought and that of Gray, et al $(1987 ; 1988)$. Tinker tells us that corporations owe society for the demands they place on society for necessary resources. If this is not an argument restricted exclusively to externalities it is unclear how the price the corporation pays in the marketplace for resources consumed fails to discharge this obligation. If it is an argument based on the benefit to corporations of collectively funded goods, such as education and law enforcement, then it is, presumably, an argument for taxation. If the argument is nothing more than that society is a precondition for socialized capital then it is true but trivial. I suspect the argument is significantly rhetorical in the sense that it implies corporations are getting more than they pay for which, from an empirical perspective, is, at best, overdetermined. This view may associate profit per se with profiteering.
} 
By means of a logical analysis of existing literature this discussion will deduce a coherent general theory of accounting. ${ }^{2}$ Hendriksen (1970, p.1) describes a theory as:

"A coherent set of hypothetical, conceptual and pragmatic principles forming the general framework of reference for a field of enquiry."

This definition offered by Hendriksen encapsulates the central idea articulated by the FASB (1976). This is the objective of the proposed theory. Most directly, I will operate on financial accounting although the proposed theory can be extended equally to other areas of accounting. Chapter one addresses the history of developments in accounting theory in general. Chapter two narrows the historical focus to the particular inputs to regulation and the development of conceptual frameworks. Chapter three develops from chapters one and two to establish an internally consistent theory of accounting, describing a user of GPFR as a basis for the proposed theory (Beaver and Demski, 1974). By narrowing GPFR user to investors, as the sole legitimate GPFR user, with supporting arguments for this limitation, it is possible to move closer to a coherent theory (Levitt, 2007; Brown, 2005). Chapter four investigates the relation between the proposed theory and financial accounting valuation bases. In particular, the debate between fair value proponents and historical cost advocates will be interrogated against the implications of the expounded theory.

\section{i. Methodology: Objective sense of the proposed theory}

In developing a normative theory of accounting there is a need to establish a minimum descriptive foundation of the world in which such a normative imperative applies. Where unspecified axioms have considerable precedent in academic accounting of the critical theoretical variety, it is not what I intend

\footnotetext{
2 The basis for this approach has support from Higson (2003); Chambers (1955); Abdel-Khalik and Ajinka (1979); Hendriksen (1982), Henderson and Pierson (1983), and Staubus (1999), amongst others.
} 
here. ${ }^{3}$ I do not intend to posit a prescription of how economies should operate. In this sense the proposal is for a normative general theory of accounting that operates on the organization of economic systems as currently instantiated. This entails the stipulation of capitalism or, more precisely, it is defined by the essential nature of the private corporation in the mixed economy. Where critical accounting theory implicitly or explicitly may challenge the private company and profit per se it is the purpose here to contextualize the proposed theory against socialized private capital (the Corporation) as an objective identity. This follows the lead of Moonitz (1961) and Sprouse and Moonitz (1962), whose basic propositions were influential on the Trueblood Report (1973) and subsequent reports produced by the AICPA and FASB.

From this base it follows that the corporation must be defined. It is identifiable as a discrete legal entity established to aggregate capital contributions to be applied to a singular objective (Enthoven, 1973; Clarke and Dean, 1993; Giroux, 1999). This objective may have myriad components, operate in multifarious businesses, and periodically prioritise particular methods for achieving its objective, such as increasing profile, sales, profits or reputation, but, always, the corporation seeks to maximize risk-adjusted returns to investors as its objective (Salvary, 1979). It must do this or it would be uncompetitive in the market for investment funds. In simple, if purist terms, the corporation whose objective function is not to maximize risk-adjusted returns to the providers of capital simply does not exist; it never attracted the support of investors (Jensen, 2001).

With the essence of the corporation established, we must now turn to consider the function of financial accounting in relation to the described object world. In light of the preceding descriptive characteristics we are drawn to

\footnotetext{
${ }^{3}$ Laughlin (1987, p. 482) argues that critical theory is motivated by a desire for a "truer, freer, and more just life for all." I read this as critical theory "aims at good things and only good things. That is, it does not aim at operationalising bad things, not even occasionally or inadvertently. So: "It intends the industrious pursuit of positive outcomes (although not positivist), fully accounting for justice, virtue and decency to all people, all of the time." Naturally all of the objectives of critical theory must remain undefined as objectivity is the vice of reifying positivists.
} 
conclude the priority of the investor-as-user. Assuming the corporation we are able to infer the priority of the investor as the primary focus of financial accounting information. Its distinguishing essential characteristic is the separation of management from ownership in the rise of the corporation. What has not been established, to this point, is the singularity of the investor's status as GPFR user. In this regard stakeholder theory has been important in informing conceptual frameworks for accounting standard setting (Laughlin, 1987). I propose reconciling stakeholder theory's only coherent form, which is also its most comprehensive formulation, with the case for the investor as sole GPFR user.

The reconciliation of stakeholder theory with contemporary developments in standard setters' conceptual frameworks' interpretation of GPFR users as investors involves an inquiry into the foundations of the social contract (Staubus, 1961). Further, it dictates investigating the nature of the dependency of the corporation on society. From this base it is necessary to examine the corporation's duties to society as logical inferences from the nature of the described relationship. It is also necessary to consider the mechanisms that would best discharge those obligations.

The allowance that society is a precondition for socialized capital does not entail any necessary obligation (Friedman, 1985; Brown, 2005). It makes no obvious sense to argue from a precondition to an obligation in terms of the corporation, as do Gray, et al (1987). If a company has an obligation to society it must logically consist in one of three categories:

1. Negative externalities: Essentially this situation is where the company is not paying for the full cost of its impact on society (Mobley, 1970).

2. Monopoly/monopsonistic power: Again, the company is essentially not paying its way by dint of the extraction of economic rents from other members of society due to its market power. Ideally, this would find a more consistent, even response in preventative/punitive regulation.

3. Licensing fee: This includes paying taxes and obeying laws. Taxes are justified on the grounds that the company is a direct and indirect 
beneficiary of numerous public goods, such as law enforcement and education (Salvary, 1979).

Regardless of whether we allow implicit/explicit obligations on corporations to society in toto, nothing of this issue importantly informs the view that such a duty could or should be discharged at the level of GPFR (Bromwich, 1992). Simply, the inference from stakeholder theory to a more extensive GPFR user definition than investor is a non-sequitur.

Beaver (1981) describes the multiple functions of financial reports. They are involved in the redistribution of wealth, they (inter alia) dictate resource allocation, and they eliminate or reduce the ability of companies to signal the market by accounting choice. The implicit focus of stakeholder theory in relation to GPFR is dispersing resource allocation. It is not very obvious why stakeholder theorists would want a competitive market at the point of GPFR user determination where this could only aggravate the subjectivity of reported accounting numbers. Deductively, the only plausible explanation is a virulent anti-capitalism that prefers any corruption of the relationship between capital and its claim to profits. Moreover, such a 'scramble' for user status and GPFR information determination would only serve, albeit perhaps wider, sectional interests, it would not advance broader societal interests in, for example, the profitability of a company as the basis for inference to the appropriate level to tax the corporation. (This is discussed further in chapter three).

Having established the investor as user, it is here that we turn to questions of stewardship, accountability and prospectivity of (and for) the entrusted aggregated capitals. Historically, the stewardship component of accountability has been prioritized to the exclusion of value relevance or prospective information. The case for this truncated parameter to accountability has largely turned on the historically favoured qualitative characteristic -reliability. Recent initiatives by major standard setters to elevate relevance and comparability over reliability, subject to execution issues, arguably extend the accountability of managers to 
investors. They become accountable not only for the company's past (stewardship) but also its future (relevance), subject to qualification in relation to unforeseeable events outside of the control of the company. This suggests an important debate in accounting revolves around a false dichotomy; accountability versus decision-usefulness. Whether we prefer accountability or decisionusefulness, nothing of the investor as user offers us an independent reason to hold such a preference. I make the case that the bifurcation between accountability and decision-usefulness is a factation that more accurately describes the dichotomy between stewardship and predictive value and that, in creating polar opposition of decision-usefulness with accountability, an attempt is made to oblige proponents of decision-usefulness to discount the account function of GPFR.

The proposed general theory of accounting is normative and, necessarily, positive. The distinction between positive and normative theories is an uncertain thing (Whittington, 1987; Arrington and Francis, 1989). Always in theory, we must grant that at some, ideally rude level, there is an (some) assumption(s) (Stanley, 1968; Abdel-Khalik and Ajinka, 1979). It is the extent to which the axioms of a theory, the sui generis components, are rudimentary that determine its veracity. Against this point, it is a risk that putative theories may say too little to be more than descriptions. It is possible to see this risk realized in new accounting history's elevation of particularism in history. An example of this is Stephen Walker's (2004) article on the genesis of the accounting profession in the United Kingdom. We are told of many particular causes for the professionalisation of accounting, including specific individuals' motivation and agency (Walker, 2004). Such 'theory' simply describes its subject and, even then, in merely, unavoidably, sketched terms. Of more direct relevance is positivist stakeholder theory. This tells us many groups with an implicit/explicit stake in the corporation are interested in it and what they do with the information they require. This appears to be nothing more than an uncontroversial description. Inference from interest in a company to a claim on that company elevates the liability of corporations to sectional demands without providing any clear reason for this sanction. 
It follows from this that it is unproductive to describe a theory as positive or normative, except as a short-hand for the magnitude of the specific theory's reliance on assumptions about the world (Arrington and Francis, 1989). Even the value relevance literature of the 'positivist' mode assumes inter alia market efficiency. It seems that a rather fine distinction between a moral descriptivism and an overtly phenomenological descriptivism is the basis for the positive/normative bifurcation. In this light then, the proposed theory is motivated by dual intentions of creation and discovery. Its axioms must necessarily be assessed by 'taste-test', although no attempt at obfuscation of these will be made. The 'discovery' component of the theory can be evaluated for coherence and logical structure. What is proposed is a theory fully consistent with sociallyconstructed objects that operates to optimize the coherence of existing social entities. I do not propose retreating into un/underspecified moral positivism, as critical theorists are apt to do. This is the sense in which the proposed theory contains an objective dimension.

The described logical coherence anticipates an argument that, at its core, will be syntactical. Stipulating capitalism, I proceed to describe the operation of the corporation as an element of that system. Deduction and abduction from this base inform the inference of investor as GPFR user. Implications of the proposed theory must, necessarily, be assessed, at least in part, by induction as the interests of the investor are not logically derivable in a complete sense. We need to be cognizant of the possibility of variability in human behavioral responses to any particular presentation of accounting information (Lee and Tweedie, 1990). In relation to this empirical research, the market is well met by positivist accounting research.

What is envisaged from the preceding discussion is that a general theory of accounting will be enunciated in terms that broadly support the direction being taken by the major accounting standards setters, the FASB and IASB. On the basis of the proposed theory these standards setters' movement towards fair value, 
prioritizing the investor and decision-usefulness, may acquire a coherent conceptual foundation (Stanton 1997; Johnson, 2005; Hague, Jones, Milburn and Walsh, 2006; Young, 2006). This has been somewhat underspecified (or implicit) in the development of concepts' statements (Whittington, 2008). I do not intend much more here than a coherent rationale for existing developments in financial accounting. Some minor adjustments are proposed and it is useful to render explicit the theoretical precepts underlying developments in conceptual frameworks that can only be inferred at this point. The proposal is for pure theory as a departure from the sub-optimal trajectory of current conceptual framework formation (Wells, 2003; Walker, 2003; Dean and Clark, 2003). This position acknowledges the constraints acting on operationalization and yet it offers the prospect of establishing an unselfconsciously rarefied theoretical base to accounting. The function of such a development may lie in the need to qualify departures from the 'ideal' state, announced against the motivations for that departure. This issue is particularly instructive of the inferred motivation behind standards setters' dilution of the qualitative characteristic, reliability, concomitant with the elevation of representational faithfulness.

The method of enquiry employed here follows that proposed by Moonitz (1961) and Sprouse and Moonitz (1962). This discussion describes the general social, economic and political environment in which accounting operates, defining accounting's objective function as a derivation from that environment. The approach operates in the manner proposed by Hendriksen (1982) (as cited in the introduction) and Chambers (1955), by advancing a theoretically coherent foundation for the development of accounting standards. In contrast to the general historical approach to accounting theory, the articulation of existing practice, the approach proposed here is derived from primitive axioms. This acknowledges and adjusts for the limitations of atheoretical, ex posteriori empirically-determined 'theory' promulgation (Whittington, 1985). These limitations include the ad hoc nature of the development of practice and the inability of such an approach to address new problems and situations arising out of a dynamic business environment. 
Dominant trends in the development of Conceptual Frameworks have broadly followed Sprouse's (1978, p. 70) view, originally articulated with Moonitz (1962) in approximate terms, that:

"A conceptual framework has been described as a "constitution", a coherent system of interrelated objectives and fundamentals that can lead to consistent standards and that prescribes the nature, function, and limits of financial accounting and financial statements."

This view, that accounting needs to serve the objectives of its economic environment in a consistent manner, was largely rejected officially at the time of its publication. The Accounting Principles Board (APB) felt that it moved too far from Generally Agreed Accounting Practice (GAAP). They were also concerned that an overarching set of principles guiding accounting standards would conflict with GAAP, at the time an amalgam of elements drawing on, and prioritizing, diverse, underdeveloped, sub-theoretical parts. ${ }^{4}$ Notably, the timorous nature of the APB in developing and promulgating standards was influential in its demise. Subsequent to this, as reflected in the Trueblood Committee Report (1973) (and subsequent reports, official pronouncements, and the FASB-developed Conceptual Framework (1974-1985), the view gained traction. Developments in conceptual frameworks and standards have demonstrated a marked and progressive trend towards coherence, notwithstanding historical cost's persistence in what is generously styled 'mixed attribute accounting'.

The primitive assumptions or axioms do not offer any view of the existing environment. They simply operate from a description of that environment, inferring optimal accounting for that environment. This may appear in conflict with the basic case made herein against historical practices of determining standards from empirical evidence of existing practice. This ostensible theoretical

\footnotetext{
${ }^{4}$ The objection that a coherent theory would conflict with GAAP, which was internally conflicted, seems axiomatic. It is circular in the sense that it asserts that something coherent will conflict with something that is incoherent. Where there is an undeniable truth to this assertion, it tends to leave one with the sense of no substantial increment to their knowledge.
} 
inconsistency, that is, deriving 'an ought from an is', is obviated by the qualitative nature of the assumed descriptive characteristic. We can allow that capitalism, the substantially private control of productive resources, is a socially constructed state of grace yet still acknowledge from its base there are certain objective implications. Within the capitalist scheme markets are the principal mechanism for exchange, for example. There is no particular obligation to provide independent arguments for private capital. We do not need to justify capitalism before expounding its technical elements. Thus, the 'is' is the existing environment in the generic sense described by Sprouse and Moonitz (1962). It consists in free labour (non-slave labour), market-based exchange and the predominance of private capital in productive resources (Sprouse and Moonitz, 1962). Allowing that environment, without preferring it or arguing for it, objective identities and relations can be extracted from it.

The basic intuition here is that any objection to the described system as a whole would be optimally targeted at the system in contention and not some apparatus of it, unless the apparatus is the singular or primary source of objection. The idea that it is productive to corrupt or disrupt a system of social and economic organization, a mode of production, through indirect means presupposes some unspecified teleology justifies any kind of vilification of that system. Beyond the dishonesty of such an approach, it appears arrogant and susceptible to the challenge that it relies on ad hominem fallacy. Simply, an objection to GPFR as the foundation for an attack on capitalism is a circuitous route to take. In this sense, the use of stakeholder theory by critical theorists is viewed here as a device, conscripted for the harm it may inflict on the operation of markets and private capitals. There is no obvious, theoretically coherent commitment to stakeholder theory exhibited by its proponents.

The proposed theory, as described, will be primarily an a priori deductive argument, operating from rudimentary assumptions about the world but 
substantially informed by a description of that world. ${ }^{5}$ From its sui generis base, it develops with an eye to the creation of a coherent, consistent whole. This foundation will be augmented (in chapter Four) by an examination of its implications in terms of the accounting valuation debate. This aspect of the discussion continues in the deductive mode but this is augmented by reference to existing empirical work. If the theory is to be instructive it must have practical, testable consequences. To a considerable degree empiricism in support of the theory must be promissory, absent its implementation. The utility of empirical work is it offers, at the minimum, the prospect of falsifiability for the theory. Specifically, falsification in the present context consists in somewhat limited speculative counterfactualism from the theory's axioms to its probabilistic implications. Where it must be granted that this is 'weak-form' falsifiability, the alternative is that no innovation or development is ever justified because it is unproved.

\section{ii. Summary}

Methodologically, a priori theorizing is the approach preferred here for the development of a normative general theory of accounting. It is necessary to look beyond the existing practice of accounting to develop a coherent theory of accounting. It is, at least, highly improbable that accounting, as practiced, could inform a theoretically coherent body of knowledge. Far more probable is the view that accounting practice has evolved from a political/cultural foundation, with conflicting priorities accommodated in an ad hoc and pragmatic manner. Moreover, it cannot, by the nature of its development, offer a referent base from which to evaluate and address new, evolving issues. For this reason the logical coherence of a theory drawn from elemental postulates is indicated, presenting the case for a deductive theory of accounting. This does not obviate the need to test the referent theory ex post, that is, empirically, against the self-described characteristics of its environment. This will involve an assessment of its success in satisfying its articulated objectives, including its targeted users and its

\footnotetext{
${ }^{5}$ Support for this approach comes from Moonitz (1961); Sprouse and Moonitz (1962); Staubus (1999); and Loftus (2003).
} 
contribution to optimal market equilibria for securities prices as the objective function of accounting. The motivation behind this approach follows Kinney (2001), Albrecht and Sach (2000), and Belkaoui (1989), asserting the need to reestablish accounting's position in the market for financial information

\section{iii. Scope and limitations: Defining the research parameters}

Accounting theory, as exemplified by the development of conceptual frameworks, has been frustrated in its progress by the too-extensive scope of its objectives. ${ }^{6}$ This fact is tacitly acknowledged by standards setters who have confined their focus to profit-orientated entities. Where standards setters may allow that optimal accounting standards would extend to cover the public sector and not-for-profit entities, practical constraints have informed the decision to focus exclusively on profit-orientated entities. Differences between these entities support the view that public and not-for-profit sector financial reports have different and more diverse constituencies (Herz, 2006; Simpkins, 2006; GASB, 2002 ; 2004). Furthermore, the objectives of these sectors are different to those of profit-orientated entities (Czerawski, et al, 2008; GASB, u.d.). It follows from this that a single set of multi-sectoral standards would be harder, if not impossible, to achieve, necessarily incorporate more diverse treatments and, by, these means, frustrate compatible international accounting standards. I follow this narrow focus for IASs in the development of a general theory of private sector financial accounting and reporting.

It is further observable that standards setters are not committed to creating a set of compatible, coherent global standards for profit-orientated entities as an ultimate teleology. It is their intention to tackle this area of GPFR first with a view to extending from the fundamentals developed in relation to profit-orientated entities to incorporate standards applicable to public and not-for-profit sectors (FASB, 2008). The narrower focus is anticipated as a first step. It is the product of

\footnotetext{
${ }^{6}$ This forms an independent, pragmatic reason to prefer a narrow definition of GPFR user but it is not the central basis for the proposed general theory of accounting. To employ this as an argument, in the context of a deductive theory, would be misguided. However, it is not so clearly obvious that it is wholly useless to support the theory ex post.
} 
pragmatic considerations, accommodating the fact that the development of universal accounting standards would be necessarily glacially slow, having to accommodate a substantially more complex array of variables. Tentatively, it is (or may be) plausible to anticipate extension of the proposed theory by recharacterising 'user' as 'beneficiary'. This has more generic implications and separates GPFR from conceptual determination about the unargued for base of whom it is that uses such accounting information. An implication of this is that a conceptual foundation to the legitimacy of user use will be required. Use is seen, in this scheme, as no claim to rights at all.

The view that sectoral accounting standards must necessarily develop along separate, at least bifurcated trajectories, for profit-orientated entities and government and not-for-profit sectors, is a controversial one. One view is that optimal accounting standards need to accommodate all sectors (Walker, 2003; Wells, 2003). Against this view, Mack and Ryan (2004) argue for the separate development of standards for profit-orientated entities as private sector principles are not applicable to public sector reporting. Instead, accountability (stewardship in this case) for the management of public funds is more important for the public sector. Hopwood (1984) also rejects the value of SAC-2, which elevates decisionusefulness, as inapplicable to the public sector. The Governmental Accounting Standards' Board (GASB) argues that, in contrast to the FASB SAC-1, investors and creditors are not the primary target of public sector financial reporting (Ewer, 2007). Society in general is the user of public sector accounting information (Ewer, 2007).

In its white paper Why Governmental Accounting and Financial Reporting is-and Should Be-Different (2007), the GASB detail the distinction between public and private sectors. The public sector has a greater propensity to longevity, a wider range of stakeholders and different revenue generating processes. Similarly, the not-for-profit sector cannot be meaningfully represented in standards produced for profit-orientated entities as assets' revenue-generating abilities are not instructive of those assets role in fulfilling the goals of the 
organization (Cordery and Baskeville, 2005). This concern is expanded by Simpkins (quoted in Sutcliffe, 2007), who argues that the pervasive cash-flow focus of IASB and FASB financial reporting objectives is an insufficient basis for the not-for-profit sector. A wider range of users need to be accommodated in notfor-profit sector reporting. Principal concerns of third sector 'financial' reporting (and accounting) need to focus on stewardship and progress towards goals.

A further limitation to the discussion is that although the proposal is for a general theory of accounting, I will not be assessing the theory against the full range of its implications. This is a necessary concession to logistical constraints. Where some of the proposed theory's implications are undemanding to infer, I will not expound those implications, or the reasons for those implications, in relation to, for example, the entity/proprietorship basis to accounting standards. Similarly, the discussion will not address the merits of consolidation of 'controlled' entities into 'parent' company accounts. The theory purports generality so it must have pervasive implications to satisfy this purport. In this sense, although the topicality and central importance of measurement bases recommends inquiry into this area, it does constitute a pragmatically-imposed constraint on the proposed thesis.

Finally, and purely as a pragmatic device, the discussion switches between the IASB and FASB in its consideration of Conceptual Frameworks and regulation development, as though they were synonymous. In a significant, historical sense this is a misrepresentation. It is only subsequent to the 2002 Norwalk agreement (Memorandum of Understanding, AICPA, 2008) and more particularly the establishment of the IASB/FASB (2005) joint project that the respective Conceptual Frameworks became functionally identical (Whittington, 2007a). In 2006 the FASB and IASB published the first draft chapters of their joint Conceptual Framework (IASB, 2006a). The greater resource base of the FASB, and its longer heredity than the IASB, tends to have supported the FASB Conceptual Framework as a starting point for the development of international accounting standards (Whittington, 2007b). What may be said now is that the 
treatment of the two boards as functionally identical captures the essence of the situation. This should be qualified to the extent that IFRS's appear to have moved ahead of SFAS's, reflected inter alia in the more extensive IFRS application of fair value to non-financial assets (Whittington, 2007b) ${ }^{7}$. This situation is in contrast to concerns raised that the IASB may experience inertia, constrained by the need for agreement between diverse national representatives (Sunder, 2007; Dye and Sunder, 2001).

\section{iv. Summary}

The discussion advances a coherent, substantially a priori, deductive theory augmented by reference to valuation methods. It respects the self-imposed parameters of major standards setters, confining its consideration to profitorientated entities. Further limitations include the inability to falsify the theory due to the general unavailability of observation sets relevant to an innovative theory. Part of this is due to the uncertainty of behavioral responses to particular information. Behaviorism could confound the operationalisation of the theory or, allowing a purest view of market efficiency, render the theory moot in terms of implications. Moreover, doubt must always attend the application of evidence from market efficiency of accounting theory and standards due to the dual hypothesis problem. That is, we can never be entirely confident of the substance of market efficiency without a corresponding confidence in the nominated model of risk assessment. Absent this, market efficiency becomes a tautology. The proposition of normative accounting standards presupposes the utility of such accounting standards and concomitant financial reporting to enhance the

As at 2005 minor differences existed between (FASB) SFAS-157, Fair Value Measurement, paragraph 5, and the IASB fair value definition. These included:

FASB

1. Explicit exit price specification

2. Reference to transactions between market participants as the basis for fair values

3. Liabilities measured at transfer value
$\underline{\mathrm{IASB}}$

1. No explicit specification of exit or entry price

2. Transactions between Knowledgeable parties in an arms length transaction

3. Liabilities at settlement value 
(Source: IASB, 2007e).

efficiency of substantially efficient markets if it aims at decision-usefulness. If market efficiency is stipulated then all fair value measurement offers financial accounting is a more robust accountability function over historical cost (qualified by the potential of third-level fair valuations, if poorly specified, to confound the 'account' function). These limitations place the principal onus on deduction and counterfactual inference to establish the veracity of the theory. 


\section{Chapter One}

\section{Developments in Accounting Theory: Its relation to Users of financial accounting information.}

\subsection{Introduction}

This chapter charts the development of theoretical accounting by the academy. Such developments fall into three dominant eras. The briefest of these, the normative era spanning 1955 to 1970 , stands as the only exception to theoretical approaches generally confounding normative theory development. This chapter serves two basic purposes. It identifies an important cause in the failure to identify a general theory of accounting and challenges the singular legitimacy of accounting positivism.

\subsection{Historical Background}

Accounting evolved as a technology for recording financial transactions. From its historical foundations it has become central to the development of socialized capital, bridging the information gap between owners of capital and its managers. This basic characterization, the agency relationship, was generally unquestioned until the 1960s (Arai, 1970). General Purpose Financial Reports were assumed to target equity investors and creditors (Gray, et al, 1987). The rise of stakeholder theory and subsequent development of critical accounting theory challenged traditional GPFR user assumptions, as these theories argued for an extension to GPFR user status. These developments contributed to factors confounding the development of a general theory of accounting. Subsequent and parallel to these developments, following the period 1956-1970, in which normative accounting theories rose to the fore, Positive Accounting Theory emerged, rapidly assuming a dominant position in theoretical accounting research (Henderson, Pierson and Harris, 2004; Parker, 1999). The succession of theoretical approaches to accounting has created an environment in which sectarian interests have been able to enlist disparate conceptual credentials in pursuit of self-interest. The contribution of the academy, outside of the normative period, to a general theory of accounting has been almost singularly negative. The 
role of the academy in accounting theory development has forced implicit moves by standards setters towards coherence (Bradbury's (2008) inference from Whittington, 2008).

GPFR historically evolved with the socialization of capital to meet the information needs of investors due to their separation from management in the rise of the corporation. The industrial revolution led to the rise of factories in contrast to the preceding period in which cottage industry and agriculture had predominated. Business scale increased from the pre-industrial, agrarian era, resulting in scale increases in business' capital requirements. The priority accorded stewardship is an anachronism dating to the feudal era (Kam, 1986; Most, 1982). Although the first joint stock company was formed in the UK in 1553, with the first modern corporation dating to 1600 in the form of the East India Company, prior to 1775 commercial accounts were generally kept for an owners own use, with no external user to consider. The industrial revolution, dating to about this time, separated financing from management (Most, 1982; Enthoven, 1973). This development entailed a demand for audited financial reports. From 1800 to 1900 corporations in the United Kingdom increased from a few hundred to tens of thousands (Most, 1982). Financial reporting in the UK, as the progenitor of the corporation in its approximately modern form and as antecedent of the progressive development of financial reporting for the corporate entity, was substantially unregulated in the nineteenth century (Watts and Zimmerman, 1979). Subsequent 'watershed' developments in accounting theory and regulation have been, and continue to be, responsive to the prevailing socioeconomic environment (Salvary, 1979), as will be detailed below.

Key developments in theory and practice have generally been reactive to negative economic developments (Dean and Clarke, 2003). One instance was the rail company boom in the US, of the period 1830, until its successive collapses in the 1870s, 1880s and 1890s, in which individual companies attempted to support inflated share prices by paying dividends out of capital (Cain and Hughes, 2006; Fogel, 1970). This practice was, at least in part, instrumental in aggravating the 
financial market disruption that accompanied the bursting of the rail company share price bubble (Giroux, 1999). Later, in the 1930s, the first attempts to develop a coherent theory of accounting were made as a response to the 1929 stock market collapse and subsequent Great (economic) Depression (May and Sundem, 1976). This influence led to an increasing recognition, reflected in regulation, of the need to augment Balance Sheet financial statement reporting with an income statement (Hendriksen, 1982). It also resulted in the 1933 Securities Act and the Securities Exchange Commission Act (1934), establishing the Securities Exchange Commission (SEC), with responsibility for the oversight of financial accounting and reporting (Bush, 2005; Giroux, 1999). The Great Depression lent impetus to the project for the development of a conceptual framework for accounting. The widespread social harm caused by the Great Depression established a key foundation for society's interest in financial reporting. This entailed regulation and the development of $A$ Tentative Statement of Accounting Principles Underlying Corporate Financial Reports in 1936, published by the American Accounting Association (Wolk, Dodd, and Rozycki, 2008).

A sporadic succession of attempts to formulate and articulate a general theory of accounting occurred between the 1936 AAA publication and the formation of the FASB in 1973. Attempts in the intervening period were substantially without immediate influence on the broad direction of accounting, until theoretical developments dating from Moonitz (1961) culminated in the Trueblood Committee report in 1973. Much of the theorizing of this period too obstinately held to the view of its function as an articulation and structuration of existing practice. ${ }^{8}$ Departures from this ill-defined atheoretical approach included the AICPA Accounting Research Report No. 1 The Basic Postulates of Accounting by Moonitz (1961) and Accounting Research Report (AICPA) No. 3 A Tentative Set of Broad Accounting Principles for Business Enterprises, by Sprouse and Moonitz (1962). It is notable that these attempts to develop a general

\footnotetext{
${ }^{8}$ It is observable that Chambers' Continuously Contemporary Accounting (COCOA) was not culpable of the charge that it was timorous in this regard. His theory will be discussed later in this chapter as an example of theory development in the 'normative era' of academic accounting.
} 
theory of accounting encountered resistance from the Accounting Principles Board (APB) (AICPA, 1962). Their basic objection was that such an approach would come into severe conflict with existing accounting practice. The generally descriptive, traditional empirical approach to accounting by the APB was important in its demise and replacement by the FASB, from 1973. The FASB was established on the basis of the Wheat Committee Report (1971) and proceeded to act on recommendations in the AICPA Trueblood Committee Report (1973) to establish a conceptual framework from 1974.

The underlying socio-economic environment has had an important impact on developments in accounting theory and regulation (Enthoven, 1973). The Penn State collapse sharpened the focus on the limits to established accounting standards and practice. Elevated inflation from the early 1970s through to the early 1980s played an important role in challenging established accounting practice. In particular, the perception of the progressively declining relevance of historical cost accounting caused the growth in rival accounting measurement bases (Mattessich, 1995). Inflation receded in the early 1980s along with the threat to historical cost accounting as a measurement base. However, current cost accounting variants had rooted themselves as alternative measurement bases. Subsequent to this the Savings and Loan crisis of the 1980s further threatened historical cost, leading to the gradual, progressive trend towards fair value accounting measurement by standards setters. The Savings and Loan (S\&L) crisis had been aggravated by the transaction basis of historical cost accounting. Companies were able to select performing investments for realization, presenting an unduly positive view of companies' financial performance and position. Further, no write-down in retained assets' value was required under historical cost. ${ }^{9}$ Possibly the most recent major ruction influencing accounting regulation has been the Enron collapse (2000) (and other significant collapses subsequent to this), resulting in public funding for the FASB.

\footnotetext{
${ }^{9}$ Provision for impairment existed under historical cost measurement but to make the case that deficient practice was responsible for corrupting historical cost accounts of the period, we must conclude historical cost reliability, defined around the verifiability of past transactions, is compromised. That the sense of reliability historical cost promotes is dubious does nothing to challenge its centrality in the claim of historical cost proponents to conceptual superiority.
} 
Support for fair value was augmented by the 1994 release of the AICPA Jenkins Report. More so than in preceding reports, the case was made for the assumption of broadly efficient markets. This was undoubtedly due to the development of finance and economic research establishing a general acceptance of the broad efficiency of markets subsequent to its formal presentation by Fama in 1969. By the time of Jenkins Report the Efficient Market Hypothesis (EMH) had survived challenges of the late 1970s and 1980s and was essentially capital markets' orthodoxy. Although Jenkins remained at least tacitly committed to multifarious GPFR users, the clear commitment to capital market efficiency lent momentum to the promotion of fair value accounting measurement and the primacy of the investor as GPFR user. In the period subsequent to this, successive reports, exposure drafts and standards have increased the prominence of fair value. This gives rise to reason to believe that full fair value is the ultimate teleology that major standards setters are targeting. A parallel development has been the progressive narrowing of the GPFR user classification. As of 2008 the IASB interprets the primacy of GPFR user as investor, both current and potential, whereas the FASB still includes creditors in its primary-user definition as well as investors. Later, I make the case that the continued inclusion of creditors is unhelpful for coherent GPFR theory development and that it is unjustified.

\subsection{The Academy}

\subsubsection{Introduction}

Academic accounting is a relatively new phenomenon. Notwithstanding its youth and theoretical underdevelopment, or perhaps because of it, academic accounting has been influential in frustrating the development of a coherent theory of accounting (Inanga and Schneider, 2005; Walker, 2003). In the modern era the academy has attempted to operate on accounting from diverse, unrelated and often conflicting atheoretical or sub-theoretical perspectives (Higson, 2003). Three distinct, if not entirely temporally discrete, predominant theoretical approaches have been adopted over the twentieth and early twenty first centuries. The first was the substantially atheoretical derivation of theory from practice. The 
intermediate period was predominated by normative accounting theories and spanned (approximately) from 1956 to 1970 (Parker, 1999; Arai, 1970). From 1970 to the current time Positive Accounting Theory (PAT) has prevailed (Henderson, et al, 2004). The succession of dominant theoretical veins, combined with the definitional aversion of the first and last approaches to the development of a general theory of accounting has confounded such a development. Further, tensions between competing theories within each era have prevented the development of a coherent general theory of accounting. Notwithstanding this, standards setters have made progress towards a coherent conceptual framework, although, without the explicit theoretical articulation that may have obtained from a less politicized environment.

I eschew a discussion of the stewardship (conservatism, historical cost) versus decision-usefulness (relevance, fair value) debate in relation to the academy. In broad terms the academy has persisted with stewardship until recent times, with none of the mainstream eras systemically favouring a change in this state. This is less obviously true of the normative era but it remains so in the current (PAT) period. On this basis it seems salient to consider stewardship/decision-usefulness in terms of regulation and its theoretical information as it demonstrates a clear trend from stewardship to decisionusefulness.

The relationship of theory as developed by the academy and the broader environment in which it exists, including the parallel development of regulation of accounting, is uncertain but it is not unitary. The broad socio-economic environment impacts both academia and regulation, creating an endogenous connection between academic theory and regulation, relative to each other and the prevailing environment (Schroeder, et al, 1991). It is worth noting that nothing about the successive mainstream academic theories offers unequivocal support for a stewardship or decision-usefulness preference as the paramount objective of GPFR. In general terms these rival objective functions of accounting seem more directly linked to the wider environment. Nowhere is this more clearly in 
evidence than between PAT theorists Watts and Barth. Neither can say we ought to prefer stewardship/conservatism or decision-usefulness/fair value yet it is possible to derive the conclusion that Watts favours conservatism, historical cost and stewardship where Barth (2000) feels we ought to aim at decision usefulness and fair value. They seem to want to couch their inherently normative positions behind in putatively objective terms.

In Watts' (1977) case the objective appears to be a 'least harm' view of regulation. He argues that the market would satisfy the demand for financial information without regulation. Costs of capital, balanced against costs of information provision, would ensure that optimal information is provided to GPFR users. Given this premise it is understandable that he would want standards as remote from representational faithfulness as possible so as to avoid disrupting voluntary GPFR market operation. This is as close as regulation can come to functional non-existence whilst existing. The opportunity for the market for financial information, as a subset of the market for capital, to signal by the provision of presently regulation-specified information would, on Watts' view, qualitatively distinguish companies. They could rationally determine the optimal level of information provision, balancing costs of information production and presentation against cost of capital. In this sense Watts' argument for conservatism in accounting standards is more accurately viewed as an argument against regulation. It is not so surprising that a theorist arguing against theoretical normativity in general would object to the inherent normativity of accounting standards. Similarly, standards are not something that are under any imminent threat, much as Watts no doubt feels they ought to be, thus his objective is best achieved by accounting regulation impotence.

Conversely, Barth seems to find much to like about decision-usefulness, fair value and relevance. We are told that prescription in accounting, such as is contained in accounting standards, is not the domain of academics. Their purview is simply to describe the world. They cannot offer indications in terms of regulatory prescriptions as this requires contemplation of a complex range of 
variables that are properly the domain of regulators who must consider all permutations and their impact on society as a whole (Barth, 2000). Barth does not tell us why this larger range of variables is beyond the academy. We are not told why academic accounting cannot operate to empirically assess the value of particular regulation against the regulators' own articulated objectives. It appears it is something that only regulators can do and then, presumably, by some arcane or abstruse process that does not entail objective empirical analysis. There is no obvious reason why positivist academics cannot contribute to an assessment of accounting prescription against the articulated objectives of that prescription (regulation). What Barth (2000) seems to be saying is that by her self-defined parameters to academic accounting research, after a certain level of complexity of the variables in contemplation, her methods, requiring statistical tractability, are of no value. This then, according to Barth, precludes them from academic consideration.

Similarly, no new insights obtain from the subsidiary 'paradigms', stakeholder and critical theories, as stewardship and decision-usefulness are both generally drawn as considerations, centrally linked to the investor. Conversely, neither necessarily relate exclusively to the investor. It is reasonable to interpret indifference of these subsidiary schools to the stewardship/decision-usefulness debate. Having said this, in a quite different sense, fair value as a conclusion achieved via decision-usefulness, instantiates market prices as objective values. A general aversion of critical theorists to the market, as the centerpiece of capitalism, underwrites these academics' aversion to decision-usefulness. Inferentially then, criticalist support for stewardship and historical cost is (at least) implicitly more in the nature of an objection to fair value.

\subsection{The Modern Era: Accounting as G[A]AP (to 1956). ${ }^{10}$}

In the pre-1956 period of the twentieth century, academic accounting was largely descriptive of the practice of accounting (Chambers, 1982). This

\footnotetext{
${ }^{10}$ The distinction here is between general accounting practices as opposed to any coherence implicit in agreement. This is reflected in the aggregation of diverse, often conflicting, accounting practices that formed the basis of theory in this period.
} 
essentially narrative approach was unconcerned to interrogate its own process for rigour and coherence. This issue is alluded to by Chambers (1982), who bemoaned the lack of deliberate, systematic thinking underlying accounting theory as the articulation of practice. If it is purely utilitarian in design, then no explicit laws underpin it. Practice does, however, presuppose implicit postulates (Chambers, 1982). Plainly, only some untenably vague postulate, such as the argument from conservatism could be inducted as a theoretical commitment (Newman and Mellan, 1967). This is approximately implied empiricism. It could be articulated as a simple modus ponens, such as:

1. Existing practice has survived and evolved over a long period of time.

2. Longevity requires the usefulness and success of the surviving technology.

3. Thus: Accounting as it is, is accounting as it should be as its longevity licenses its value.

4. Thus: The sole legitimate domain of academic enquiry in accounting is to expound existing practice.

This general approach is overdetermined in a number of regards. It is not clear that longevity entails the optimality of current practice. It is not clear how a purely historical, ex posteriori approach to theory could address evolving problems in a dynamic environment (Whittington, 1985). Myriad causes may inform extant accounting, thus we cannot know whether its usefulness and success are the products of capture, (that is it may have greater or lesser service potential to particular vested interests), or some other factor confounding its objective superiority. From this, we must reject the conclusion deduced at 4 also as overdetermined. However, as previously noted, it was this approach that prevailed in the first half of the twentieth century. Paton and Littleton (1940) articulated this position, advancing the view of accounting as centrally concerned with stewardship, accrual accounting, matching and measurement in terms of historical cost (Beaver, 1981). 
There are reasons to doubt the quality of this early approach to accounting inquiry. It is only possible to very loosely infer the theoretical basis to such an approach. More than this, it is not clear that the putative theoretical base, the argument from conservatism, is particularly coherent as a relation to accounting theory. In the first instance, if existing practice is optimal, what incremental advantage is there in articulating that practice? Such practice evolved in the absence of its articulation. It is not clear how perfection could be improved upon. This objection may overstate the case in two regards. It may be that some preexisting articulation of existing practice is allowed and that current 'best practice' is optimal. We can allow these objections and still find reason to reject the guiding atheoretical intuition informing the codification of existing practice. Existing practice is the progeny of myriad, conflicting traditions. Existing accounting practice's development was ad hoc and its 'principles' existed, oftentimes, in tension with each other. How, for example, can true and fair be reconciled with a transaction-basis accounting where, but for realization, the value of an asset held by a company is almost invariably some multiple or fraction of the dated transaction price? If true and fair is not faithful representation then what other thing is it?

\subsection{The rise of normative accounting theories}

During the period of incumbency of traditional inductive empirical accounting theory, and subsequent to it, academic accounting turned to focus on normative accounting theory from around the mid-1950s (Staubus, 1961; Zeff, 1982). Approximately from 1956 to 1970 normative accounting theorists came to the fore, trying to develop a general theory of accounting (Henderson, et al, 2004). This approach operated in a prevalently deductive mode and oscillated between the true income approach (versus historical cost) and the 'user needs' approach (Whittington, 1985). Amongst academics contributing to the deductive/normative approach to accounting theory was Chambers. His proposed accounting system prioritized investor needs which he assumed would be best met by Continuously Contemporary Accounting (CoCoA). As an archetypal example 
of the internal coherence obtaining from such a theory, and the possible limitations of it, the discussion turns to consider Chambers' theory.

\subsubsection{Continuously Contemporary Accounting}

My argument for a coherent theory of accounting is similar in motivation to that of $\mathrm{CoCoA} .{ }^{11}$ The central intuition motivating CoCoA was that investors need to know the exit value of the company at any point. Underlying this view was Chambers' preference for information on firm adaptability relative to a dynamic business environment. Where the present discussion differs is in the referent basis to reporting as an issue tied to investor interest in the firm as a dynamic element of its environment. Fundamental to this position is that investors specifically exchange the adaptability of cash for the expectation of superior returns particular to the 'going concern' assumption of specific firms. The view I take is that there is no rational basis unseating the 'going concern' assumption in a general sense, without independent, firm-specific reason to do so.

CoCoA was widely questioned subsequent to its formulation and articulation. Chambers (1976) identifies a number of characterizations of the approach that challenge its operationalization. The Sandilands Committee Report (UK) (1975) raised the concern that if the dollar equivalents of a firm's assets rises faster than the index used to measure changes in the purchasing power of money, this would lead to unrealized holding gains recorded in the balance sheet. There is nothing untoward in this unless an assumption of the transaction basis of historical cost accounting is made as a non-negotiable dogma. Chambers (1976) is untroubled by this. It appears to be that the Committee was asserting that Chambers' proposal to improve on historical cost was flawed as it was not typeidentical with historical cost (or, at least, it did not use all of the same assumptions as historical cost). It is difficult to know how, or to what purpose, Chambers may have responded to such an observation.

\footnotetext{
${ }^{11}$ Some problems with CoCoA may have resulted in its failure to gain widespread support but more probably its conflict with entrenched interests was responsible for this. The theory has been more widely vilified than is justified. Chambers details the misconceptions surrounding his proposal for accounting.
} 
The Sandilands Report also observed that a problem existed with nonvendibles, that is, firm-specific (often) intangible assets. Although Chambers responded that a firm's acquisition of such assets as goodwill and research and development acts to reduce the ability of the firm to respond to short-term circumstances, and might therefore be valued at zero at the acquisition year-end, this is the least satisfactory of Chambers' responses. The exit price-basis proposed by Chambers to entity valuation strangely oscillates between excessive optimism and excessive pessimism. We can infer from the exit price basis to a liquidation basis to accounting (at least in terms of the balance sheet). By adding that liquidation is sub-optimal, given any incremental cash-generating faculty that a company has in relation to the asset over its salvage value, and further stipulating CoCoA's principal relevance where liquidation is circumstantially imposed, we must, in Chambers' scheme, infer zero valuation to firm-specific intangibles. This appears to depart from faithful representation. Conversely, exit prices, realized by dint of necessity, would place in question the conservatism (standard usage) inherent in the excess of pessimism described. We have, in effect, a salvage valuation basis, disrupting the going concern assumption without evidence to assume that the entity's viability is in doubt. In general terms such valuations would be most relevant in times of sustained market dysfunction, rendering salvage values obsolete due to the widespread need to liquidate. ${ }^{12}$

If we allow that the criticism of excessive optimism applies only to special market situations, and that we cannot normalize a system of accounting around such special cases, we must still acknowledge that this is the general circumstance of CoCoA's greatest relevance. That is, an accounting valuation-predicated on a liquidation basis will be most apposite to a period of trend decline in the economic cycle. Perhaps more importantly, notwithstanding its name CoCoA must, for practical purposes, be continually contemporary accounting. Allowing

\footnotetext{
${ }^{12}$ Essentially, CoCoA would be most relevant in a fast moving, declining market. The values it delivered as measures of firm adaptability would not be reliable indicators of realization values due to an implied assumption that realization en masse would further erode values. This condition of obsolescence would be further exacerbated by the continual nature of financial reporting against the continuous movement in markets.
} 
the logistical constraint to periodic reporting we are left with a valuation basis that is, whilst generally glum, not nearly glum enough when the circumstances occasioning its greatest relevance become generalized.

A final reason to reject Chambers $\mathrm{CoCoA}$ is that the theory aims at accounting valuation coherence and standardization yet fails to deliver it. Chambers (1976) claims that mixed attribute measurement (Net present value, value-in-use, realizable value and replacement cost, or historical cost) are replaced by a singular method. Assets particular to an entity must be valued at nil or on a salvage basis where they have a residual value. Thus we would end up with a balance sheet that reports the scrap value of a company. Essentially, this would value firm-specific intangibles at nil, firm-specific physical capital at salvage, and generic assets at market less disposal costs. Importantly, none of this is fatal to the theory only so long as the balance sheet is regarded as a minimum guarantee of value in normal market conditions. This seems too specific a set of circumstances to recommend the theory for the general purpose.

Beyond Chambers' contribution other notable academics involved in the normative period include Staubus, Sterling and Hendriksen. In Staubus' case his argument was primarily targeting decision-usefulness. The common theme in this approach to accounting theory and research is that it makes the case for an axiomatic formulation of accounting. This entails the advantage of generality which is highly economical for developing systems (Mattessich, 1955). This, Mattessich argues, brings order to the ad hoc. Against this view Dean and Clarke (2003) and Salvary (1979) argue that such an approach makes accounting a simulacrum of the thing it purports to represent. Their view is that it disrupts faithful representation and that the conceptual framework project itself is fundamentally ill-conceived. Further, they argue that the existing social, cultural, political environment in which business operates provides the necessary concepts and constraints for veridical financial reporting. On this view conceptual frameworks actually constrain coherent, useful financial accounting and reporting. 
There are some concerns that may be raised in relation to the objections to normative accounting theories by academics rejecting the idea of those theories per se. Their argument is inherently founded on an at least loose empiricism in their inference to the inefficacy of existing and past conceptual frameworks. This is not inherently problematic except that their empirical bases are politically influenced, evolving and inchoate standards of the past and (then) present. Alternatively they are the normative theories of the 1950s and 1960s which can only be challenged counterfactually (speculatively) or deductively. As in the case of Chambers theory (previously discussed), these accounting systems have not been categorically invalidated. Implicit in the preceding discussion of Chambers theory, the only substantive challenge to it is that it presupposes an objective function of the balance sheet that is not a necessary conclusion.

The second issue is that financial reports are always, and necessarily, incomplete representations of a company's operations. They cannot be comprehensive descriptions. It is the role of a normative accounting theory to establish parameters to support the maximum possible veracity of those summaries. It follows that Mattessich's (1995) view is correct that care must be taken not to impound systematic measurement, information selection, or representation bias into the nominated model. The model must provide us with a good sense of the essence of the thing it represents.

During the period in which normative accounting theory rose to the fore in academic accounting, from the 1960s until the present, a parallel, subsidiary development in academic theory gained significant influence in the form of stakeholder theory. Stakeholder theory's significance to accounting theory lay in the basis it created to underpin a diverse GPFR user definition. This influence is evident in a number of official reports including: Trueblood (AICPA, 1973), The Corporate Report (ASSC, 1975), the Stamp Report (1980), the Conceptual Frameworks of the IASB (1989) and FASB (at least until recent times), and The Solomons Report (Solomons, 1989), amongst others. These reports identify a diverse range of financial accounting and reporting users and information. This, in 
turn, has been obstructive of coherent accounting theory development due to the diversity of objectives it entails (Jensen, 2001; Beaver and Demski, 1974).

From the 1970s, critical theory developed in the academy, challenging the prevalent views held by existing academics about ontology, epistemology and methodology. This emerging paradigm exacerbated the influence of stakeholder theory by employing it to license its anti-capitalist-motivated agenda. It argued for particularism, embracing a heterogeneous range of research methodologies (Parker, 1999; Funnell, 1996; Tinker, 1980). Moreover, it engaged stakeholder theory in a virulent attack on the existing economic system. Important academics operating in this mode include inter alia Laughlin (1987), Tinker (1980), Arrington and Francis (1989). Their use of stakeholder theory was and remains arguably a pragmatic tool applied to frustrate the relationship between capital and profit. There is no clear objective causally linking critical theory to stakeholder theory. In this sense it is possible to infer that stakeholder theory is employed as a device rather than a conviction.

\subsection{The rise of PAT and its claim to singular legitimacy}

The prevailing contemporary academic accounting theory arose from about 1970 (Henderson, et al, 2004; Parker, 1999). This was the date from which positivist empiricism gained currency, later being formalized by Watts and Zimmerman (1986). Chua (1986) qualifies a generally critical view of PAT, arguing it introduced rigour to academic accounting. This is somewhat true yet positivism also made the case that it was an entire paradigm, sufficient as a basis to underpin all accounting research. It is this latter claim that challenges the proposition of normative accounting theory. PAT argues that the normative theories of accounting advanced through the 1960s were developed from the basis of assumptions about the users and functions of accounting information that were never objectively established and that all subsequent theoretical developments from such foundations have no validity. Gonedes and Dopuch (1974) make the case that the normative theories of the 1950s and 1960s could be used to justify any argument. The positivist tells us, unlike earlier empiricism, that standard 
development is not within the remit of academic accounting (Gonedes, 1975). Instead accounting research should concentrate on the behaviors of accountants and issuers in terms of their choice of accounting treatments and presentations (Gonedes and Dopuch, 1974; Gonedes, 1975; Watts and Zimmerman, 1986).

PAT as developed by Watts and Zimmerman (1986) purports to offer no prescriptions for accounting practice. Its claim is to simply describe, explain and predict practice (Gonedes and Dopuch, 1974). It is empirically based, in contrast to preceding a priori normative, deductive accounting theories (Whittington, 1987). However, PAT must make assumptions, including what constitutes an interesting question and the efficient market hypothesis. PAT relies on the assumption of market efficiency as the foundation for its typical correlation analysis to derive probabilistic inferences (Whittington, 1987). The distinction between deductive and inductive, between normative and descriptive theories is one of degree. The positivist's claim to objectivity, in this light, is ambitious.

The PAT theorists' objections to normative theory, arguing for the limited impact it has had on practice (Watts and Zimmerman, 1979), is, in one sense, untrue and in another, inferentially overdetermined. In the first case normative theories, such as Staubus' decision-usefulness theory of accounting and Sprouse and Moonitz's (1962) call to reference accounting's objective function against derivation from essential elements of its environment, have substantially informed developments in accounting standards. This relation of accounting to its environment was officially propounded in the Trueblood Committee Report (1973) and, subsequently, was influential in the development of the FASB conceptual framework from 1974-1985. It is undemanding to infer the significant influence such developments have had on practice. The second basis to reject Watts' and Zimmerman's (1979) inference is that even if there had been no influence of normative theory on practice it is overdetermined to argue the worthlessness of this class of theory. It is plausible to assume that no such theory sufficient to alter practice was developed. Lee and Tweedie (1990) argue that many accounting theorists of the normative mode prescribed solutions without 
establishing user needs or decision models. This may, equally, be used as an argument for perfecting such a general theory of accounting, employing such user decision models and needs as an information base for normative theory.

What PAT theorists seem to want to argue against is regulation per se. Watts (1977) makes the case that in unregulated markets audited GPFRs lower agency costs. He cites substantially unregulated nineteenth century UK corporations as evidence of this proposition. This view, that unregulated financial reporting would deliver optimum information levels, is supported by Gonedes (1975), Berry and Waring (1995), and Edwards (1989). It operates on the assumption that a failure to regulate would incentivise the company to optimize (and increase in such instance) information production to lower the cost of capital. This view holds that companies would aim at Pareto optimization as a rational choice (Aivizian and Callen, 1983).

This hypothesis is strained at the outset by its confusion of legal and natural personalities. To say 'the company' ought (would), if it is to be considered rational, deliver the information required by the market such that the furnished information had no negative implications for the value of the company, either in terms of the excess cost of capital from under-delivery or the excess cost of production from information overproduction, presupposes a legal fiction is personally motivated. Simply, the company is the aggregation of its investors' contributed capital. Thus the argument is trivial. It is, in approximate terms, the position that investors (the company) are interested in their own interests and will target their own utility maximization. While I do not challenge this undemanding proposition, it is unclear that it is anything but a tacit rejection of the agency theory context that it implicitly recruits as an axiom.

Watts (2003) argues that agency costs of debt could be controlled far better by covenants restricting dividends to a predetermined maximum percentage of profit. We must assume that he means debt covenants should include the basis for calculating profit and, also, that company returns of capital are (should be?) 
governed by terms contained within debt covenants. What emerges is that Watts is opposed to regulation as an instantiation of a normative accounting theory. It is available to infer that he comes by his championship of conservatism for the same reasons. He defines conservatism as:

“...the differential verifiability required for recognition of profits versus losses".

His explanation for the survival of conservatism is that it best addresses contracting and litigation risks (Miller and Young, 1997). It seems reasonable to ask if this control of litigation risk comes at the cost of saying too little. Watts (2003) tells us that the elimination of conservatism is likely to impose additional costs on investors and the economy. ${ }^{13}$ Furthermore, conservatism is unlikely to have unintended [any consequences at all additional to an unregulated market for GPFR?] consequences. We might inquire here if this is an implicitly normative argument for conservatism. It seems Watts (2003) is arguing from a fundamental objection to inevitably normative accounting standards to the conclusion that such standards, if we cannot get rid of them, should be as far from the margins of informational relevance as possible. That is, they should be kept out of harm's way. This is an argument against regulation simpliciter.

What Watts (1979), Watts and Zimmerman (1986), and Sunder (2007) seem to hold ideal is voluntary financial reporting. This, it is implied, can be read in terms of 'body language' or silences (signaling). It seems curious that Watts' implied objection to fair value co-exists with his conviction that markets will deliver financial information efficiently. GPFR standards will never be exhaustive of all possible useful information and signaling is still possible with incremental information over that which is required by standards. However, standards do allow for managers' accountability to shareholders for minimum information provision and subsequent sanctions.

\footnotetext{
${ }^{13}$ Curiously, Watts' empiricism seems to let him down here. He seems to be saying he thinks this is the case, he is not telling us he has observed that the increase in costs is a probabilistic inference in any statistical sense.
} 
The case is made by Parker (1999) that the abandonment of the normative accounting theory project of the 1950s and 1960s, and the rise of positivism from 1970, produced accounting based on scientism (Wells, 2003; Gambling, 1974). This scientism leverages off the success of the methods of the physical sciences (Ryan, 1980). There is no automatic sequitur in the translation of the success of these methods in relation to physical matter, to social relations. Notional objectivity sponsored the view of accounting theory progress with ostensible rigour inherent in statistical testing of large samples in support of theories (Sterling, 1979; Parker, 1999). PAT also produced predictive models of economic and social behavior. Despite this, Parker (1999) argues that academic accounting has been in a stasis due to the reluctance of PAT researchers to translate their research into evidence for accounting policy development. From the preceding paragraph then, we would like to know, on the basis of evidence, why accounting should target conservatism. It almost seems as though positivists end their contribution without articulating their last sentence. This proposition is nowhere more in evidence than in Barth's (2000) previously discussed article Valuationbased Accounting Research: Implications for Financial Reporting Opportunities for Future Research.

One further challenge that has been made to positivism is that advanced by Christensen (1990). He argues that PAT can more accurately be described as sociology of accounting and accountants rather than an accounting theory. Notwithstanding Watts and Zimmerman's (1990) counter to Christensen's challenge, that accountants are essential to accounting simpliciter, and that the distinction between the study of accounting theory and accountants entails an arbitrary dichotomization, PAT does appear to be essentially ethnographic in nature. We might say here that Watts (2003) isolates a precondition of accounting as the thing itself. Although this may not be universally disagreeable as a characterization, it is unlikely to be one that sits well with positivists. We might add that it is inchoate as an ethnography as it does not go inside of its subject. Where Watts and Zimmerman (1990) contend that debt and compensation 
contracts, and political processes explain accounting choices, and that these supply the only important questions, it is likely that we can enhance the function of accounting by reducing accounting choices. This is one objective function of a coherent theory of accounting.

An objection to PAT that Chua (1986), raises is that it is founded on a dubious ontology and discredited epistemology. PAT assumes an orderly view of society, discounting the view of conflict in social relations of classical political economy (Chua, 1986; Cooper and Sherer, 1984). This is done by positivists without specific arguments for this ontological commitment. Further, it assumes realism of the 'objects' of its investigation, clashing with the socially constructed view of the world advanced by criticalists and post-modern theories (Chua, 1986). The positivist does not need to rely on such a strong claim as the assumption of an orderly society so much as a general tendency towards order, underwritten by mutual assurance in Hobbes' 'comfortable seats'. The only caveat to the guiding positivist intuition is that society supplies sufficient, appreciable net benefits to (at least) the majority of its members. I expound a realist ontology in chapter three. At this point I will not challenge Chua's (1986) ontological objection (inferred: from parsimony). It is simply the purpose here to identify the existence of this objection to positivism.

In relation to Chua's (1986) objection to the positivist epistemology, that PAT relies on a now discredited commitment to verificationism, this objection is rejected. The verificationism of the logical positivist school has been shown to make overdetermined positive statements about the certainty with which we may know a thing. However, there is no clearly identifiable need for positivism to make such confident assertions. The practical implications of verificationism can be otherwise obtained from Popperian falsificationism or the instrumentalism of Milton Friedman (Henderson and Pierson, 1983). Unless I have missed something, the falsificationism or instrumentalism that Chua (1986) finds more epistemologically justifiable are no more than more cautious approaches to the same basic sense that obtains from verificationism. The former two are licensed 
by 'justified true belief' rather than an explicit assertion of facticity and that is the sum of their practical differences. To describe this as a fundamental theoretical flaw is to hang too much hope for the critique of positivism on a negotiable, malleable tenet. Given the penchant of positivism for correlation analysis its descriptivism is really only probabilistic inference from inductivism in any event.

Chua's (1986) concession to PAT, that it introduced rigour to accounting research, has some merit and it is in this that positivism has a contribution to make to general accounting theory; as a methodology. Provided PAT operates on externally sourced questions, such as those posed by regulators, and does not $a$ priori determine the interest inhering in the questions it asks, such research can potentially provide empirical evidence concerning a normative theory, against the referent theory's self-described view of the world. For these reasons, and as a counterweight to questionable theoretical developments that consist in a substantial part of post-structural and critical accounting theory research, PAT has a useful contribution to make to the development of academic and practical accounting. What is less certain is that PAT constitutes an entire paradigm. As Whittington (1987) argues, PAT has some fairly incoherent epistemological commitments. Although I have rejected Chua's challenge (above), a priorism is spurned selectively by positivism, with deductive logic deemed unproductive yet mathematics and, more particularly probability, held to be legitimate tools. The key point is that positivism in accounting does not own its essence and it cannot if it is to sustain its claim to singular accounting theory legitimacy. Reason seems to exist for positivists to relax this assumption.

\subsection{Agency theory}

Notably, the discussion has not directly addressed agency theory to this point. The discussion has implied and assumed the principal/agent relationship and its entailment that each party would behave as rational economic agents concerned to maximize their own utility in their mutual relations (Whittington, 2008). This axiom is unproblematic in two independent regards. In the first instance the guiding intuition of the agency relationship can be inferred of all 
arguments proposed for any classification of GPFR users, however broad or narrow. Regardless of our user definition we suppose each group so defined will use the information for their own ends. For it to be otherwise we would have to, for example, assume environmentalists only interest in company financial reporting was to be secure in the knowledge that investors were achieving sufficient returns. Naturally any claim to user status is motivated by the claimant groups' own interests. Inferentially, the pursuit by each group of its optimal utility presupposes that groups' individual interests will not feature in rival claimants calculations. For this reason the agency theory assumption of opportunistic behavior between diverse groups is uncontentious between the various theoretical protagonists and may therefore be stipulated. Secondly, for present purposes high specification of the agency relationship is not required. Simply, I make the case that soundly theoretically grounded GPFR can offer some minimum guarantee of control over managers behaving without regard to multiple period employment, without constraint by personal beliefs or informal social sanctions. ${ }^{14}$ These considerations obviate the need to expound agency theory at length.

\subsection{Summary: The influence of the academy and influences on the academy}

The discussion to this point has described the major developments in the accounting theory of the academy. These developments have reflected movement from inductive empiricism through to normative (or prescriptive) accounting theory. The final (and current) mainstream theory guiding academic accounting has been the new empiricism of positive accounting theory. Where the earlier period of empiricism held an at least tacit view that prevailing best practice formed the basis to develop accounting principles around it, contemporary empiricism (ostensibly) offers no opinion on this, they hold their function as purely descriptive and predictive. Subsidiary theoretical developments have occurred parallel to these prevalent academic accounting theory developments since the 1960s. Stakeholder theory gained significant influence over the academy from the 1960s and, from the 1970s, critical accounting theory began to develop

\footnotetext{
${ }^{14}$ Arguably, the assumption of single-period temporal parameters around employment of agents, inherent to agency theory, asserts an unsustainable view of human rationality. For this reason my basic stipulation of agency theory is 'weak-form'.
} 
to challenge the mainstream. The influence of these schools of thought on the development of a general theory of accounting is considered further in chapters two and three.

The academy and more particularly accounting academics have exerted some influence on accounting practice and regulation. This influence has, notwithstanding the normative period of academic accounting of the 1950s and 1960s, been substantially obstructive to the development of a general theory of accounting. In some sense accounting academia may be too self-conscious because of the comparative youth of accounting as a discipline beyond practice. In contrast to critical theorist perceptions it is not so clear mainstream accounting's retreat into credentialism through scientism, that is the aping of the methods of physical science, is motivated by capitalism's legitimization (Richardson, 1987). Had the academy been so motivated it would have maintained the course of normative accounting. The basic problem with this criticalist view is that we must first be convinced of their view that accounting has evolved to certify capitalism. I argue that it is no less likely that it does nothing more cynical than adopt the context of its environment. Moreover, mainstream accounting theory seems to reflect more volubly a lack of any clear intent rather than an ulterior motive. If we are to allow the criticalist view we must also allow that the 'hegemony' interprets as much power to accounting as the criticalists do themselves. It is difficult to see how the hegemony could not secure similar advantages with any other, similarly abstruse system of financial accounting. Further, such power would have had no reason to belay forcing a 'conducive' normative theory if it had such agency. Notwithstanding the confounding nature of the academy, and possibly in part because of it, standards setters have progressively charted an independent trajectory, quietly establishing an understated coherence to their conceptual frameworks and standards. This is something Whittington (2008) implies is a standard setters 'secret agenda' (Bradbury, 2008). 


\section{Chapter Two}

\section{The Development of the Accounting Conceptual Frameworks}

\subsection{Introduction}

Accounting regulation and its referent theoretical foundations have reflected the influence of the academy to a degree but standards setters, from no later than the early 1970s, have contained this influence with remarkable success. We can date the earliest attempts to develop a conceptual framework to the 1930s but the influence of such a theory only comes into evidence subsequent to the Wheat and Trueblood Committee Reports and the establishment of the FASB in 1973. Where the academy has been influenced by seasonal attachment to diverse, and oftentimes nebulous and conflicting theories, regulation has substantially developed a distinct and progressive trajectory. The linearity of this trajectory, contra Watts and Zimmerman (1986), has been informed by the central intuition behind the normative accounting theories of the third quarter of the twentieth century. It reflects directional coherence in the often subtle devices it has employed to progressively narrow the relevant variables involved in the formulation of a conceptual framework. Against the substantial success of standards setters in quarantining regulation from accounting academy influence, political forces have partly frustrated, if not confounded, the development of a coherent conceptual framework (Gerboth, 1973). Notwithstanding political influences, arising out of the competing demands of a diverse constituency, regulators have moved quietly towards an understated coherence to conceptual frameworks and standards development and promulgation (Dalessio, Seiler and Jones, 1999).

\subsection{A brief history of developments in regulation and its theoretical base (Conceptual frameworks) 15}

In the wake of the 1929 US (and global) stock market crash the US government moved to increase regulation of financial markets. This led to the 1933 Securities Act and its 1934 amendment creating and empowering the SEC

\footnotetext{
${ }^{15}$ Appendicies one and two provide a brief sketch of developments in accounting regulation and theory.
} 
with oversight of financial reporting (Beaver, 1981; Fogarty, Hussein and Ketz, 1994; Giroux, 1999). The 1933 Act supported a preference for investor-focused financial reporting (Beaver, 1981). It was in this context that the demand for a general theory of accounting arose (Most, 1982). No longer was existing Generally Accepted Accounting Practice considered adequate, as it was seen as implicated in the economic malaise of the time. The widespread economic and social harm caused by the market breakdown provided an insight into the ability of financial market turmoil to spread across society as a whole, causing high levels of unemployment (Carcello, 2007; May and Sundem, 1976; Sunder, 2007). This environment led the AAA, formerly the American Association of University Instructors in Accounting, to issue A Tentative Statement of Accounting Principles Underlying Corporate Financial Statements in 1936 (Wolk, et al, 2008). This is the earliest authoritative, explicit promotion of a deductive approach to accounting theory, supporting the post-1933 shift in regulatory focus to investors and creditors (as distinct from management) and the information focus of GPFR (Watts and Zimmerman, 1979). Revisions followed in 1941, 1948 and 1957 (Zeff, 1979). Parallel developments occurred when the American Institute of Accountants (AIA) produced A Statement of Accounting Principles in 1938 (Zeff, 1979).

These early developments were advanced sporadically in the subsequent period until the establishment of the FASB in 1973. From 1939 until the establishment of the FASB in 1973, regulation of accounting fell, under the auspices of the SEC, to the Committee on Accounting Procedures (CAP) and, from 1959 to 1973, to the Accounting Principles Board (APB) (Burton, 1978). The AIA (later, AICPA), under urging from the SEC, established the CAP which, during its incumbency, produced fifty-one research bulletins. Despite this, CAP failed to develop a coherent accounting structure, causing it to be replaced by the APB in 1959 (Weinstein, 1987). The APB was tasked to develop a conceptual framework for accounting. 
Over the period 1959 to 1973 , the APB adopted a pusillanimous approach to the development of a conceptual framework (Burton, 1978). Its approach was largely a product of its environment in that it tended to formalize existing practice (as in the previously described inductive-empirical period), without any explicit theoretical base to operate from. The motivation behind the formation of the APB, as successor to the CAP, had been the unsatisfactory nature of existing practice. When, in 1961 and 1962, Moonitz and Sprouse and Moonitz produced AICPA accounting research papers no.s 1 and 3 on accounting postulates and principles the APB rejected them as "too radically different [from existing practice] for acceptance at this time" (Zeff, 1979, p. 212). The 1965 issue of AICPA Research Study No. 7 Inventory of Generally Accepted Accounting Practice for Business Enterprises (Grady, 1965), took a more conservative tack than the 1961 and 1962 research studies. Subsequently, the AAA monograph A Statement of Basic Accounting Theory (ASOBAT) (AICPA, 1966) took a more radical stance, advocating current cost accounting (Lewis and Pendrill, 2004).

The 1966 ASOBAT may be seen as an important turning point in a sense. It rejected past approaches, including Grady's report (1965), aimed at justifying existing practice and assuming its value. This challenged the approaches of Paton and Littleton. In this monograph a substantially deductive approach was employed. The 1966 ASOBAT also took the view of accounting as a financial information reporting system. The aim of it was, as such, to provide economic information to allow informed judgments and decisions by information users. The case the committee producing ASOBAT (1966) made for current cost was its relevance to users (AAA, 1966). It also held that while there were many users, their needs were similar (Trueblood Report, 1973; Young, 2006). This device gained currency from this point, muting the implication of diverse information needs from diverse users.

In 1970, after five years of study and a succession of drafts, the APB produced Statement No. 4 Basic Concepts and Accounting Principles Underlying Financial Statements of Business Enterprises (Accounting Principles Board, 
1970; Beaver, 1981; Zeff, 1979). The APB acknowledged its statement was largely descriptive of existing practice and not, as had been sought, prescriptive. It centred essentially on what accounting was at the time, some of which was inconsistent with other parts. It was not very useful as a tool in setting standards (Johnson, 2004). It did, however, initiate the move to elevate the information perspective over that of stewardship in accounting standards (Beaver, 1981). The general lack of achievement of the goal to establish a conceptual framework by the (voluntary) APB led to growing criticism of it within and beyond the accounting profession (Zeff, 1979; Weinstein, 1987). This led the AICPA to commission two major studies. These were to become synonymous with their authors, former SEC Commissioner Francis Wheat (The Wheat Committee Report, 1972) and the Trueblood Committee Report (1973), led by former Institute President, Robert Trueblood (Zeff, 1979).

The 1972 issue of the Wheat Committee Report and 1973 issue of the Trueblood Committee Report, respectively recommended replacing the APB with the FASB and provided the postulates giving direction to the (subsequent) FASB conceptual framework project. The Wheat Committee recommended the creation of a seven-man, full-time Financial Accounting Standards Board (FASB) to replace the volunteer-staffed APB. It was proposed that the FASB would be established under the auspices of the Financial Accounting Foundation (FAF), composed of representatives of the AICPA, FEI (Financial Executives International), AAA and NAA (National Accounting Association). The Financial Accounting Standards Advisory Committee (FASAC) was also established, to provide research on questions of interest to the FASB (Schroeder, et al, 1991). Initially the FAF was to have a budget of between two and a half and three million dollars, composed of contributions from the preparer community. The APB terminated itself on the thirtieth of June 1973 to be replaced by the FASB on July the first (Zeff, 1979).

The FASB gained support from the SEC when, in December 1973, the SEC issued ASR No. 150, declaring that the, "standards and practices 
promulgated by the FASB in its statements and interpretations will be considered by the Commission as having substantial authoritative support and those contrary to such FASB promulgations will be considered to have no such support" (SEC, quoted in Zeff, 1979, p. 219). From this base the FASB began work on the development of a conceptual framework based, in substantial part, on the recommendations of the Trueblood Committee. Progressively from this date the conceptual framework has shown an increasing focus on prospective, decisionuseful information that, while conceding multiple users, increasingly prioritised the investor and creditor as the target of GPFR. These trends were reflected in the post-Trueblood era in the 1976 Conceptual Framework for Financial Accounting and Reporting issued by the FASB. This trend was confirmed in the following year by a committee of the AAA's issue of Statement on Accounting Theory and Acceptance (Zeff, 1979; Shillinglaw, 1979).

From 'Trueblood' (1973) the priority accorded financial reporting information related to, "information useful in making economic decisions". It may be suggested that this does little to narrow the field of required information or, at least specified, within financial reports. The case may be made that all users of financial reports are concerned to do so because of economic decisions. Whether the issue is a wage claim, litigation or a demand for the company to act to remedy harm caused to society or the environment, the decision will, in some sense be economic. This is somewhat true, but by specifying economic decisions inference to the priority of purely economic decisions is available. This is one of the devices I suggest standards' setters have used so that it suggests its preferred interpretation. Clearly, given such an interpretation, investors and creditors are implicitly preferred over other potential users.

Over the period to the late 1970s the user definition of GPFR was little changed in its formal enunciation. Despite this, subtle shifts in emphasis occurred within the explicitly acknowledged stakeholder conception of users. We see an important shift around and following the 1973 Trueblood Committee Report. In that report, following from Moonitz and Sprouse (1962), diverse users included 
external users who had limited authority to command information, who rely on that information for economic decisions. However, these reports recommended accent on prospective information, including forecasts and historical cost augmentation with current values where historical cost is inadequate (Most, 1982). This is an implicit argument for investors and creditors as users, signalling a significant move in future trends in standards. Furtherance of this trend was in evidence in the 1978 Statement of Financial Accounting Concepts (SFAC No. 1) by the FASB. Explicit reference to users as investors, creditors and others making economic decisions, combined with the investor user primacy principle (FASB, 1978, paragraph 34) affirmed the narrowing of GPFR users (Stanton, 1997). Where SFAC No. 1 identified 24 user groups it identified common information needs, consistent with those of sophisticated investors. Decision-usefulness emerged from SFAC-1 as a priority as well (Schipper and Vincent, 2003).

From 1974 to 1985 the FASB developed SFACs (the conceptual framework) numbers 1-5 (Zeff, 1979; Mattessich, 1997). SFAC-2 (1980) Qualitative Characteristics specified the objective function of GPFR as serving the public interest by providing financial information that enables the efficient allocation of resources (Flegm, 2000). This embodied the previously discussed reconciliation of stakeholder theory in its widest sense with investor as sole GPFR user. We also see an attempt by the AAA (1980) to reconcile the dual priorities of relevance and reliability. This was done by their discussion proposing that verifiability, possibly the most rigid plank in the defence of historical cost when, as it is commonly interpreted, it is held to be achieved only as an historical, documented transaction price, is interpreted as meaning a value that occurs where experts working independently of each other arrive at a similar valuation (Henderson, Pierson and Harris, 2004). SAC-3 also explicitly elevated relevance and prospective information, identifying a predictive and confirmatory function for such information. This basic view informs an element of my reconciliation of relevance with a comprehensive sense of accountability. 
In the socio-economic context of successive challenges posed to historical cost by inflation through the 1970s and the Savings and Loan crisis of the late 1980s, the impetus from historical cost accounting valuation to fair value was spurred by the AICPA Jenkins Committee Report (hereafter: Jenkins, 1994, cited in, Colson, 2005). Another environmental development informing Jenkins was the prior and contemporary developments in finance theory, supporting the general proposition of market efficiency. Significant implications of this for Jenkins and of Jenkins for accounting were the support it lent to fair value accounting measurement, investor-as-user, and decision-usefulness as the priorities of financial reporting. Jenkins $(1994 ; 1995)$ held that the central function of GPFR lay in its facilitation of efficient capital allocation by investors and creditors. Jenkins (1994) held that financial reporting was important to capital allocation in deep and liquid markets, phraseology that was to inform the specification of the preferred (first level) of fair valuation in subsequent accounting standards. Jenkins (1994) employed the 'principal user', possibly dating to 'Trueblood', to describe investors, creditors, and their advisors (Luscombe, 1995). This replaced a similar operation in earlier articulations of accounting concepts, whereby myriad users were acknowledged but it was held all user needs would be met by information sufficient for investors as the holders of residual interest in the corporation. This further supported the priority attached to prospective information, with constraints proposed on information only where it would compromise the reporting entity's competitive position (Jenkins, 1994).

The trend towards fair value measurement by accounting standards setters that begun in the late 1980s continued through the 1990s, resulting in a shift towards standards requiring fair value (Ramana and Watts, 2007; Hitz, 2007). The traditional priority of stewardship was progressively eroded, from no later than the Trueblood Committee report $(1973)^{16}$, in favour of decision-usefulness and relevance (Hitz, 2007). This underpinned the move to fair value which was demonstrated to have greater relevance by much of the empirical work of the

\footnotetext{
${ }^{16}$ Although APB Statement No. 4 could be said to have identified and advanced the information perspective, it did so timorously (Beaver, 1981).
} 
academy. This was, in turn, an emerging trend concomitant with the trend towards international accounting standards, beginning in 1973 with the establishment of IASC. The trends more immediately corresponded and supported each other with the initiation of the IASC conceptual framework in 1989 (Whittington, 2008). This articulated the main purpose of GPFR as providing decision-useful information and, whilst acknowledging many users, held that they were typically investors (Alfredson, Leo, Picker, Pacter, Radford, and Wise, 2007). This initial stage supported mixed-attribute accounting but with a trend towards fair value (Nobes and Parker, 2004; Chorafas, 2006: Whittington, 2008).

The development of international accounting standards for financial reporting has been accompanied by a progressive commitment to fair value (Alfredson, et al, 2007; Turley, 2008). This trend towards fair value is reflected in a succession of standards allowing or requiring full fair value measurement. The 1998 IASC Draft IAS 39 proposed full fair value as an option (Camfferman and Zeff, 2006). The IASC successor organization, the IASB, Joint Working Group (JWG) proposed fair value for all financial instruments regardless of the purpose for which they were held (Chorafas, 2006). In 2006 Herz, Chairman of the FASB, found fair value to be the most relevant measure of all assets and liabilities (White and McNally, 2006). By 2005 International Accounting Standards (IAS) requiring the use of at least some fair value measurement included: IAS's 11, 16, 17, 18, 19, 20, 26, 33, 36, 38, 39, 40, and 41 and International Financial Reporting Standards (IFRS) 1, 2, 3, and 5. Standards requiring fair value by reference to another standard included: IAS 2, 21, 27, 28, 31, and 32, and IFRS 4 and 7. Standards not requiring any fair valuation measurement largely included statements of items pertaining to current period cash, such as the statement of cash-flows, income taxes and borrowing costs. Also standards in which no relevance to measurement arises, fall outside of the influence of fair value measurement, such as standards pertaining to accounting policies and the presentation of statements (Deloitte, 2008). 
These trends in International accounting standards setting development have been mirrored (or mirror those) by the FASB. The move towards convergence, manifested in the Norwalk agreement between the FASB and the IASB in 2002, and the joint standards development project from 2005, has ensured a closing gap between the competing standards (Whittington, 2008). Each standard setter must be cognizant of relevant developments and measure their own pace against that of the other. The FASB's movement towards increased use of fair value is reflected in a number of developments in its standards. These include:

- Financial Accounting Standard (S)FAS 115 (1994) in which US GAAP requires fair value for many investments.

- FAS 133 (2000) Requires fair value for derivatives.

- FAS 157 and SFAC (Statement of Financial Accounting Concepts) 7 (2006) establishes a common definition of fair value (White and McNally, 2006).

- FAS 159 (2007) expands the ability to use fair value for certain financial assets and liabilities (PricewaterhouseCoopers, 2008).

The preceding list is not exhaustive of instances of the growing influence of fair value in US (FASB) accounting standards and it does not reflect the fact that the standards are, at this juncture, mixed attribute. What is in evidence is the clear trend in standards, both of the FASB and IASB towards fair value accounting measurement.

\subsection{Broad trends in the development of conceptual frameworks}

The broad trends in conceptual framework development involve the fundamental precepts that inform accounting regulation development. These include such objective functions as stewardship counter-posed with decisionusefulness. Also, the development of conceptual frameworks concerns itself with qualitative characteristics and the tension between these. This issue has been central to the relevance/reliability debate. A derivation of this conceptual-level 
debate is the valuation debate between fair value and historical cost. In broad terms the debate has been for traditional accounting, entailing the priority of stewardship, reliability and historical cost, over the ascendant decision-usefulness, relevance and fair value. There is no precise tipping point between these rival approaches. It is not even possible to locate the first seed of the latter's ascendance to prominence in certain terms. All that can be done is to chart approximately the rise of decision-useful, relevant, fair value accounting against traditional stewardship-focused, 'reliable', historical cost.

There was no clear challenge to the traditional, feudal foundations of accounting until the 1950s, when the academy advanced the idea that accounting should be decision-useful (Morley and Stamp, 1970). ${ }^{17}$ If we unshackle the operative term 'useful' from its substantially redundant attachment 'decision' we are left with the unremarkable conclusion that (at the very least, implicitly) the theories of Chambers ( $\mathrm{CoCoA})$ and Staubus (the decision-usefulness theory of accounting) were the genesis of decision-usefulness against the incumbent stewardship delimited 'accountability' view of accounting. ${ }^{18}$ I pose challenges to the ostensible distinction between accountability and relevance. I define relevance as a synonym of decision-usefulness combined with stewardship. We would be logically drawn to conclude this even if our decision was just whether or not management had discharged its duties in relation to the stewardship of resources entrusted to them. We do not really see a substantial reflection of this move towards decision-useful accounting in 'official' views until the 1966 publication of ASOBAT, the 1970 APB Statement No. 4 and the Trueblood Committee Report of the AICPA (1973) (Storey and Storey, 1998; Coy, Fischer, and Gordon, 2001). I infer this period is the tipping point between traditional accounting and

\footnotetext{
${ }^{17}$ It is argued by Kam (1986) that stewardship was inherently conservative to pre-empt the stewards' risk of overstating the value of an estate, with concomitant later period value diminution. Likewise, from the nineteenth century, auditors observe that there is little risk of being sued for understating company values. This approach effectively mitigates the risk of errors in accounting by means of saying nothing relevant at all, expressed in terms of historical cost.

${ }^{18}$ It seems likely that useful information must also be decision-useful. Confirmatory value cannot be segregated from decision-usefulness or else there is no utility to the confirmation. At the least, confirmation provides some foundation to assess prospective information (IASB, 2008b).
} 
the new era of investor-focused information in the US, a trend that would become international only later.

In terms of the previously described eras of regulation development, promulgation and research by the CAP and APB, they were a substantially nonnormative, descriptive approach. It was this reluctance to prescribe accounting regulations that led to the demise of first CAP, and latterly, after it had also failed to make significant headway improving existing practice, the APB. CAP survived from 1939 to 1959 and its successor, the APB spanned from 1959 until, following the Wheat Committee recommendation, it was replaced by the FASB. While it is not possible to assess the impact of the academy in any precise way, abductively, we might infer both were products of their broader environments. The 1929 stock market crash gave impetus to standards' development but, without a significant heredity immediately prior to this point, offered little specification of what standards might look like (May and Sundem, 1976). In this context it is unremarkable that standards setters would attempt to move cautiously, codifying existing practice. The difficulty that lay in this approach was that existing practice was the operationalisation of diverse, inconsistent traditions in accounting and, therefore, its formal articulation was essentially descriptive, and then, descriptive of all too many options. These problems were almost certainly compounded by the volunteer status of the respective Boards' members.

I locate the impetus to change to more overtly prescriptive accounting regulation to the period 1966 to 1973 . At the beginning of this period the AAA produced a monograph A Statement of Basic Accounting Theory in 1966. This appears to be the genesis of the priority accorded to investors and creditors (Young, 2006). This monograph also promoted decision-usefulness, establishing the origins of the regulatory trend towards prospective information. It is noteworthy that this trend occurred despite widespread resistance (Young, 2006). Sixty per cent of respondents to the FASB in the 1974 discussion memorandum on financial reporting objectives opposed the provision of decision-useful information (Armstrong, 1977). This trend in regulatory focus was tacitly 
supported by APB Statemnent No. 4 Basic Concepts and Accounting Principles Underlying Financial Statements of Business Enterprises (1970) (Zeff, 1979; Johnson, 2004).

Following the Wheat Committee-recommended establishment of the FASB, this organization moved to develop a conceptual framework to identify principles from which it would develop its standards (Giroux, 1999). The conceptual framework project, beginning in 1974, shortly after the 1973 establishment of the FASB, largely operationalised recommendations developed in the 1973 Trueblood Committee Report. Trueblood continued the recently developed trend in accounting regulation focus, advancing the priority of investors and creditors as financial reporting users. Trueblood was influenced by a stakeholder conception of users, although this was qualified by the priority attached to investors and creditors (Parker, 1982). This committee also stated that the, "basic objective of financial statements is to provide information useful for making economic decisions" (Trueblood, 1973). Trueblood's focus was on prospective information with a concomitant challenge to historical cost and its auxiliary assumption of matching (Flegm, 2000; Hawkins, 1973). Objections have been raised to Trueblood's findings that the correct financial information communication would mechanistically entail correct resource allocation. The FASBs direction was clearly established in its Statement of Financial Accounting Concept No. 1 (SFAC No. 1), targeting (explicitly), "investors and creditors and other users." Although SFAC 1 identified thirty-four user groups, the acknowledged priority was investors and creditors. This was reinforced at paragraph 34 by the stated aim of GPFR to aid, "rational investment, credit and other similar decisions." SFAC 1 (1978) also specified a preference for external users without the power to require information, favouring investors. This affirmed the trend since 1966. From this time a functionally linear trend in accounting regulation from its historical bases of stewardship, historical cost and reliability to relevance, decision-usefulness and fair value occurred. ${ }^{19}$

\footnotetext{
${ }^{19}$ This is a slightly anachronistic usage, where current cost and other variants of contemporary values were proposed in the intervening period. I use it here as a short-hand.
} 
The search for a conceptual framework began in earnest from the 1970s. It is argued that this development was a reaction to external events, with particular significance attached to the collapse of Penn State (1975) and the perceived role of existing accounting practice in this (Dean and Clarke, 2003; Salvary, 1979). Undoubtedly the external economic environment acts on accounting and accounting regulation but this analysis ignores the importance of the FASB's concern for its own prospects as an institution. The aggressive pursuit of a conceptual framework may be seen, in this light, as much as a reaction to exigencies created by competing political imperatives. Empirical evidence of the risk to the survival of a regulator of accounting is available in the demise of the CAP and APB. In this sense the FASB's active pursuit of prescriptive accounting theory and standards may be viewed as a necessary, pragmatic policy of selfinterest.

Following the Trueblood Committee Report (1973) a succession of official reports were produced as a response to the recommendations of Trueblood. In 1975 the accounting standards steering committee (ASSC) produced the Corporate Report. This affirmed the decision-usefulness objective of financial reporting proposed by Trueblood and also recognized many GPFR users, qualified by acknowledgement that their information needs were similar. The novelty of the Corporate Report consisted in its view of a 'national interest' view of stakeholdership. This curiously may be used to support the priority of the investor as user of GPFR. In 1980 The Stamp Report was the Canadian Institute of Chartered Accountants (CICA) response to Trueblood, essentially supporting the general trend towards the decision-usefulness of GPFR. Subsequently, in 1988 the McMonnies Report of the Institute of Chartered Accountants of Scotland (ICAS) and the Solomons Report (Solomons, 1989) supported the general movement towards relevance, decision-usefulness and prospective financial information (Smith, 1996). 
From the 1990s the FASB pushed for greater use of fair value accounting standards. This was mirrored in developments in the international accounting standards of the IASC. The 1989 IASC Framework for the Preparation and Presentation of Financial Statements affirmed decision-useful, investor-focused information. As previously described, these trends found support in the Jenkins Committee Report (AICPA, 1994) which made the case for market efficiency and fair values. Progressively the FASB and IASB (post-2000, as successor to the IASC) consciously moved to reflect common values and accounting treatments. To the current period we observe a progressive narrowing of GPFR user definitions, reflected in 2008 in the FASB characterization of primary users as investors and creditors and, in the IASB pronouncements, as current and prospective investors (Whittington, 2008). This conclusion obtains only from the primary user device. Lenders are still explicitly identified as users, as are creditors, that is, parties such as employees and suppliers owed, in general, shortterm debts by the company. We also observe the elevation of relevance and concomitant deflation of reliability. Reliability is now a secondary qualitative characteristic, or enhancing characteristic, forming one part of representational faithfulness.

The significance of the changed primary qualitative characteristic reliability, to representational faithfulness (OC 2-14; BC 2.13-BC 2.24, FASB, 2008), in the IASB discussion paper and ED, is that it mutes the mutual exclusivity of relevance and reliability (IASB, 2005). The trend towards representational faithfulness as a primary quality of financial reporting began as early as the late 1980s (Hendriksen and Van Breda, 1992). This is consistent with the IASB's prioritization of relevance in its qualitative characteristic hierarchy (Whittington, 2008). Faithful representation includes the elements: verifiability, neutrality and completeness (IASB Framework, 1989, QC 16). Further, the definition of verifiability has assumed the form: 
"Verifiability implies that different knowledgeable observers would reach the same general consensus, although not necessarily complete agreement... [as to value measurement]"

(IASB Framework, 1989, QC 23).

This uncouples reliability from representational faithfulness, derived from past transaction-based historical cost by employing an indirect definition of verifiability (Whittington, 2008). This has been an important move by standards setters in the trend towards the coherence of singular measurement. Notably, assets are no longer "the result of past transactions", with IASB Framework 49(a) eliminating this as redundant (Whittington, 2008). Where this is semantically and grammatically reasonable it is unlikely that this change was motivated by pedantry. It is more plausible to infer this is an element of standards setters' attempt to undercut historical cost.

\subsection{Summary of broad trends in regulation development}

In broad terms, regulators moved from a descriptive operation of accounting regulation development from existing practice to an investor-focused, decision-usefulness perspective. This development dates to the period of the mid1970s. This trend has reduced the influence of stewardship as an element of accountability and its reliance on, and implicit support for, historical cost accounting measurement, matching (of revenues and expenses), its transactionbasis to accounting measurement and its assertion of reliability. In its stead regulators have moved to prefer relevant, prospective, decision-useful information that is investor-focused. This trend has been augmented by the relegation of reliability as an element of representational faithfulness rather than a primary qualitative characteristic in its own right (Whittington, 2008).

\subsection{Political influences on regulation}

Throughout its history, accounting regulation has been subject to a diverse range of political influences (Solomons, 1979; Tan, 2007; Elbannan and McKinley, 2006). Partisan constituents have pursued their sectoral interests in 
preserving existing accounting foundations and in challenging those foundations and treatments (Iqbal, Melcher and Elmallah, 1997; Miller and Redding, 1988; Benston, Bromwich, and Wagonhofer, 2006). The influence of culture on accounting has also been observed (Riahi-Belkaoui, 2002). Accounting is generally acknowledged as a societal institution and its democratic legitimization operates to justify this fact (Ordelheide, 2004; Solomons, 1979). That is, the legitimacy of accounting establishes an onus on accounting to satisfy society's requirements of it. One central structural political influence on accounting has been the move towards common global standards. An under-acknowledged cause of this trend is Markowitz's portfolio theory (Clark, Hebb, and Wojcik, 2007). ${ }^{20}$ This, in turn, has at least implicitly supported the move to standardize accounting about a fair valuation basis. Politics have had a complex series of influences on accounting regulation. The preceding discussion suggested political considerations caused the FASB to forge ahead with a distinct prescriptive approach to regulation that departed markedly from existing practice. Other influences can be seen in the lobbying of industry groups, including opposition to a move away from historical cost by bankers and protest against the expensing of employee stock options, proposed by SFAS (FASB) 123. Against this background standard setters, since 1973, have made consistent, often discrete progress towards a coherent conceptual framework and fair valuation in accounting standards. This is, in part, due to their legitimacy agenda, which has made the Board substantially non-partisan (Fogarty, 1992). This does not entail that it has not been unconstrained, as is reflected in resistance to a number of FASB proposed standards. It is reflected in the fact that the FASB has promoted controversial standards, some of which it has had to back down on, that I infer the organization's freedom from bias. This inference is conditioned by limitations to the FASB's power.

\footnotetext{
${ }^{20}$ Portfolio theory creates an important pressure for cross-sectional comparability. This is significant for international accounting standardization because optimal geographical (and concomitant sectoral) diversification indicates international investment allocation. This, in turn, indicates the need for standardized financial reporting.
} 
Some reasons exist to infer that the contemporary accounting valuation debate, consistent with past debate, observes a sub-optimal trajectory. It has been argued that the FASB has fallen captive to constituent groups (Levitt, 2007; Stigler, 1971; Richardson, 1981). Also, it is notable that PriceWaterhouse Cooper's opposition to regulation, proposing self-regulation by the accounting profession, has been in evidence from at least the start of the shift in regulators' intentions towards current and, more recently, fair values, that is, since the mid1980s (Berton and Schiff, 1990). This general influence of the profession on the regulator has been an enduring factor confounding the independent operation of the Board and its progress towards a coherent conceptual framework and standards derived from such (Levitt, 2007).

The potential for improvement in this condition arose with preparercommunity independent funding for the FASB provided under the SarbanesOxley Act (SOX). ${ }^{21}$ However, the introduction of public funding, compared with independent funding, continues to constrain the independence of the FASB (Levitt, 2007). The case has been made that the FASB, and FAF (Financial Accounting Foundation) Trustees who select the members of the FASB, should possess a demonstrable regard for the investing public. Levitt (2007) has proposed a mission statement prioritizing the investing public to help to avoid the present convolution in accounting standards, instantiating transparent, comprehensive and cohesive accounting information. Present standards' complexity reflects diverse constituents' demands (FASB, 2002).

This general situation feeds into accounting debate as the generative theories of particular standards, however ill-defined, are progressively perverted by compromises to vested interests (IASB, 2006b). It follows from this that empirical evidence for, for example fair value, is modeled and tested around dilute, confused forms of the original theoretical foundations (Herz and

\footnotetext{
${ }^{21}$ An interesting if tangential question is whether 'constituent' demands have grown in disproportion to evolving standards, subsequent to the levy-based FASB vote from public funds, established under SOX. Certainly, this would entail valuable leverage to donees of the marginal FASB funding, especially given the ability of the preparer community to protest the inefficacy of a substantially better financed FASB.
} 
MacDonald, 2008). The growing size of FAS-133 Accounting for Derivatives reflects this influence (Levitt, 2007). Once a relatively brief document, FAS-133 continues to grow into (presently) over eight hundred pages of rules and interpretations. This development reflects the importance attached to partisan constituencies in the evolution of accounting regulation, in what has been a persistently highly politicized field (Tan, 2007). Bratten (2004) argues that the litigious US environment poses unique risks of rent-seeking behavior against auditors if the move to principles-based accounting is too precipitous. In this context, auditor demand for rules establishes a significant source of the complexity in US accounting regulation.

The case may be made that the described situation exemplifies accounting standards' setting as an area that is uniquely vulnerable to capture (Levitt, 2007; Stigler, 1971). The aggregate importance of financial accounting relevance to the investing public must exceed the gains secured by particular vested interests as those interests gain only as a function of their ability to exploit the agency relationship for economic rents from such exploitation, less transaction costs and 'disinformation' costs of exploitation. In the case of accounting regulation the concentration of vested interests, coupled with the structure of regulation and the regulator's dependence on preparer funding, functionally assure the capture of the regulator, at least partially. In this context it is not obvious that the existing structure of regulation is conducive to the development of a general theory of accounting for business enterprises or, that even if this is achievable, the principles of such a theory will translate into standards. This, however, stands as an argument for levy-based funding of the standard setter, directly channeled to that body, sufficient that it is not dependent on the preparer community. The case for fair value, except as it has manifested under the current structure as a dilute component of mixed attribute accounting, is not centrally conceptually implicated in this issue.

In general terms the debate between fair value and historical cost proponents is highly political (Zeff, 1991; Fearnley and Hines, 2003). Frequently 
arguments are employed to confuse important issues rather than address them. The following discussion considers the rival positions. An assessment of the merits of the respective arguments is made. This references back to the postulates and principles described in the preceding chapter.

Beyond 'constituent' resistance the tension between private standards setting and government control of the regulatory process has been influential on the FASB (CFO, 2007). Prior to 2002, funding for the FAF, the parent body of the FASB, was sourced from product sales and voluntary contributions. Subsequent to the enactment of SOX (2002), section 109, funding came via a levy paid by public issuers. The SEC controls this funding, requiring annual budgets from the FASB for SEC approval. In 2007 the Commission delayed Board funding for four months, until it was granted greater power by the FASB to determine the composition of the Board (Rappeport and Leone, 2007). This poses risks to the neutrality of the FASB as the SEC is subject to direct political pressure from constituent-enlisted Senators and Congressmen. The specialized nature of political interest in accounting issues, which is largely reactive to lobbyist pressure or adverse economic circumstances, has shown a tendency to compromise the integrity of ostensibly democratic influence exerted over the SEC, through Congress.

The politics of accounting regulation has been significant in the development of international accounting standards (Zeff, 2002; Chorafas, 2006; Alexander and Archer, 2000; Street, 2007; Benston, et al, 2006). The IASB has been beset by risks of interference, constraining its ability to too tightly specify standards or eliminate accounting options (Zeff, 2002). The organization has encountered aggressive responses to any requirements it has attempted to impose that constituents find objectionable. Through to the late 1990s the IASC (predecessor to the IASB) was regarded very much as an inferior standard setter by the FASB and SEC (Volcker, 2001). At this point it was a voluntary organization, composed of up to eighty members that was, in general, viewed as producing minimal substantial contributions to standards development. Being 
composed of numerous member countries, the IASC had difficulty achieving significant progress (Street, 2007). Further, some professional bodies selected delegates as a reward for service to accounting in general rather than due to participation in national standard setting, potentially being represented at the IASC by people without any interest or proficiency in the standard setting process (Street, 2006).

Under the leadership of the UK, that which was known as G4+1 evolved as a rival international standard promulgator. This 'union' was composed of English-speaking countries with broadly consistent views on the objective functions of financial accounting. Tension arose between the respective bodies, in particular, when G4+1 proposals were assumed under the IASC banner without acknowledgement (Zeff, 2002). The European Commission moved from effective disdain for the IASC to a supportive position, largely as a reaction to concerns that their standards setting autonomy would be subsumed by US GAAP (Camfferman and Zeff, 2006). A realization by the major standards setters that conflict between them would be mutually damaging led to the IASC's acceptance of its need for structural change, promoted to it by the SEC and FASB (Zeff, 2002). In 2000 the IASB assumed a structure similar to the FASB, paving the way for concord in subsequent years, facilitating continuing progress towards convergence.

The political influences that beset the IASC (and, later, the IASB) were distinct from, but no greater than, domestic political pressures on the FASB. Through the 1990s the FASB had to retreat from a number of proposed standards, including: their proposal to take fair value adjustments to marketable securities into income, the mandatory twenty year maximum amortization of acquired goodwill, and expensing Employee Stock Options (ESO's) (Zeff, 2002). Lobbyists enlisted the support of numerous government agencies, including Senators, the Chairman of the Federal Deposit Insurance Corporation, The Secretary for the Treasury, and the Chairman of the Federal Reserve Board (Zeff, 2002). In the 1990s pressure for more 'pragmatism' on the part of the Board led to 
an increase in Board representatives from industry, from one to two (Mattli and Buthe, 2005). The requirement for a simple Board majority (4-3) was replaced with a supermajority (5-2) requirement when instituting standards due to lobbyist pressure (Mattli and Buthe, 2005). The power of the US enforcement mechanism, through the ability of the SEC to suspend trading in non-(FASB) compliant companies is positively related to the strength of lobbying in the US (Zeff, 2002).

Additional factors motivating convergence were the 1997 Asian crisis and, in 2001, the collapse of Enron. The Asian crisis, precipitated by a slump in Thailand's sharemarket, had far-reaching affects. The 'contagion' crisis demonstrated a need to increase financial reporting rigour (and financial asset market regulation) to developing countries, providing independent support for the development of IFRS's. Enron can be said to have qualified the self-assurance of the FASB, and the SEC in the FASB. This qualification was influenced by the somewhat disingenuous "rules versus principles" debate. The disingenuity was in that the implied mutual exclusivity takes a gratuitously simplistic stance, that the conceptual framework is, in one breath, viewed as a peculiarly American vice, and in another, a virtue of non-American accounting regulation. Nonetheless, Enron precipitated SOX and a more 'sheepish' FASB and renewed plaudits for principles-based regulation (Millstein, Bajpas, Berglof, and Claessens, 2008). These factors were significant in the impetus behind the new (2000) IASB and its role in standards setting.

It was in this context, and in the FASBs explicit responsibility to converge with IASB standards, that control of domestic political forces operated to commend FASB support for the International standards setter (Zeff, 2002; Camfferman and Zeff, 2006; Benston, Bromwich, Litan and Wagenhofer , 2006; Street, 2006). This, in turn, required an international organization more effectively structured than the IASC to advance accounting standards standardization (Street, 2007). The IASC need for a $75 \%$ majority to pass standards, the lack of standards setting inclination or aptitude of many delegates, and the cumbersome size of the IASC, led to US (FASB; SEC) pressure to transform the IASC into a smaller 
Board of professionals, supported by an expanded staff (Street, 2007). These initiatives resulted in the replacement of the IASC with the IASB in 2000 (Zeff, 2002; Street, 2007; Volcker, 2001). Subsequent to this development, progressive steps towards common standards is in evidence. Standards are now developed endogenously between the FASB and IASB, in a functionally continuous feedback loop.

The conventional view of accounting (GPFR) is that it should account for the managements' stewardship of investors' contributed capital using historical cost. This has served a variety of interests well. This has led those interests attending their own advantage in historical cost accounting to resist developments in regulation away from traditional accounting foundations. An important group who resist the trend towards fair value is the banking sector. I identify this group for separate consideration as it is instructive of the importance of the narrowest possible user definition. The banking industry has expressed general objections to any movement away from historical cost accounting, using their creditor status to advance arguments that are inseparable from their issuer role. In effect this revisits the now widely discredited consideration of managers as users. That is, their resistance to fair value relates essentially to the heightened volatility fair value entails for their financial assets (Alkon, 2006).

The banking industry has expressed concern that the increased volatility of fair value accounting for financial instruments will adversely impact their cost of capital (Alkon, 2006). This, it is argued, has resulted in increased share price volatility subsequent to FAS 133, a standard introducing fair value accounting for derivatives. $^{22}$ Evidence collected by Alkon (2006) suggests no such realized (in the share price) volatility would occur as markets had already priced it in. What is not clear is why banks felt any increased share price volatility would be unjustified as a reflection of inherent industry risk, enabling the more efficient allocation of capital (away from the banking sector). Further, the concern raised

\footnotetext{
22 This standard introduced a scale of varying degrees of fair value relative to the 'hedge' or speculative character of particular derivatives.
} 
by banks that fair values may cause breaches of reserve requirements, as they could not control recorded accounting values by retention or realization, is an argument against bank prudential regulations simpliciter or at least an argument to lower reserve asset ratios.

Banks specifically argued that the market value of their loan portfolios may not reflect their full economic value to the bank (Carroll, Linsmeier, and Petroni, 2002). This is an argument for a firm-specific discounted cash-flow advantage in holding a particular asset. Another argument made by the banking industry was that, in their capacity as creditors, the conservatism of the historical cost realization basis for recognition better enabled them to assess the credit risk of potential debtors (O'Brien, 2005). This argument offers the appearance of disingenuity as it presupposes banks' credit risk modeling cannot adapt to any change in accounting numbers. The assumption that this provides a margin of safety is uncertain. It is almost certainly untrue of the historical costs of newly established companies in sharply falling markets. Moreover, the heterogeneous nature of historical cost valuations provides a highly variable safety margin where there is no obvious reason why banks could not lend against fair values at a reduced percentage of that value. This argument importantly identifies the reason for the priority I have given to a narrow user definition. The argument confounds accounting regulation progress in that it frustrates identification of the substantive reasons for objection to particular regulations. Thus, an independent basis for the user-as-investor is its practical advantage.

Another 'user' group that has identified itself as such is Financial Executives International (FEI). They have argued for historical cost measurement (Cunningham, 2004). As former CEO of FEI, Cunningham argued on behalf of her members, in the 2004 issue of Financial Executive article "Fair Value. Fair for whom?", that relevant information that was not reliable was useless (ToppeShortridge, Schroeder, and Wagoner, 2006). The disingenuity of this argument against fair value was reflected in her subsequent acknowledgement that financial analysts would prefer to retain the competitive advantage they had in deriving fair 
value information from historical cost accounting reports (Fink, 2006). This is effectively an argument for industry enclosure by proxy rather than a concern for the relevance or reliability of accounting information. FEI has been remarkably consistent in their opposition to developments in accounting regulation, reflected in (then) FEI President Phil Livingston's opposition to expensing ESOs (Zeff, 2002). Again we see a diverse GPFR user definition confounding coherent standard development, elevating the particular interests of the ostensible user. It is not clear that analysts as users are other than derivative users and that this derivation is a function of investors-as-users.

The persistent resistance of FEI to accounting change is admittedly extremist. The voluble objections of Livingston to expensing ESOs reflected the general commitment of the organization to financial reporting opacity and obfuscation. To argue, as Livingston did, that the treatment of such employee compensation in the US was not going to change, that it was an intractable issue (Zeff, 2002), and that the IASB should therefore leave it alone, transpired not only to be incorrect, it was manifestly partisan. The comment was made against the backdrop of the rise of technology companies and their penchant for ESO largesse. That an organization of (presumed) credibility could argue so insistently for the vested interests of 'employees' (management) of technology companies (amongst others) should have been reasonable grounds to discredit the views of the organization. Their argument was predicated on an heredity of theft concealment and the putative right that heredity warranted to its continuation. Nonetheless, the organization has been a vocal and influential participant in the politics of accounting regulation.

The role of politics on accounting regulation took one of its most extreme manifestations in the vociferous protests following the FASB ED (1993) proposal to expense ESOs (Ratliff, 2005). The exposure draft (ED) (1993) that proposed a requirement to expense ESO was diluted in SFAS 123 to a recommendation to expense ESO. Various suspect arguments were raised including: 
1. That ESOs do not need to be expensed as their impact is already reflected in the subsequent dilution of equity investors' interests upon issue of securities, pursuant to the terms of the options or, as is now the case, reflection of the impact is made by the fully diluted basis (Hagopian, 2006).

2. Where options have no intrinsic value, that is, where the current market price is equal to or greater than the issue price, they entail no cost to shareholders.

3. Stock options are impossible to value where they are subject to certain restriction/conditions that do not apply to market-traded options.

4. It was argued that expensing ESOs would have a detrimental impact on US business by lowering earnings, reducing innovation and competitiveness in the international marketplace (Ratliff, 2005; Schroeder and Schauer, 2008).

In relation to these arguments, number one, while true, it is always true of any expense that it will dilute the claims of shareholders. It is not obvious what construction might be put on employee compensation other than viewing it as an expense. In relation to point two (above), if the options have no value, thus entailing no cost to the company, why do employees want them? Further, if employees were to be paid the equivalent value in cash, and we grant that options are not an expense to the company, why are salaries an expense? Protests over SFAS 123 delayed the implementation of obligatory ESO expensing. It also involved intervention by politicians (Ratliff, 2005). In relation to point 4 , this assumes a profound level of market inefficiency. It is not clear that the change would have a significant impact and, if it did, whether that impact would have been broadly negative. It may have anticipated the deflation of the 'tech bubble'.

\subsection{Summary}

A diverse range of political influences impact accounting regulation. This has been seen in arguments for and against specific accounting treatments and changes in these over time. These political forces have operated on and between standards setters with, until recently, an implicit 'demarcation dispute' between the IASC and FASB (and FASB-plus, G4+1). Until the succession of the IASC, by the IASB, the SEC and FASB view of the superiority of their organization was 
probably warranted (Volcker, 2001). FASB control of political forces has almost certainly contributed to the advancement of the IASB (Street, 2007). The central intuition behind the proposed theory of accounting is that, from both a practical and conceptual perspective, the more we can narrow the definition of GPFR users, and the more we can filter out the influence of political forces on standards development, the greater the basis for confidence in developing a general theory of accounting (Miller, 1999; Dalessio, et al, 1999). We can eliminate numerous confounding influences. I also make the case that standards' setters have discretely, incrementally been guided by this intuition and that they have been remarkably successful in implementing an understated, conceptually coherent conceptual framework and standards, against a challenging political environment.

The preceding discussion serves a number of basic functions in relation to the proposed theory. It establishes the factors preventing the formation of a coherent theory of GPFR to this point. In some sense this qualifies the improbable presumption of a viable theory of accounting that has been unattainable to this point. Beyond this, the elements that a coherent theory of GPFR must contain are inferred from an examination of historical developments. Specifically, the central importance of accounting as a constraint on market breakdown is inferred as the fundamental societal interest in GPFR is inferred from the reactivity of accounting regulation. This supports the view of accounting reports aimed at informing investor decisions. Secondly, from Moonitz (1961; 1962), Sprouse (1962) and Hendriksen (1982), I extract the central intuition for specification of the descriptive characteristics of the socio-economic environment. These factors provide a frame for the development of my theory. 


\section{Chapter Three}

\section{A general theory of accounting}

\subsection{Introduction}

This chapter relates contemporary accounting theory to its historical development, explaining why it has failed to achieve coherence. From this base, I argue for the establishment of a theory of GPFR, drawn from identified postulates. The objective is an internally consistent, externally optimal theory that establishes a framework for the development of GPFR standards.

\subsection{The current state of accounting theory}

Accounting to this point has been characterized by the underdevelopment of a referent theory (Hendriksen, 1982; Higson, 1983, Staubus, 1999; Inanga and Schneider, 2005; Zeff, 1971; Loftus, 2003). In the 'positivist era' this has led to sub-optimal theorizing that relies on sophisticated methodologies but delivers insubstantial conclusions (Inanga and Schneider, 2005; Stamp, 1984). Against this, normative theories involve risk in the assumptions they must make (postulates) about the desired state (Inanga and Schneider, 2005). Part of the reason a coherent theory of accounting has failed to evolve is that heterogeneous user definitions entail accommodating irreconcilable imperatives of different users (Beaver and Demski, 1974; Benston, et al, 2006). It has been suggested suppressing user heterogeneity would aid coherent accounting theory development (Beaver and Demski, 1974). The FASB have acknowledged the barrier to a coherent conceptual framework, describing "much of the detail and complexity in accounting as demand-driven" (FASB, 2002, pp. 2-3). Further, relaxing the assumption of the self-containment of individual financial reports would reduce the dichotomous, conflicting relationship between stewardship and decision-usefulness (Gerboth, 1973; Beaver and Demski, 1974; Crowther, 2002). Coherence has also eluded accounting theory due to the influence of culture on accounting (Belkoaui, 1981; 1989; Riahi-Belkoaui, 1995; 2002; Iqbal, et al, 1997). These factors have, in aggregate, frustrated coherent accounting theory. 
The identified problem with the existing state of accounting theory is that it has fairly consistently been a product of consensus by compromise. As cited in the introduction, Higson (2003) locates this as the central reason for the failure to achieve accounting theory progress. Where I have specifically identified this approach within the period to 1950, it has been more pervasive than this. Existing concepts such as decision-usefulness are defined around observed practice and investor behavior (Inanga and Schneider, 2005). Arguably, accounting is still in a pre-science phase of its development (Henderson and Pierson, 1983). The period of high-sounding stakeholder theory has frustrated accounting theory development (Henderson and Pierson, 1983).

Accounting theory development has also been frustrated by a multiplicity of theories that have been about different things (Higson, 2003). Included in this array of theories are concepts of stewardship, the agency relationship, accounting as a study of accountants, and ranging interpretations of objective functions of accounting. Dichotomies drawn in absolute and mutually exclusive terms have contributed to this problem (Fields, Lys, and Vincent, 2001). It is purposive of general accounting theory development to recognize that positive theories are also necessarily normative in part, and that no normative theory is meaningful of anything more than opinion without positive elements (Higson, 2003; Whittington, 1987; Tinker, Merino and Neimark, 1982). This is acknowledged in the theory proposed by Sterling (1970). In essence a normative theory must lever itself from a sensible view of the world (Demski, 1973). In this sense we can infer to the false dichotomy between positive and normative theories. This discussion will also discuss another important yet false dichotomy; that asserted between decision-usefulness or relevance and accountability.

The aggregation of these forces confounding theory is causally significant but it does not address the central problem for accounting theory. Accounting is very closely proximate to its practical implications. It is this closeness, that of the endogenous nature of the influence of accounting and its domain, that conditions progress towards a coherent conceptual framework and, even more so, financial 
reporting standards. High-level abstraction is less available in accounting than in many other fields of enquiry because of the immediacy and nature of accounting's practical implications. This makes accounting generally more inherently political than, for example, finance or economics. This is a function of accounting as, at one level, an applied technology and, at another, the entailment of compulsion in accounting regulation. Normative accounting theory analytically entails prescription (what should be). In a regulatory context, it is close to what is (in regulation). Conversely, in finance, disagreements consist between different descriptive accounts of reality. Any, or none, may be correct, but their substantial character more clearly references against discrete, particular predictive successes and failures. For accounting, to this point, there is not even consensus over what would constitute success or failure. This, at least partially, may explain the differential progress between conceptual frameworks and the standards generated from them (Weinstein, 1987).

\subsection{Foundations for a general theory of accounting}

An important contribution to the development of accounting theory was made by Ijiri .The described essential elements of a theory of accounting include (Ijiri ,1971; 1975; 1983):

1. Novelty: The theory must tell us something new and interesting (substantial) about the world.

2. Defensible: The theory must be defensible either in logical or empirical terms, or, more probably both. It must be supported by evidence.

3. Availability through dissemination: A theory of accounting must be presented in the 'public' sphere. This relates importantly to people operating within the discipline and would entail such things as conference presentations or publication in books or journals.

These criteria reflect the need for a theory to have some (possible) influence and to be subject to review and critique by experts (Inanga and Schneider, 2005). 
These criteria are generally uncontentious and, prima facie, offer no reason for challenge.

A further contribution to the development of accounting theory is that of Hendriksen (1982). He made the case that all testable theories require deductive and inductive elements. Following from this, we must stipulate testability as a criterion for sound theory development. Deduction requires the following theoretical elements:

1. The formulation of general or specific objectives of financial reporting.

2. A statement of postulates of the social, economic, political environment in which accounting operates (I reverse the order of these, holding 2 as the basis for 1).

3. A set of constraints to guide reasoning.

4. A structure to express the theory.

5. The development of a set of definitions.

6. The formulation of the principles of policy derived from logic.

7. The application of principles to specific situations and the development of procedural rules (Hendriksen, 1982).

By taking the practical consequences of 7 , derived from 3, 4, 5, and 6, in relation to the described environment (2) and objectives (1), the basis to inductively test a theory arises. ${ }^{23}$ This requirement to test a normative theory is also supported by Henderson and Pierson (1983).

\footnotetext{
${ }^{23}$ The described environment informs the assumptions of the theory as a set relation to that environment. Testing the theory, a priori of application of a proposed theory, must consist in counterfactualism. This involves redrawing accounts on the assumption of principles derived from the stated theory, and examining the results' relationship with subsequent market movements. This is similar to capital asset market research (in some instances) in relation to fair value, where researcher estimates have been applied as the basis to compare the respective value relevance of fair value measurement against historical cost or mixed attribute models.
} 
More recently Walker (2003) has summarized the essential elements of a theory of an accounting conceptual framework. He states that the theory's assumptions must be consistent with external user behaviors and practices, it must be expressed clearly, demonstrate an internal consistency and provide a comprehensive guide to financial reporting practice (Walker, 2003). This entails a conceptual framework must hold a clear view of the objective function of financial reporting from which logical, coherent standards can be developed. $\mathrm{He}$ makes the case that ideally a conceptual framework would cover all sectors but the diversity of users this would entail provides support for separate profitorientated financial reporting, [consistent with the views expressed by Sprouse and Moonitz (1962)]. The descriptive characteristics of the theory allow the use of induction (Walker, 2003; Miller and Redding, 1988). The theory must also be of a general nature and enable prediction (Kam, 1986).

\subsubsection{The socio-economic environment}

An examination of the broad social, economic, and political environment will form the source of the postulates for the proposed theory of accounting. Nothing about this approach requires that the contemporary environment is a necessary or ideal state. This discussion is not centrally concerned with the philosophical question of determinism versus voluntarism. Equally, I am unconcerned to espouse a moral positivism of the critical accounting theorist kind. In simple terms then, the position taken here relies on the assumption of the key elements of extant society as a relation to accounting as a technology operating within that/those societal systems (Hawkins, 1973). Key descriptive characteristics forming the postulates for the proposed theory include the existence of society, capitalism in the generic sense of the mixed economy, the rise of the corporation, free labour, the centrality of the market as a determinant of distribution and price, and globalization and its implications.

Before addressing finer points of the prevailing socio-economic environment it is useful to consider existing social organization in terms of its most general qualities. This is not a sufficient basis for the specification of 
accounting postulates but it is a precondition for establishing those postulates. Existing social organization is structured as (largely) democratic societies. The accent I would place here is on society. This involves the implicit agreement to collective protection against reduced individual freedoms (Cudd, 2007). In terms of democracy, this only qualifies the particular focus of society's elements. It informs the view of Hobbes' society as the sovereign to sovereign as the populace in general (Cudd, 2007). It is difficult to see how a legal fiction, the corporation could exist, outside of such an arrangement (that is, society) (Marcoux, 2008). This point is one I return to shortly.

The broad environment in which contemporary accounting operates was described by Moonitz (1961) and Sprouse and Moonitz (1962). They describe an economic system in which most productive assets are owned privately, in which labour is free, that is non-slave labour, and in which the market is the primary mechanism for the distribution of goods, services and equities determining the prices for these. The growth in the corporation as a central component of capitalism is observed by Most (1982). The corporation grew rapidly as an institution over the nineteenth century in the United Kingdom and concomitantly, and subsequently, in the US and the rest of the world (Giroux, 1999). The industrial revolution was the force propelling this rise. From 1760 Britain began to transform from an agrarian, cottage industry-based economy into the largescale factory production-based economy of the industrialization (Alexander and Britton, 2004). The increased scale of business increased individual business capital requirements (Most, 1982; Alexander, Britton, and Jorissen, 2007). This, in turn, created the need to aggregate individual investor capitals. From this, society's interest in the capitalization of business was reflected in the legally enshrined corporation and its liability limitation to investors contributed capitals. $^{24}$ The separation of management from financing established the need for the provision of financial information by management to investors.

\footnotetext{
${ }^{24}$ The limitation of liability actually applied to paid and promised capital, the total sum reflected in the par value of shares. This is not important for the present purposes but it entails that where shares were not fully paid (to par), further investor liability to that amount existed.
} 


\subsubsection{Globalization}

Globalization has been a more general condition in the development of modern economies than the term's most recent coinage would suggest. In the period to the First World War the world economy demonstrated a linear trend towards integration with expanding trade and investment flows. The inter-war period, and until the 1970s, reversed this trend with national economies inclined towards regulated markets and fixed exchange rates (Padoa-Schioppa and Saccomi, 1994). This period was characterized by insularity and autarkical national economies, operating on substantially mercantilist lines. The period of isolationism seems best explained by abduction, to the combined influences of two world wars and the Great Depression causing a period of trend reversal, rather than a Pareto Optimal alternative. International trade did, however, begin to expand in the immediate post-war period, creating pressure on the Bretton Woods agreement (Padoa-Schioppa and Saccomi, 1994). Progressively, from the late 1970s, national currencies have been floated, facilitating international trade and investment flows (Wray, 2007). From this basis I stipulate globalization as a longterm, persistent trend and fundamental feature of modern economics (IASB, 2007). Globalization has been central to the progressive impetus towards convergence (Jermanowicz, Prather-Kinsey and Wulf 2007). Global capital flows have created increasing pressure for international GPFR comparability (Hughes, et al, 2007).

The trend towards globalization has heralded an era coined the "Great Moderation". This is a term for a period of historically low inflation and GDP volatility across the developed world, within a period, dating to the early 1980s, of sustained economic growth (Bernanke, 2004; Stock and Watson, 2003; Willis, 2003). To this date no precise specification of the causes of this idyllic state has been forthcoming. A variety of reasons are posited, including: An improvement in macro-economic management, ${ }^{25}$ the operations of central banks, the absence of

\footnotetext{
25 Bernanke, 2004; A similar confidence in monetary policy was felt shortly after it was first introduced in the late 1920s (Degen, 1987). The quality of central bank stewardship of the economy (US) is questioned by Schwartz (2008), and Friedman (1999).
} 
negative supply shocks ${ }^{26}$, and structural changes in the economy supportive of stability. These include increased labour market flexibility (Willis, 2003) and the emerging predominance of less volatile service industries (Bernanke, 2004). A concomitant (trade-off?) of the 'Great Moderation' were elevated exchange rate and asset market volatility, which has increased markedly since the early 1980s (Issing, 2003; Wray, 2007; Yamaguchi, 2003; Dymski and Pollin, 1992; Campbell, 2005; Crockett, 2003). Another potential explanation, one that relates to the recent economic malaise, for these developments is that of financial market liberalization from the early 1980s (Friedman, 1999; Wray, 1992; PadoaSchioppa and Saccomi, 1994; Kregel, 1992; Kindleberger, 1992; Dynan, Elmendorf and Sichel, 2005; Checcetti, Flore-Leganes and Krause, 2005). Allowing that the progressive increase in (typically) developed, Anglophone country national and household debt is related to finance industry liberalization, we have reason to infer the 'wrinkles' have been, until recently, inflated away by the availability of credit through above trend endogenous money supply growth. ${ }^{27}$ Given prior stipulation of globalization, increased global asset market volatility is anticipated as a central structural development in the current economic era (Bordo, Mizach, and Schwartz, 1995; Brousseau and Dretkin, 2001; Fergusson, 2003; Borio, English and Filardo, 2003; Mussa, 2003). ${ }^{28}$

The significance of globalization in relation to accounting has been in the progressive trend towards global standards to facilitate global investment flows (Iqbal, Melcher, and Elmallah, 1997; Hopwood, 1989; Rutteman, 1989). The ascendancy of international accounting standards and their need for a uniform measurement base has occurred parallel to growing challenges to historical cost accounting measurement (Bromwich and Hopwood, 1983). It is possible to infer

\footnotetext{
${ }^{26}$ Nakov and Pescatori, 2007; Summers, 2005, provides a contrasting perspective.

${ }^{27}$ Dynan, et al, 2005; Debelle, 2004; Dynan and Kohn, 2007; Lansing, 2005; Greenspan and Kennedy, 2007; Faulkner-MacDonagh and Muhleisen, 2004; Dynan, Johnson and Pence, 2003; and Friedman, 1992.

${ }^{28}$ The value attended to this issue is in the basis it provides to challenge objections to fair value on the basis that fair value reflects increased volatility. Inference: Fair value affords the impression of greater volatility. Volatility has increased, thus, fair value better reflects reality. Stated this way, this objection seems fairly weak.
} 
the case for fair value has been advanced by the pursuit of global standards. Independent of its inherent qualities, reason exists at the pragmatic level of its established traction, that there is reason to prefer Fair value. This is a significant counter to pure theoretical proposals such as that entertained by van Zijl and Whittington (2006), in favour of deprival value.

\subsubsection{Summary}

Against the backdrop of the current environment and developments in accounting theory and regulation, the proposed theory will be advanced, informed by the central intuitions of Ijiri (1971; 1975), Higson (2003), and Hendriksen (1982). Their approach follows in the mould of accounting theory development of the normative era, relating postulates as rational inferences from the existing environment. The current state of regulation, particularly at the level of conceptual frameworks, reflects a general trend towards the coherence promoted in the normative era. This discussion will outline an explicit theoretical basis to the theory of accounting implied by standards setters. I interpret a tiered ability to propound pure accounting theory. Due to the essentially political nature of accounting, coherent theory will be most contentious in relation to standards, and then in varying degrees to particular standards (Rutteman, 1989). Conceptual framework development, with less immediate or obvious implications will be less difficult to achieve and, beyond this, academic theoretical development will be the least contentious arena due to its distance from application. It follows that academic accounting is circumstantially situated (and indicated) as best-placed to assert and expound otherwise implicit theoretical developments in accounting. Academic accounting is also best positioned to elaborate normative accounting theory, independent of conceptual framework developments. This is the central motivation of this discussion.

\subsection{GPFR user defined}

\subsubsection{Introduction}

The discussion to this point has presaged identifying the investor as the sole GPFR user. This conforms with the central intuition expressed by Beaver and 
Demski (1974) and Jensen (2001), who argue that if the objectives of accounting (and corporations) are posited as being very broad, their function, will be too complex to be achievable. Where Jensen (2001) focuses on the corporate function the present thesis concerns itself more directly with the relation of that function to GPFR information provision. These parameters bypass the need for an independent assessment of the institutional legitimacy of the corporation. Instead, the corporation is held here as an objective entity and accounting, as a fixed relation to the objective function of the corporation. This view is informed by Sprouse and Moonitz (1962) and draws on the prevailing socio-economic environment, describing the central elements of the environment as the basis for postulates underpinning GPFR. No stipulation or case for the necessary or optimal nature of that environment is made.

The preceding discussion of stakeholder theory importantly impacts views of GPFR users. As noted, this theory has led standards setters and academics to infer to an extensive array of users (stakeholders). Stakeholdership has historically been identified with use. I have made the case that use does not warrant the right to use. Further to this point, as a relation to a societal view of stakeholdership, and stakeholder theory as a derivative of social contractarianism, the case is made that the investor as sole GPFR user can be reconciled with society's best interests. In part, this issue will be considered by addressing the question of who is not a stakeholder and the reasons for this.

Specific foundations for assessing the user status of GPFR will be outlined. This discussion includes objective functions of GPFR and the respective groups' ability to access their reasonable information requirements (Most, 1982). I will consider the current versus potential investor debate, making the case that they are type identical and that by specifying one, the other is necessarily implied. This issue relates to the reconciliation of stewardship with decision-usefulness as subsets of accountability and relevance. The guiding motivation for this approach is the development of a logically-derived, coherent accounting theory that, 
accommodating pragmatic considerations, aims at narrowing the determinative variables that form the theory's postulates and principles.

\subsubsection{The Determinative Characteristics of a GPFR User}

With the grant of the previously described socio-economic environment, certain characteristics mark out the legitimacy of a user of GPFR in their financial report use. Their relation to the company's financial metrics must be an essential one and the general user's need cannot be satisfied by the ability to require the information (Staubus, 1999). The essence of the company is that it is a legal fiction designed to facilitate the aggregation of investors' capital. The aggregation of capital to facilitate business scale in pursuit of profit maximization at any given level of risk is the corporation's objective function (Jensen, 2001). The essential relationship between capital and the company is that capital has an indefinite lifespan and that, in its absence, there is no corporation. It is not governed by specific contracts, with fixed and pre-determined terms, it cannot directly compel satisfaction of its information demands, and it is always a residual interest, after the satisfaction of all liabilities (FASB, 2007a). This point is one Staubus (1959; 1999) has expounded, identifying equity investors as having the greatest information needs, being subject to harm from excess information, existing in a uniquely non-contractual relationship to the company, and requiring the greatest degree of attention to isolate the residual or equity value of a company (Liam, u.d.; FASB, 2007a).

These factors place investors in a position of unique risk in the capitalist/mixed economic system (Staubus, 1991; 1959). It has been argued (Jensen, 2001) that the satisfaction of the information requirements of investors will satisfy the needs of all other GPFR users. This view is one that major standards setters have adopted (Trueblood, 1973; FASB, 1978). It is not an uncontentious position but it is consistent with the generic utility function of the corporation; to aggregate capitals to maximize profit. It can improve this function of profit maximization where the information demands of investors are satisfied, without consideration of other user information needs, by enhancing the 
efficiency of the market in capital allocation through the reduction of information asymmetries between management and investors (Jensen, 2001). This proposition is an argument for utility maximization through efficiency and concomitant economic growth (Lev, 1988). As previously, this is qualified by silence regarding wealth redistribution. If this is an important question, and it may even be stipulated that it is, it is not one with relevance to GPFR (Bromwich, 1992). To adulterate GPFR would create a lottery for information claims based on the relative power of the claimants. This, presumably, would entail more conservative general outcomes than are anticipated by the stakeholder/critical theorist proposition of diverse GPFR users.

In contrast to Lev (1988), minimizing information asymmetry between naïve and sophisticated investors presupposes inherently complex information can be presented simply. This is rejected in view of the risk that simplification would entail an unjustifiable reductionism. For this reason the sophisticated user, the analyst, is a suitable proxy for (the investor) accounting regulation to target. This view challenges Cunningham's (2004) position that fair value accounting threatens her membership's (FEI) competitive advantage, yet, secures support from that position. Cunningham is implicitly arguing that fair value takes the investor too close to the knowledge her membership sells those investors. Logically, information simplification entails selection risk and 'leaps of faith' on the investor's part. This presumption that direct targeting of the naïve investor is the objective of GPFR appears impractical and functionally unattainable. Logically, the sophisticated investor would re-establish their competitive advantage, and utilize the time not spent analyzing financial reports, augmenting this information elsewhere, assuming that the simplified GPFR satisfied their information needs in the same manner that analysis of current GPFR does.

\subsubsection{Investors as GPFR users: Current and Potential?}

The recent focus of disagreement and debate surrounding international accounting standards has evolved now that the GPFR user primacy of the investor 
has been established in the stance taken by the IASB and FASB (2007; 2007a; 2007b). Tentatively, the IASB have advanced the idea of potential investors as GPFR users since 2005 (IASB, 2005). The debate now concerns whether the focus should be on current or potential investors (Lee, 2006). This has been used by historical cost advocates as a means to re-energize the distinction between stewardship and decision-usefulness and the debate surrounding it, linking the interests of current investors with stewardship and stewardship, somewhat questionably, with historical cost. ${ }^{29}$ There are reasons to hold current and potential investors as type-identical, both as a continuous set and with homogeneous information needs. Investors, however long-term, are subject to dynamic personal circumstances that may dictate the realization of investments at any given point. Beyond predictable changes including buying a house and retirement, unpredictable circumstantial changes, such as illness or injury, may alter the investor's propensity to hold investments. Similarly, outside of a dogmatic commitment to portfolio theory, company-specific and macro-economic or socio-economic changes may unseat the original reasons for investing in a particular company. Regardless of the intention to buy and hold, dynamic personal and environmental circumstances entail that long-term investors do review their portfolio, with changes to it in prospect. For these reasons the current investor is, at least conceptually, always the potential investor, whether in their decision to buy, hold or sell. Following from this the potential investor must have company financial information as the counterparty to the buy or sell choices available to the current investor. Even in the hold choice, the potential investor has a need for GPFR to establish the basis for bidding the company's securities in order to influence the current investor's decision (or to refrain from doing so). The current investor's interest lies in a well-formed, well-informed market that delivers the company's fair value, such that portfolio review decisions involve only investor-specific variables. This entails that GPFR is targeted at current and potential investors.

\footnotetext{
${ }^{29}$ This issue is addressed later in this chapter in the reconciliation of the two objective functions of GPFR.
} 
This interpretation has been rejected by Bush (2005) who argues that, in contrast to the US, accounting in the United Kingdom has developed to prioritize stewardship. He argues that this is appropriate as the shift away from a central concern for stewardship is focused on the interests of the trader (Bush, 2005). It is doubtful whether traders would generally trade on fundamental information. It is more likely they would trade the market price action following the release of such information. The case is made that US standards address the issue of secondary market pricing rather than long-term investors (Bush, 2005). This argument is disingenuous to the extent that it implies investment is impossible via the secondary market. It would only be with considerable reservation that we could characterize equities bought on the secondary market, held for twenty years, as a trading operation. Bush's view necessarily presupposes that all necessary information is contained within a single report and that decisionusefulness/relevance implies any current or potential investor will only ever need forecasts without reference to a substantive basis for confidence in those forecasts. It seems the demarcation is drawn too starkly between stewardship and decision-usefulness in the current debate. The self-containment implication of single period GPFR is unreasonable. Decision-usefulness does not obviate the need to include some historical information. It also allows that multiple GPFRs over a period are a single text and that the information contained in any single report only acquires its full context by being read in conjunction with previous reports (Crowther, 2002). Moreover, the assumption that financial accounting is the only source of company-specific financial information seems to establish a far too stylized situation to be meaningful as a referent basis for the key objectives of GPFR. If GPFR was the sole source of such information its value would be manifold its current value and, thus, provided only that its value was paid for by all of those to whom it was valuable, extensive attention to stewardship and decision-usefulness would fall within the cost-benefit constraint.

More fundamentally, Bush's (2005) view relies on an apparent logical contradiction. The position that investors buy and hold indefinitely assumes portfolio theory which, in turn, presupposes market efficiency. This is derived 
from the basis to portfolio theory that, just so long as an investor is sufficiently diversified, they can simply hold their portfolio, assuming a predetermined level of risk, without any subsequent adjustments. This necessarily assumes efficient pricing at the original transaction date, and that all risks, over an indefinite period could be known at the purchase date, yet Bush wants to tell us that successive accounting fair values, also assumed objective variables as a derivation from market efficiency, have no incremental value to the investor in supporting or challenging the generative basis of the investment decision. Curiously, Bush does not argue against relevance and fair value on grounds that such information is already implied in current share prices. His concern is that decision-useful, relevant, fair value information-focused GPFR undermines stewardship. The discussion returns to this point shortly.

The case has been made that GPFR usefulness to investors is determined by whether investors use it or not (Lee and Tweedie, 1990; Bartlett and Chandler, 1997; Epstein and Pava, 1993; Anderson and Epstein, 1996; Wilton and Tabb, 1978). Their empirical research supports the view that investors make limited use of financial accounting information and that the extent to which it is used is positively correlated to the sophistication of investors. There are unstated assumptions with the inference from general use to usefulness. The hypothesis assumes systematic market inefficiency such that sufficient rewards do not accrue to sophisticated investors over time by exploiting the information contained in GPFR, sufficient for those investors to fully exploit their advantage, eliminating economic profits. If such rewards did accrue the assumed market inefficiency would be eliminated by the operations of sophisticated investors. In such case, by whatever means the naïve investor selected their portfolio, whether by the movements of the planets or by consulting chicken entrails, they would be paying a price that reflects the information contained within financial reports. Thus, in a certain sense, naïve investors secure a free-rider advantage from GPFR that is effectively an implicit use of that information. 
The only alternative hypothesis that suggests itself is that private investors do not use GPFR because it has no possible utility to them. This is an argument against financial reporting simpliciter. We would not even be able to allow Watts' (1977) value ascription to voluntary financial reporting. Simply, financial reports, if they have any value at all, only have value to the limits of the fees preparers earn producing them. This would seem to be a curious manifestation of welfarism. Instead, we might take the view that where GPFR has little individual utility, its value as part of the broader financial information set, consists in its production and dissemination and does not require its general use. In the absence of this, GPFR information would be immensely valuable to the individual investor but given publication, its value is implied.

A final consideration favouring the investor as GPFR user arises with the variable reporting requirements imposed on various business entities based on their ownership structure. By isolating the distinguishing characteristics of publicly listed, profit-orientated entities from businesses with lesser or no general purpose financial reporting requirements, the basis for those requirements on publicly listed entities must, presumably lie in their difference or some essential aspect of it. Sole traders, partnerships and private companies have no general purpose reporting requirements imposed on them. Given this, we must reject limited liability as a foundation for the more extensive reporting requirements imposed on publicly listed companies (Marcoux, 2008). It may be argued that public companies are often larger than other business structures and that this relates importantly to their ability to influence wider society. This, in general, is true but it does nothing to unseat the societal interest in GPFR as a function of financial reports' service value to investors. Moreover, satisfaction of magnitude differences is presumably by tax rates and the proportional need for legitimization that attends scale in a reputational sense. Any contrary argument is likely to be nothing more than a 'Trojan horse' conduit to an attack on socialized capital in its most overt form -the publicly held corporation. This, arguably, supports the efficient operation of markets in securities' pricing as supportive of the greatest long-term general social benefit. The essential element distinguishing publicly 
listed entities is that ownership of these entities is by the investing public. It follows logically that the reason and optimal achievement available to GPFR is satisfaction of investors', separated from management, information demands, enabling informed capital allocation (Lev, 1988).

\subsubsection{Who is not a stakeholder in GPFR?}

Stakeholder theory tells us that GPFR should accommodate any group that uses external financial reports. Early views of stakeholdership typically suggested contemplation of GPFR users as management, investors and creditors (Smnett and Grasino, 2008), or managers, owners and social control agencies (Vatter, 1964). The important commonality is that management generally featured in earlier views of legitimate GPFR users. Stakeholders are those who, "can affect or are affected by the achievement of a firm's goals" (Freeman, 1984). They are also defined as, "those who depend on a company for the realization of their goals and on whom the company is dependent" (Steadman and Green, 1997). This typically includes, but is not limited to: regulators, investors, management, government, creditors, customers, suppliers, employees, unions, and public interest groups (Renman, 1968). To these groups Vergoosen (1994) adds analysts and competing companies. Stakeholder theory envisages and supports a diverse range of GPFR users, with wide-ranging information needs. Accommodating this perspective is functionally preclusive of a coherent accounting theory. The influence of stakeholder theory on the academy and regulators has been previously noted. ${ }^{30}$

Stakeholder theory has developed from its original base to include greater specification of the stakeholders in contemplation and the means of establishing their priority. One development of the theory is the substantially descriptivist view of Mitchell, Agle and Wood (1997). It asserts the achieved priority of stakeholders who possess legitimacy, power and urgency. Where stakeholders possess two or more of these qualities, their stakeholdership has force. The problem here is that the model does nothing to specify what it is that constitutes

\footnotetext{
${ }^{30}$ For a formal discussion of the philosophical bases to diverse GPFR users versus investor-onlyas-user, see Gaa (1986), supplemented by Deschamps and Gevers (1978). Also, Stanton (1997) offers a brief discussion of the 'moral basis to a 'right' to GPFR by different users.
} 
legitimacy in substantive terms. The descriptivism of stakeholder theory must inevitably rest on an at least covert normativity. What 'positive' stakeholder theory indicates is that activist, noisy (urgent) parties with (coercive) power have influence over the company. What versions of normative stakeholder theory want to say is that they also have legitimacy. I explicitly reject this proposition. Not only does it make a distinct element in the model a necessary entailment of other elements but it implicitly relies on the view that the "good currency" (Schon, 1971) of stakeholder theory is a reason to accept it. Popularity (convention) as a robust predication basis for an academic theory is doubtful, without abandoning logic. This argument of Schon's is incoherent as it is inherently deterministic and, therefore, it conceptually contra-indicates any operative role for normativity. That is, if theories that are popular (that have 'good currency') are self-evident facts in the world that should not be challenged, yet we should use these theories, the use of which is not negotiable, it is unclear what the operative role of the normative injunction to action means. Alternatively, it is consistent but objectionable, warranting anything with popular appeal. The position supplicates before current academic convention without independently establishing a case for the veracity of positions taken by the academy.

There are a number of fundamental flaws in stakeholder theory. Possibly the most basic is that it is a non-sequitur of its generative theory, social contractarianism. Hobbes's position was that, in exchange for the protection of society against untrammeled trespasses on any individual by any other (except the Sovereign), each individual (at least implicitly) ceded their full autonomy to the Sovereign. Assuming democracy, without requiring it, the abrogation of autonomy is to society in toto, in exchange for a collective guarantee. Nothing about this theory entails stakeholder theory as a sub-societal extension of interested groups' claims to GPFR user status. The generative theory supports only a whole-of-society interest. Moreover, stakeholder theory is poorly specified. ${ }^{31}$ No answers are given to questions about how much or what

\footnotetext{
${ }^{31}$ It is observable that attempts to give stakeholder theory a more determinative, substantive character, such as Roberts and Mahoney (2004), offer only tentative proposals. This is informed
} 
information any particular group should be given. Allowing the cost-benefit constraint there must be limits to the satisfaction of the diverse information demands supported by the theory. Beyond this pragmatic constraint there may be conflict between stakeholders. This would entail that for information required by one group, another group require it be withheld (Staubus, 1999). For these reasons stakeholder theory, in its standard forms, must be rejected as definitive of the composition of GPFR users. From this base, particular groups' claims to GPFR user status must be assessed on their individual merits.

Although standard interpretations of stakeholder theory are rejected, the view that society has an interest in the corporation is justifiable. Just as society regulates the interactions of individuals, at least to the extent of ensuring certain standard forms of interaction, so it must also regulate business entities' interactions, between each other and between individuals, and in their interaction with the wider physical and socio-economic environment. The social contract would collapse if incorporation licensed ultra-societality. Nothing of this proposition, however, indicates important implications for information provided by way of GPFR. It may indicate taxation and governmental demands for financial information may be required within the regulatory and legislative context but the power to compel the provision of information removes such information from the general purpose. Special purpose financial reporting is already required for taxation purposes and any concession to other legislation as requiring accommodation within GPFR would entail the illogicality that GPFR must satisfy yet to be enacted laws as well as existing legislation. An entailment of this is that it is uncertain how broad societal interest can be advanced by expanding the definition of GPFR user beyond investors. This position may be argued for independently by the societal utility that obtains from the optimal allocation of resources within society, achieved by well-informed securities markets operating efficiently to eliminate unexploited economic profit opportunities (Jensen, 2001). This supports the investor as sole GPFR user in

by allusions to morality, fairness and the normative proposal to apply ill-defined understandings of these concepts to accounting. 
furtherance of society's interest. Notably, this 'national interest' argument was prominent in the Corporate Report (1975).

The 'national interest' conduit to society's interest finds support in the inferred motivations behind financial reporting regulation. The Securities Markets Act (1933) and subsequent amendment (1934) were motivated by the social dislocation caused by the Great Depression (May and Sundem, 1976). Deductively, it follows that society's principal interest in financial reporting is to avoid market breakdowns and concomitant economic and social turmoil. This view supports the investor as sole GPFR user and investors' information needs as paramount. To the extent that financial reporting can obviate the adverse implications of economic and asset market cycles, it can logically only be in the provision of the best possible information to investors and potential investors to inform economic (investment) decisions that take account of the economic substance of companies. No consideration occluding such information provision could more than occasionally achieve superior outcomes, and then only by random happenstance.

The discussion now moves to establish the respective bases for rejecting all other (non-investor) claims on GPFR. Focus is given to the more important and recurrent claims of (ostensible) users. These have been argued for in academic literature (Gray, Owen, and Maunders, 1987; 1991; Laughlin, 1977; 1987; Tinker, 1980) and in official reports, including those of major standards setters (IASB, 1989; FASB, 1978), the AAA (1966) and AICPA (1973). Although the general trend since 1973 is towards narrowing the user definition, in part by prioritizing investors (and creditors), through the use of the primary or principal user device, many users have been specified over time. I focus on those user groups who have had the greatest significance (and official acknowledgement) as 'constituents' of the standards' setting process. This term seems to have been applied casually to anybody who deems themselves a user of GPFR, without assessing the merits of their claims. 


\subsubsection{Labour/Unions}

Labour and unions have been identified historically as separate GPFR users (OECD, 1986). This is rejected on the grounds that the union claim is purely derivative of its representation of labour. In this sense, as with the analyst-investor user relationship, a case for focusing the financial reporting information required arises. Here, I relate the labour/union distinction to the naïve/sophisticated investor distinction. The strongest claim appears intuitively to lie with the greatest disadvantage; that is with naïve labour. This must be qualified to the extent that financial reporting is a technology; it is a practical application. It is observed that individual investors make limited use of GPFR (Lee and Tweedie, 1990). Similarly, and almost certainly more so, individual workers have limited resources or inclination to understand financial reports or, assuming their understanding, to make meaningful decisions on the basis of that understanding. For this reason, although the legitimacy of the unions' claim to GPFR stakeholdership is derivative of its representation of labour, that representation along with the resources and sophistication that unions are able to bring as the users of GPFR, supports the equality of their claim to rights with those of labour (Dan-Cohen, 1986). For ease this might be styled 'sophisticated labour'.

The case for labour's use of GPFR consists in its right to assess the financial strength of a company as a relation to job security and in developing pay demands (Alexander and Britton, 2004; Lee, 2006; Macve, 1981). In the first case it is uncertain what use labour makes of GPFR in assessing job security. Further, it is not obvious in the most important situation of high general levels of unemployment, what particular use commodity labour (and this is largely the type of labour we have in contemplation here) could make of company financial information where their choice is substantially negatively defined between insecure employment and unemployment. Moreover, any conclusion about security of employment predicated on the financial metrics of a company is overdetermined. All that a company's financial strength will assure is that this single cause will not threaten employment. As a company's financial strength pertains to meeting claims to unpaid wages, this risk is short-term, generally 
minor in nature, and information sufficient to identify this risk is already available in GPFR. There is no case made, nor any evident case to be made, that financial information suitable for the needs of risk capital providers is insufficient for the purposes of labour given statutory and contractual protections. Finally, the service potential of generic labour is unimpaired by particular job loss concomitant with redundancy due to company liquidation.

The second basis for labour's GPFR usage is that it informs wage claims (Alexander and Britton, 2004). This argument assumes that productivity and profitability establish a foundation for wage claims. The case is made that three bases exist for general wage level increase (Foley and Maunders, 1977). These are cost of living adjustments, pay parity with workers doing the same work outside of the company, and productivity increases (Foley and Maunders, 1977). In the case of the inflation-adjustment and pay parity, these bases are satisfied readily without firm-specific financial information, establishing no independent basis for labour GPFR user status. In relation to productivity increases the assumption must be that this is a function of labour intensification to support the inference from productivity increases to pay claims. Where increased profitability and productivity are functions of increased physical capital or improved operations management or technology and process it is unclear how such productivity increases importantly relate to a claim of labour on the company. Moreover, if such arguments for labour GPFR use are allowed it may have perverse implications for capital investment, given a reduced incentive to management and capital. Thus, the productivity argument for labour's GPFR use is rejected.

Labour's GPFR use has been addressed as an important if erroneous argument, in part pragmatically; because it is likely to impose the greatest incremental demands on GPFR information provision over that meeting investor needs (Macve, 1981; OECD, 1986). This is reflected in the level of disaggregation unions, in particular, would prefer (Macve, 1981). Curiously, the purpose of disaggregation is primarily to support segmentally or divisionallypredicated, profitability/productivity-based wage claims. The interesting anomaly 
contained in this argument is that standard arguments, and even the conception of unionization, presupposes a generic 'labour's worth' proposition. It must be assumed, on this basis, absent general productivity or profitability growth, that superior specific divisional performance, while supporting wage increases for the pertinent division, must ceteris paribus undermine other segment or division wage claims or, possibly, indicate wage reductions elsewhere in the company. It is not certain that unions would be comfortable with this conclusion. Taken as a whole, labour's claim to GPFR user status has no objective basis. Moreover, the case has been made that labour's needs are best met by the fair value information I argue is optimal for investors (Clarke and Craig, 1991).

There will be numerous situations in which profitability is regulated by factors extraneous to labour productivity. This would entail the logical implication that where profitability is the operative basis for pay claims, assuming constant labour productivity and input price increases for a company whose endproduct is price-constrained by market competition, that independent of labour's role in declining profitability, a pay decrease is indicated. If we allow that the company's input cost increases are indicative of general 'cost-push' inflation, the case may be made that profitability supports worker pay decreases in a period of elevated inflation. This would approximate the present situation in New Zealand retailing. The issue here is that the pay claim bases clash with each other. This does not logically reduce to invalidating all labour claims. Labour valued at a given amount at any date is a real variable, thus, inflation adjustment might be indicated such that its real value is preserved nominally. This has no implications for GPFR.

\subsubsection{Auditor, Management, Preparer interests in GPFR}

I have taken issuers', management, and auditors' use of GPFR as a single class of claim due to their derivative user status. In each case the claim to stakeholdership has no substance independent of the (ostensible) user's agency relationship with the investor. This does not entail that the operationalisation of GPFR through technical input into the development of accounting standards by 
these groups is contra-indicated. It is not obvious where better sources of such advisory contributions might be found. What is more certain is that, as a set relation to the previously described world, nothing about optimal capital market efficiency indicates a concern for the vested interests of non-investors, independent of these parties service to investors. In particular, managers' claim to GPFR user status as a function of their compensation calculation is disingenuous. This is a simple matter of contract and it is available to specify contractual terms for the calculation of compensation upon achieving certain objectives, based on financial reporting standards prevailing at the time of the contract.

The discussion of derivative GPFR users is important as these groups have, in large part, informed the development of accounting regulation. To some extent management and preparers have been removed from the equation by aggravating the aesthetic challenge of the acronym GPFR to its more precise specification GPEAFR or general purpose external accounting and financial reporting. The preference of preparers for reliability (Johnson, 2005), to reduce their risk, can give rise to increased management discretion, through reduced recognition in financial statements predicated on the basis of reliability concerns (Booth, 2003). It is not clear why regulation would consider the requirements of managers regarding the information they provide themselves when they have access to any information they deem necessary (Storey and Storey, 1998). Beyond this, in relation to preparers, the case can be made that their independent concern to mitigate litigation risk lacks credible motivation. Where prioritizing stewardship and conservatism supports this 'interest' it does so in an ad hoc manner. Elevation of litigation risk can be priced into audit services and/or insured against. Moreover, the mitigation of litigation risk stands in conflict with the role of GPFR in supporting market efficiency. For these reasons the GPFR user status of derivative users must be rejected.

\subsubsection{Lenders}

Lenders have maintained a tenacious claim to GPFR user status. Furthermore, the acceptance of lenders as GPFR users has possibly been one of 
the most significant constraints to the development of coherent accounting standards. The following factors dictate that this claim should be independently assessed. Lenders claim to have an interest in GPFR in determining the credit risk involved in extending particular companies access to debt. This argument seems difficult to justify as debt is supported by contract through which debt providers may specify the information they require to assess their preparedness to enter such a contract and to determine the applicable interest rate. That is, the debt provider is positioned to require a special purpose financial report (SPFR). Secondly, it is unclear how information sufficient to meet the needs of residual interest holders (equity investors) is not also sufficient to meet the needs of debt providers, with their priority claim on the company's resources.

A significant claim of lenders is that the demarcation between debt and equity is not as distinct as is implicit in the case I make for rejecting creditor GPFR user status. Not only do hybrid instruments, such as preference shares, exhibit some of the characteristics of both debt and equity, but debt contracting risks obtain. The latter point relates to altering company risk profile (post-debt assumption) where management incentives obtain from increased leverage. This argument is sound in the limited sense that management can, in effect, notionally transfer equity risk to debt providers without paying a premium (in interest rates) for this. Giving weight to the context in which such opportunism would occur, allowing that the lender is situated to contractually specify debt to equity ratios, where such specifications can be circumvented it is uncertain what advantage would accrue to the debt provider by having their user status in contemplation when formulating GPFR. Moreover, information satisfying to the investor would, necessarily, identify this management strategy. To suggest otherwise is to suggest that investors are unmoved by the level of debt, and concomitant cash-flow implications, that a company has.

There is an independent practical reason to reject the GPFR user status of lenders. The banking industry has pressed their claim to this status to argue, for the most part, for their interests as issuers and managers. In connection to their 
resistance to fair value the key case that is argued for is that banks' loan books have firm-specific value that is greater than their fair value. I address this issue later, in the case for fair value (chapter four). Beyond this, the banking industry argues that fair value increases volatility which has negative implications for Banks' cost of capital and their satisfaction of regulators' prudential requirements. This seems to be an argument for industry privilege rather than an objective, unbiased input into accounting regulation. Banks are, in effect, arguing for a less than efficient risk-adjusted cost of capital than the market would otherwise deliver and for the ability to, in substance, be unrestrained by reserve asset requirements. Against these non-creditor related arguments banks argue that historical cost and conservatism provide a greater margin for safety in GPFRs when determining debt provision. These arguments and their flaws have been previously detailed. I recapitulate them here purely to demonstrate the convolution of creditors' (lenders) arguments for GPFR user status. Lenders want to smooth their incomes by selective realization to convey the impression of lower risk (or volatility) than reflects economic substance, in support of the lowest possible cost of capital. This is one reason to reject the user status of lenders.

\subsubsection{Lobbyists/Government/Regulators}

Lobby groups' interest in financial reports is less obvious than the previous groups. Regardless of the particular concern the lobbyist has with the operation of a company it is, at best, only indirectly linked to a company's financial reports. Even if the concern is, for example, a company's generation of excess profits this is information that will necessarily be made available to the investor. That is: industry type, revenue, EBITDA, net profit (NPAT), tax paid and owners' equity. In the case of other lobbying, the relation between the lobbyists' agendas and GPFR is likely to be less direct. Where there is no question that lobby groups are external, and they use GPFR, with no power to compel information from the company, it is not obvious what basis their claim would consist in. Investor-focused GPFR, augmented by the organs of democratic process, appear sufficient to satisfy any possible legitimate claim lobbyists may 
have to company-specific information. The lobbyist use of GPFR, as a claim to particular specifications of GPFR information content seems tenuous.

Further to the rejection of lobbyists as an important GPFR user, it is available to argue such interests are met by government's ability to compel financial or other information from a company. The lobbyist concern is satisfied indirectly through government. This governmental ability is observable in the divide between tax accounting and financial accounting. From this view the target of GPFR, external users who lack the ability to command the information they require [who have a legitimate, purposeful foundation to seek the information they do], describes the investor only.

This specification does not entail an obstinate rejection of the inclusion of any information, supplemental to that required by investors directly, just because it does not address investors' direct interests. Where it is cost effective to provide information that will otherwise be compelled, or that, in the absence of such information, will give rise to political or reputational costs greater than the cost of the provision of such information in GPFR, it is in the investor's interest that such information be provided as GPFR. The investor's interest is (or may be) wider than GPFR information necessary to make a rational decision to buy, sell, or hold shares in an entity. Again, any decision on the inclusion or exclusion of such information in or from GPFR will turn on the interests of the investor. This applies to any secondary claimant to financial accounting information and would certainly extend to providers of debt financing. The ability of such other users to require special purpose financial reports aligns the investor's interest with certain interests of other potential users. It does not, however, a priori establish the claim of those users to exert an influence on GPFR. 


\subsubsection{Summary}

The case has been made for current and potential investors as the sole legitimate users of GPFR (Staubus, 1961; 1999). This case looks at the central function of financial accounting and reporting in its environment, relating that environment to the objective function of GPFR. This view reconciles the investor's particular utility with the utility of society and is therefore unreliant on sui generis axioms more demanding than the reification society (Bierman, 1979). Rival GPFR user claimants are demonstrated to hold no legitimate claim to consideration (user status) in relation to external company financial reporting that expressly targets groups without the ability to specify or command that information. Proffered reasons include: the ability to require specified company financial information, no legitimate purpose for that information, the sufficiency of investor-targeted information, and, in terms of their preclusion from user status, the tension between investor and other interests. To this we might add that, as the owners of the reporting entity, investors pay for the provision of information (GPFR), establishing a default assumption of limitation of such information to investors unless reasons to conclude otherwise exist.

\subsection{Stewardship versus Decision-usefulness: A false dichotomy?}

Standards setters have been progressively moving towards a preference for decision-usefulness since the late 1960s-early 1970s (Stanton, 1997). Despite this, the debate over which objective accounting should aim at has persisted, with significant resistance to the ascendancy of decision-usefulness and relevance as, respectively, the primary objective function and qualitative characteristic of financial reporting. Opponents to developing trends in accounting conceptual frameworks and standards typically prefer the traditional approaches to accounting, including historical cost measurement, stewardship, conservatism, and matching. This general position rejects fair value and the subsumption of stewardship into decision-usefulness, believing that it should be a separate accounting objective, at the minimum, equal to decision-usefulness. The position of standards' setters is that there is no obvious mutual exclusivity between stewardship and decision-usefulness (IASB, 2006a; IASB, 2007). The broad line 
taken in this discussion supports the position of the IASB, augmented by the stewardship function of multiple period reports and other sources of companyspecific information and macro-economic data, taken as a single text (Crowther, 2002).

An important component characterizing the debate between stewardship and decision-usefulness is its relation to the debate between the precise specifications of accounting information users. The primacy of investor-users is largely an achieved assumption. This has reduced the field of possible arguments for particular accounting objective functions, qualitative characteristics and concomitant arguments for measurement bases and specification of standards, on the basis of diverse users/stakeholders. In this context the present/potential investor bifurcation appears to be a device to re-form the battle lines between the trend in conceptual frameworks and regulation towards decision-useful, relevant, fair value accounting and traditional historical cost, stewardship-focused, conservative accounting. The dichotomy between present and potential investors has been addressed. It is not clear that there is any substantive basis to the distinction beyond its potential utility to an axiomatic presumption for, as a de minimus, the equality of traditional accounting approaches. The dichotomy is rejected here as artificial as is the non-sequitur often generated from it; a conclusion in favour of the primacy of stewardship.

\subsubsection{What is Stewardship?}

The IASB conceptual framework describes stewardship as information showing:

“... the results of stewardship of management, or the accountability of management for resources entrusted to it. Those users who wish to assess the stewardship or accountability of management do so in order that they make economic decisions [including] whether to hold or sell their investment...or...to reappoint or replace the management." 
(IASB Conceptual Framework, 1989,

paragraph 14)

Stewardship-postulated conceptual frameworks tend to represent a conventional view of the agency relationship in which the risk of interests' divergence between managers as agents and their principals, the shareholders, arises (Stittle, 2003; Watkins, 2007; Benita, 2003). The stewardship function of accounting is intended to control for this risk. This feature is reflected in the IASB's Preliminary Views on an Improved Conceptual Framework for Financial Reporting: The Objective of Financial Reporting and Qualitative Characteristics of Decision-Useful Financial Reporting Information (2007). This concern is expressed in terms of stewardship as requiring information about management's safe custody of assets and compliance with regulations (OB 27). It requires information about the probity and competence of management (Lennard, 2007).

The stewardship concern recognizes the separation of management from investment and other financing (Watkins, 2007). The suggestion made by stewardship advocates is that a dynamic economic environment requires a dialogical interaction between management and investors and that stewardship as an objective function of GPFR establishes the basis for this dialogue. Such advocacy relates stewardship as a fundamental element in modern corporate governance (Lennard, 2007). Another general aspect of the stewardship focus is a tendency to emphasise past transactions and events.

The arguments for stewardship as the primary (or at least distinct) objective of GPFR tend to reference this function back to historical cost, matching, conservatism and control of agency risk. It is available to argue that this general line of argument describes an excessively stylized view of the world. To allow this view it is necessary to accept that all the information we require (or that may be required) is contained within financial reports and that no other source exists, even in the form of previous annual reports. To prioritise stewardship, except as an incidental accomplishment of the historical information 
contained within GPFR, seems to devalue other sources of information (Crowther, 2002). Less than a reliance on alternative information sources, the subsumption of stewardship by decision-usefulness, presupposes that historical information within particular financial reports will directly satisfy the retrospective component of accountability while including prospective information with predictive and confirmatory value.

Independent of the previous point there is no obvious sense in which management's stewardship can or needs to be described by anything other than the sequence of share price movements, adjusted for any bonus issues, combined with the timing and amounts of any dividends paid. This would provide all the requisite information to assess the stewardship of the company in terms of a view of market efficiency implicitly granted by Bush (2005). Arguably, historical information's primary purpose is to establish the context for interpreting futuristic information. The investor needs to be able to assess the substance of management's forecasts on the basis of the documented accuracy of historical forecasts. Outside of this, little obvious value attends to stewardship as a basis for action outside of special cases, including proving directors' liability for losses. This is all the more so where significant shareholders are able to command information and have at least de facto power to influence the composition of boards. Under such conditions the individual or aggregated influence of significant shareholders, in combination with proxy voting and individual shareholder indifference obviate the utility assumed of stewardship as an objective of GPFR.

The decision-useful/stewardship debate was importantly informed by the 1983 contribution of Ijiri. This was essentially an argument for the independence of stewardship and the rehabilitation of historical cost in the face of growing initiatives of standards' setters and some academics towards variants of current value accounting and decision-usefulness. The argument broadly consists in 
demonstrating that stewardship or accountability ${ }^{32}$ is "not entirely encompassed in the decision-usefulness concept" (Coy, et al, 2001). This proposition was further expounded by Gjesdal (1981), who demonstrated the differential rankings of qualities and objectives obtaining from an incentive objective (stewardship) and a decision-objective. It is not very clear what substantive objection to decisionusefulness is being raised. The clearest argument is that the decision-usefulness conceptual framework does not explicitly consider questions of fairness, except as an (implicit) relation of neutrality and freedom from bias (Gjesdal, 1981). Conversely, stewardship explicitly judges fairness in relation to agreement. Fairness is indeterminable without an agreed metric against which to measure it (Coy, et al, 2001). Wading through the opacity of that ostensible definition we are not given substantial cause to challenge decision-usefulness. In one sense the explicit fairness asserted of a stewardship-informed conceptual framework offers no meaningful specification, in another, we are asked to infer unfairness of market-determined distribution decisions without independent argument. Moreover, no reason is given to suppose fairness issues hinge on GPFR and cannot be developed after the preparation and presentation of GPFR, at a societal level, accommodating social contractarianism, contextualized by the machinery of democratic representation.

Beyond the 'fairness' objection to decision-useful conceptual frameworks other implications of the choice between decision-usefulness and stewardship are identified. These are, in general, poorly specified and functionally meaningless. Stewardship is said to acknowledge the endogenous relationship between the supplier of accounting information and its users. Conversely, decision-usefulness focuses purely on the user (Coy, et al, 2001). It is not very clear why this is objectionable. Perhaps more clearly, the case is made that stewardship focuses on objectivity, verifiability, and stability (Gjesdal, 1981), whereas decisionusefulness conceptual frameworks accent relevance and reliability. This is instructive of the nature of the distinctions Gjesdal (1981) draws more generally,

\footnotetext{
32 Following from Wheat (1971) I question the synomity assumed by certain academics of stewardship and accountability. Arguably, the former is a subset of the latter.
} 
in that they are not clearly specified. More simply, stewardship accents reliability as direct verifiability by reference to a transaction price and decision-usefulness is concerned with relevance and prospective information. It is nothing more than an elaborate, convoluted conduit to the relevance/reliability debate.

Consistent with the position taken by the majority of the IASB (2006) (Preliminary Views) the case for stewardship as an aspect of decision-usefulness seems logically justified. Moreover, the focus lent to GPFR development by a single objective provides independent practical support for the proposal. Distinguishing stewardship as a discrete, parallel objective to that of decisionusefulness is unlikely to entail any incremental advantages over its implication from decision-usefulness (IASB, Preliminary Views, 2008, BC 1.35). This is amplified where historical cost is assumed (without necessary warrant) as a derivation from stewardship. It is not clear how the account function is served by non-comparable, temporally heterogeneous valuations, instantiated as objective variables about nothing more tangible than a transaction basis. There is some suggestion that stewardship-accented accounts would emphasise detailed accounting for related-party transactions. It is again not certain that such information would be unimportant in a decision-useful context. Where it is generally agreed that stewardship and decision-usefulness are not mutually exclusive, stewardship advocacy turns on distinctions in terms of emphases (Lennard, 2007; Williams, 2007; FASB, 2006).

\subsubsection{Decision-Usefulness}

Decision-usefulness first emerged in the normative accounting era, either as the implicit or explicit underpinnings of theories that gained fleeting currency in that period. As previously discussed, where the currency of such theories of accounting receded in the academy with the rise of positive accounting theory, regulation, as an inherently normative accounting theory, has been more significantly and persistently influenced by the central intuitions informing this period. Decision-usefulness, despite traces dating to the depression-era (Bush, 2005), probably dates in its explicit articulation to Chambers CoCoA. However, it 
is from 1966-1973 that it established itself officially and, only in 1970, in APB Statement No. 4, that it appeared as important conceptual framework information (Henderson, et al, 2004; Coy, et al, 2001; Storey and Storey, 1998). Since this time it has progressively challenged the incumbent objective function, stewardship (Rayman, 2006; Roberts, Weetman, and Gordon, 2005).

Proponents of stewardship argue that the subsumption of stewardship by decision-usefulness deflates the account function of GPFR (IASB, 2005; Laughlin and Puxty, 1981; Anson and Lamourex, 2006). Resistance to the primacy of decision-usefulness has been noticeably substantially British. This may reflect the embedding of stewardship in the British accounting tradition, against the decision-usefulness focus of US accounting regulation (Bush, 2005; Grixti, 2005). This proposition is reflected in the affirmation of the central importance of stewardship by the Association of British Insurers (ABI, 2006), the International Corporate Governance Network (2006), arguments raised in the paper produced for ICAEW by Bush (2005). The view also finds support in the alternative views to the IASB's general preference for decision-usefulness, reflected in IASB Chairman, David Tweedie's advocacy of the distinct, parallel treatment of stewardship as an objective separate from decision-usefulness. We seem to see here the importance of tradition and culture on the views of accounting theory promulgation. In relation to the descriptive characteristics I have established, acculturation should optimally be subjugated by accounting's primary objective function.

The question of what decisions are important should be raised here. The investor needs to know whether they should buy, sell, or hold. In this context it is undemanding to a priori posit the assertion that the information investors require relates to the current value of a company, the company's prospects, and a contextual basis to assess prospective information. The current value of assets and liabilities is required. In addition, information about management's expectations of future cash-flows will form an important input into investors' assessment of the value of the company. The context for this information is provided by information 
about past performance and forecast reliability. It is further supported by details of the assumptions underpinning management forecasts. The case made here for fair value is that where valuations are not available at levels one and two, or where any part of levels one and two valuations reference illiquid markets, level three valuations are indicated. These level three valuations should offset the risk of management discretion by supplying quantitative information about the assumptions made in relation to primitive variables (Ryan, 2008). This enhanced information provision is proposed as an augmentation of existing applications of fair value. It is also a key reason for advancing the sophisticated investor as a suitable proxy for the investor simpliciter.

A secondary observation here is the point drawn from the discussion of investor use of GPFR in the research by Lee and Tweedie (1990). Although they find investor use of GPFR is a positive correlate of investor sophistication, the implication of the inaccessibility of (then) current GPFR in regard to naïve investors as an indication of deficient usefulness to such investors does not obtain. This was previously discussed as the free-rider advantage to naïve investors of the operation of sophisticated investors eliminating unexploited profit opportunities. To this I add the competitive market for the supply of information that, assuming no systematized friction in the market for the supply of such information, should operate to minimize inefficiencies in the market. If we reject this assumption, I would make the case that this is an argument for the regulation of that market rather than presenting an argument for GPFR simplification. The central point here is that no reliance is placed on investors' widespread use of GPFR to establish its general usefulness to investors.

Consistent with the view maintained by the IASB (and FASB) the position taken here is that decision-usefulness embodies stewardship as well as forecast information. This position has been subject to challenge on empirical grounds (Gassen, 2008). Gassen's study of US companies established the mutual exclusivity of the rival GPFR objectives. Certain limitations are acknowledged in relation to validity issues of this study. Most fundamental amongst these is the 
uncertainty between the articulated accounting objectives and the reflection of these in operational terms in the studied companies. At the least, the study is no more than equivocal evidence against the view argued for here of the compatibility of the respective objectives. It is uncertain what function stewardship would have where it could not influence a decision, except where its provision obviated the need to make a decision. We might allow this limited concession to stewardship as a manifestation of agency risk mitigation, ultradecision-usefulness. Even this concession exists by warrant of imputed decisionusefulness, approximate to the free-rider advantage previously described of the naïve investor who does not directly use GPFR.

\subsubsection{Summary of the debate}

Against the position adopted by standards' setters and by many advocates of the separate, equal (or primary) role for stewardship in standards' promulgation, the view taken here is that stewardship and accountability are not synonymous. Instead, accountability is composed of stewardship and decisionusefulness. Moreover, stewardship is historically decision-useful information. All such information is relevant. There is no clear reason why the account function cannot be extended to forecasts. This follows the Wheat Committee Report (1972) in which stewardship was taken as a subset of accountability. On this reading, accountability is a supra-category, approximately describing the same temporal parameters that relevance does.

Prospective information-accountability must be less stringent than the historical account function. Necessarily, the general environment might change to such a degree that the basis for the forecasts is undermined. Accountability requires the realism contained in the assumptions supporting forecasts, the degree of foreseeability of extra-company economic environment changes from those serving as postulates for the forecast, and the role of company-specific (that is, controllable) factors contributing to the in/accuracy of forecast information. Nonetheless, it is conceptually plausible that the decision-useful focus extends the accountability of management to investors. No sound reason presents to assume 
that accountability conflicts with relevant, decision-useful information from this perspective.

The view outlined is that accountability involves no conflict with prospective information. Further, there is no obvious loss of value to accounting conceptual frameworks by decision-usefulness' subsumption of stewardship. The purpose of the incidental nature of stewardship, essentially delimited to its decision-usefulness, is to focus the objective of GPFR in the move towards its coherent conceptualization. The distinction lies in emphasis. In a sense prospective information is a decision-useful increment, with the grant that the cost/benefit constraint may potentially reduce historical information contained within GPFR. This issue will turn on the extent to which historical information aids decisions. Accountability approximately complements relevance in the sense that they interact and they both have (at the least) similar temporal parameters in relation to the life of the company. ${ }^{33}$ By hypothesis, neither quality, relevance or accountability could be assured absent each operating in an endogenous relation to the other. This entails that the stewardship/decision-usefulness debate persistently observes a sub-optimal trajectory, concerned as the traditional view is, purely to frustrate the move to useful, current value, relevant financial reports in favour of temporally remote and heterogeneous values, that systematically extends the capacity for opportunistic behavior. The reconciliation of ostensibly conflicting qualitative characteristics and objective functions drives off of the narrow user basis previously argued for. The focusing of accounting postulates proposed by major standards' setters observes the fundamental intuition informing the theory proposed here. General accounting theory will be most expeditiously achieved by a coherence derived from the simplicity inhering in the theory's underlying postulates. These preconditions create a circumstance conducive to theory coherence. Where the discussion to this point has not made this explicit, some loss of detail would be an acceptable price to pay for the economy of generality.

\footnotetext{
33 Abductively, accountability is fractionally briefer in that relevance predates IPOs, whereas accountability can only reasonably apply subsequent to public issue.
} 


\section{Chapter Four}

\section{Fair value: An Implication of the Proposed Theory?}

\subsection{Introduction}

To this point the discussion has considered accounting as a financial information technology with an identifiable objective; to provide information useful in enabling investors to make economic decisions. Specifically, GPFR should aim at providing a unique source of company-specific information that is useful for informing the market generally whether to buy, sell or hold a company's equity securities. This basic conclusion is examined in relation to fair value as a potential entailment of the theory. The reason for selecting the accounting measurement basis debate as an area of focus is that it has generally been one of the most vexed issues in financial accounting (Whittington, 2007a). For this reason it is likely to be a suitable testing ground for the proposed theory. It is also, arguably, not an entailment of the theory. The distinction that I would draw here is that although fair value is not a necessary, mechanistic entailment of the proposed theory, some sense of current value accounting is. Furthermore, the momentum behind fair value gives sufficient cause to infer from the proposed theory to fair value. This qualification accommodates the operative role of accounting as a company financial event recording technology. To argue for valuation method perfectionism would be to remove the theory from serious prospects for its influence. In this sense it would be nothing more than a counterfactual hypothesis, such as Chambers' CoCoA. Moreover, by stepping back from fair value as operationalised, instead preferring fair value coherence as a measurement system based on economic substance, many of the conceptual objections to fair value are addressed.

Contemporary debate over accounting valuation methodology centers on fair value versus historical cost (Herz and MacDonald, 2008). Traditional historical cost accounting has become increasingly challenged by standards setters' trend towards a fair valuation basis for accounting (Chorafas, 2006; King, 2006; Hitz, 2007; Whittington, 2008; Bradbury, 2008; Deegan, 2004). The debate 
picks out the preferred qualitative characteristics for the respective positions, as articulated in standards setters' concepts statements. Fair value advocacy prioritizes relevance whereas the position of historical cost proponents is that reliability is the paramount qualitative characteristic of GPFR (IASB, 2006b). The debate develops to lay claim to the implication of reliability in relevance and relevance in reliability. This debate tends to be drawn in polemical, rhetorical terms in which mutual exclusivity is implied yet the possibility of either characteristic presupposes at least a minimal possession of the other. This debate poses questions of the kind, 'how can unreliable information be relevant' and 'in what sense is information reliable if, having no relevance to current values, nobody would make a decision based on it' (Toppe-Shortridge, et al, 2006). The central contention of this discussion is that the debate has a logical conclusion and that, on balance, subject to some specification issues, this favours fair value.

\subsection{Historical cost}

Historical cost is the traditional method of accounting valuation. It is formally defined by the IASB conceptual framework (1989) as:

"assets are recorded at the amount of cash or cash equivalents paid for or the fair value of consideration given to acquire them at the time of acquisition. Liabilities are recorded at the amount or proceeds received in exchange for the obligation, or in some circumstances (for example, income taxes), at amounts of cash or cash equivalents expected to be paid to satisfy the liability in the normal course of business."

(Quoted in Stolowy and Lebas, 2006, p. 158)

Historical cost involves recording financial statement items at their cost to the company at the transaction date. That is, historical cost expressly reports something that has happened. ${ }^{34}$ This allows verification of the recorded values, against invoices and receipts. Further, changes in recorded values (of fixed assets)

\footnotetext{
${ }^{34}$ This contrasts with fair value, which posits a counter-factual value in the event that a transaction that did not occur, had occurred.
} 
are regulated by the depreciation schedule selected by the company up to the point of asset realization or liability settlement. Depreciation is calculated on the original value, with a range of methods available. This choice of method and the rate of depreciation provides some scope for managerial discretion and error. Tests for impairment may also be applied to measurement under historical cost accounting, although where impairment is applied the basis for historical cost's superior objective characteristic, that is its reliability, is obviated. The central foundation for historical cost advocacy is that it is more reliable than fair value, depending on a lesser degree of subjectivity (Stolowy and Lebas, 2006). Furthermore, impairment under historical cost exhibits a systematically negative bias as only impairment that reduces an asset's value below the depreciation schedule are allowed.

\subsubsection{The case for historical cost}

The case for historical cost has generally been advanced on the basis that it has greater reliability than fair value. Historical cost numbers consist in actual prices paid by an entity or value received at the transaction date. They do not require assumptions, estimates or other subjective assessment (at the point of original recognition). This view favours the original interpretation of verifiability, as an analytic entailment of a past transaction price, as the central condition of reliability. A central concern raised by historical cost advocates is that many fair value measurements do not involve an arms-length (or, in fact, any) transaction (Toppe-Shortridge, et al, 2006). By eliminating appraisals and valuation techniques historical cost proponents contend that the scope for manipulation is reduced (Toppe-Shortridge, et al, 2006).

The principal concerns of historical cost advocates surround the absence of an arms-length transaction and the introduction of subjectivity to accounting valuations where no market price exists. This concern relates to levels two and three of prescribed fair valuation methods (discussed in further detail under "fair value"). From this objection it is possible to infer an implied historical cost view of historical transaction prices at fair value, at the time of the transaction, 
consistent with the definition articulated by the IASB (1989). In this context, some grounds to allow the objective character of transaction-basis accounting measurement exist, but only at the point of asset acquisition or liability assumption. It is not nearly so obvious that the economic substance of financial accounts would be supported in relation to realization as a precondition of recognition. This point relates to certainty, obtaining from realization, acknowledging that until realization of an asset or discharge of a liability occurs, it is inappropriate to recognize income under historical cost.

Historical cost advocates point out that historical cost does not rely on the subjectivity inherent in fair values derived from model-based valuations. Where a market price is not available for a similar asset, adjusted for differences, or there is no market-based price at all, fair value specifies mark-to-model. The model is to use as much market-based information as possible. Historical cost proponents argue that such valuations are highly subjective, potentially embodying management bias. A wide range of model valuations is permitted. This risk is obviated by historical cost which records such assets at acquisition cost, less accumulated depreciation. Once the basis for depreciation is established no opportunity for management's manipulation of the recorded values exists other than impairment.

In terms of initial recognition historical cost broadly relies on the assumption that the parties to the transaction acted rationally. That is, historical cost in such case, eliminates subjectivity without loss of relevance (IASB, 2006b). Limited circumstances challenge this notion where the transaction (acquisition) was the result of a bad decision, where costs exceed the recoverable amount, such as costs of construction of a building adversely impacted by delays, or where the acquisition was a bargain. Outside of such special cases, initial recognition at historical cost seems to capture reliability and relevance. Notably, such historical costs are generally functionally fair values (IASB, 2006b). 


\subsubsection{Structural advantages of historical cost}

An advantage of historical cost claimed by its proponents is that it is symmetrical in its treatment of both sides of the balance sheet. Where fair values are widely employed for assets, liabilities are valued at their nominal value (Chorafas, 2006). A mismatch occurs where assets are marked-to-market and liabilities are recorded on an accruals basis of cost amortized to impairment (Chorafas, 2006). This view of the balance sheet symmetry of historical cost versus the asymmetry of fair value is not an essential property of fair value so much as an objection to mixed attribute accounting. In this sense the issue does not describe a qualitative feature of either system so much as it identifies problems with implementation, complicated by entrenched, diverse interests that operate to confound the comprehensive use of fair value.

A related advantage claimed of historical cost is that it is a simple basis for accounting valuation. This case is made by one of historical cost's more vocal proponents, Flegm $(2004 ; 2005)$, that the growing complexity of accounting standards and guidance is due to fair value measurement. Arguably, Flegm (2004) is conflating the complexity of contemporary accounting standards with the rise of the influence of fair value measurement (Squires, Smith, McDougall, and Yeack, 2003). FASB guidelines have grown to over 100,000 pages of rules (Squires, et al, 2003). This significantly complicates interpretation and application. The case for principles over rules (Flegm, 2004; 2005), whether independently valid or not, does not address the historical cost/fair value debate. As Levitt (2007) and Schuetze (2004) have argued, although fair value is somewhat more complex than historical cost, it is substantially in compromises, largely generated out of resistance to a coherent fair valuation system, that standards have proliferated and their volume swollen (FASB, 2002). This is more instructive of a problem attending mixed attribute accounting, as a consequence of resistance to fair value, than it is of fair value per se.

Historical cost is favoured by the banking industry for the lower level of volatility it entails in financial statements. This concern is more extensive, 
although to a lesser degree, being raised by industries reliant on hedges, or speculative use of derivatives. The case is made in relation to non-hedge instruments, in particular, that the information value of fair value adjustments (particularly to long-term financial instruments) is uncertain where the loss or gain may never be realized. There are concerns that the increased volatility of fair value may increase the cost of capital for certain industries. It is not clear that these arguments reflect a virtue of historical cost so much as a flaw. The case may be made that increased volatility reflected in the financial statements is better reflective of the underlying volatility in the market and, thus, economic reality and as a base for the assessment of managerial performance. This argument for historical cost seems to be an argument motivated by the desire to obscure the economic substance of certain events. It is a management/issuer GPFR user based argument and therefore, in the context of the current theory, able to be rejected.

\subsubsection{Bases to question historical cost}

Given the lengthy tenure of historical cost as a preferred valuation method it is unsurprising that it has encountered periods of resistance and threats. What is possibly more remarkable is the tenacity with which it has repelled such threats, oftentimes with little beyond its incumbency to recommend it. The external catalysts for threats to historical cost include the elevated inflation of the 1970s and early 1980s which served to cast doubts about the currency of historical cost accounting until the mid-1980s. This pressure abated as inflation was brought under control by the early-mid 1980s. Subsequently, market crises of the late 1980s revealed the opportunism that historical cost allowed due to the realization basis for recognition it entailed. Where such an approach was a central element of prudence or conservatism by intent, it allowed managers to cherry-pick performing assets for realization, while retaining poorly performing assets at their cost price. During the Savings and Loan crisis, spanning the mid-1980s and into the early 1990s, this behavior exacerbated the market slump when markets rebalanced. The cumulative influence of external forces has led to the rise of current cost accounting variants, against the incumbent, historical cost. This 
section considers arguments against historical cost as an accounting measurement base.

The general problem associated with historical cost accounting measurement is its lack of currency (Herz and MacDonald, 2008). This, it may be argued, compromises its decision and value relevance. This problem is compounded by a general lack of comparability between entities and between particular assets of an entity (Kirkman, 1985). The transaction date basis for valuation inherent in historical cost discounts the heterogeneity of transaction points. If we grant that, given historical cost measurement presupposes a transaction between willing parties, what historical cost represents in accounts is a range of transaction point fair values. This measurement base is, then, systematically mixed-attribute, due to temporality. This issue is further complicated by depreciation schedules applied to fixed assets on the basis of management selection based on expected useful life. As discussed, historical cost accounting representational faithfulness is negatively correlated with inflation. Possibly more importantly, as previous crises have revealed, managerial manipulation of their results is possible under historical cost's transaction basis for recognition. This is of particular significance because it presents incentives for managers to behave dysfunctionally in an organizational sense, realizing better performing assets and investments while retaining lesser quality investments that have performed poorly, so as to avoid the transaction (sale) that would trigger recognition in the company's accounts. These are the substantive problems with historical cost.

A central concern with historical cost is that accounting is performed in nominal units (national currencies) and that these complicate international and inter-temporal comparability. This may have been less problematic historically where pre-debasement currencies were the nominal unit of account but the rise of fractional reserve banking and the decline of the gold standard have complicated comparison. Wherever broad money supply grows in excess of GDP growth, a variable inflationary affect is imparted to asset markets. More obviously, the 
general price level adjustment bases to accounting measurement were proposed in relation to consumer price levels in the 1970s and 1980s (Whittington, 2007; Tweedie and Whittington, 1997; Kirkman, 1985). Certain counterintuitive results obtained from such proposals, including positive balance sheet implications for heavily (monetary) indebted companies with countervailing real assets (Clayton and Blake, 1984; Lucas, 1981). The effect of these difficulties, combined with reestablished control over inflation globally, led to the dissipation of impetus for such proposals although current value accounting had gained some traction by the mid-1980s (Kirkman, 1985).

A number of periods through recent history have demonstrated the ability of management to postpone presenting the substantive economic nature of companies underlying businesses due to transaction-based accounting (Landsman, 2006). This occurred during the Savings and Loan crisis of the late 1980s and subsequently, in the lack of recognition of declining values in the US auto industry due to structural overcapacity (Schuetze, 2006; Toppe-Shortridge, et al, 2006). Where historical cost accounting provides for impairment of assets this disconnects it from its purported reliability, which consists solely of an historical transaction price as an objective reality. Both the auto-industry and post September 11 aircraft and airline industries have avoided write downs that would have attended a fair value accounting of the relevant company's assets due to industry overcapacity. Instead, value decrements are dictated by depreciation schedules which, on a 'useful life' of asset basis, will not account for expectations of actual use or changes in these. This is not substantially obviated where some part of the depreciation calculus relates to actual use as the fixed asset is implicitly permanently impaired on an embedded value basis.

There are circumstances where, in times of market or industry decline, historical cost offers too-favourable an impression of certain companies but it is also potentially unrepresentatively pessimistic. In relation to contemporary times historical cost understates the value of the oil industry, natural gas and, more generally, the value of intangible assets (Schuetze, 2006; IASB, 2006b). The case 
may be made that where historical cost systematically undervalues internally generated intangibles, partial recognition under fair value in its present form could be improved with the addition of conceptually coherent modifications to fair valuations of such assets. Nowhere is this proposal inconsistent with fair value, reflecting the embedded value of intangibles.

Historical cost can actually inflate values relative to current value (fair value as one variant) during periods of economic decline or turmoil (Churchill, 1977; McNeal, 1977). This would be true of relatively new companies and companies that have acquired significant assets in the period directly preceding general market decline. This could establish GPFR values for a company that support the security of debt funding where the underlying economic reality is that the debt is inadequately secured (Churchill, 1977). This risk is greatest during recessions, disrupting bankers' arguments that historical cost provides a 'margin of safety'. The margin of safety inferred is unreliable, potentially non-existent and, in any circumstance, no basis to make a rational lending decision.

The magnitude of lobbying for historical cost provides an indication of its objectivity-challenged nature. By inference to opportunism inherent in the voluble support historical cost garners from some quarters we have reason to question the substance of the positive claims made in its support. Previously discussed instances include Colleen Cunningham's (former CEO of FEI) argument that fair value is fundamentally flawed by its reliance on subjective, model-based valuations (Toppe-Shortridge, et al, 2006). This is revealed as the disingenuous pursuit of sectoral interest that it is by her subsequent argument that investment analysts would prefer to retain the competitive advantage they have in converting historical cost accounting information into fair value-based accounts (Fink, 2006). Although unstated, Cunningham may attend some value to the disinterest of external model-based valuations but essentially the argument is motivated by analyst advocacy. I have outlined the case that analysts are not independent GPFR users, their use is derivative. It follows that anything that complicates investor 
information accessibility, such as accounts that establish a need for information processing intermediaries, is a deficiency in GPFR.

\subsubsection{Summary}

Historical cost has a long tradition in accounting valuation. Over time traditional accounting has come under threat due to widespread dissatisfaction with its relevance to investors. Periods of elevated inflation, the Savings and Loan crisis of the late 1980s, and the progressively growing gap between book values and market values, have all raised doubts about the relevance of historical cost accounting. This development has been reflected in a trend towards fair values by major accounting standards setters. Against this trend, historical cost has considerable trenchant support from diverse interests. The position is substantially encapsulated in the relevance/reliability debate. This debate has observed a suboptimal trajectory as the defence of historical cost valuation obstinately promotes an interpretation of reliability as a truistic entailment of verifiability as a function of records of an historical transaction. Drawn in these terms the argument is that fair value is not reliable because it is not historical cost. Reasons exist to resist such circularity where the reliability assumed of historical cost has no currency. All that such reliability warrants is the value derived from an historic transaction is factual of the historic event. Nothing essentially about this kind of reliability tells us anything a rational decision maker would rely on.

\subsubsection{Fair Value}

\section{What is Fair Value Accounting?}

Fair value is a current value-basis for accounting measurement. It has been gaining influence in accounting standards since the 1990s, against the (then) incumbent, historical cost. Fair value accounting measurement is defined by the FASB as:

"The price that would be received for an asset, or paid to discharge a liability, in a current transaction between marketplace participants in the reference market for an asset or liability" 
(FASB, cited in King, 2006, p. 47)

The definition applies conditions of willingness on the parties to transactions, their knowledgeability, and that the transaction price is not due to liquidation (AIMR, 2007; Landsman, 2006; FASB, 2006b). Fair value is composed of three basic levels (Elad, 2004):

1 Market quotes for identical assets or liabilities.

2 Estimates from a market for similar or related assets or liabilities, adjusted for differences.

3 Model valuations with as many market inputs as possible. (Landsman, 2006; FASB, 2006b; Hague, et al, 2006; IASB, 2006b).

Although fair value favours prices in deep and liquid markets, it is not expressly a market value or an exit value (Elad, 2004; Cairns, 2006). ${ }^{35}$ It recognizes unrealized changes in the market price of assets and liabilities, distinguishing it from the transaction (realization) basis for recognition under historical cost (Bies, 2005). Regulators specify a preference for level one valuations (Hitz, 2007). Where these are not available, level two is preferred and, finally, where model valuations are the only available option, these are to be used, employing as much market-derived input as possible (Herz and MacDonald, 2008). The case is made by Ryan (2008) that level two values are justifiable where they are, as described in standards, estimates from (active) markets for similar assets, adjusted for differences. However, a second allowable class at level two is prices delivered by inactive markets (Ryan, 2008). ${ }^{36}$

Fair values are progressively more important in the development of international accounting standards (Rutteman, 1989; FASB, 2006; IASB, 2007c;

\footnotetext{
${ }^{35}$ Although, as noted by Hitz (2007), accounting standards do not distinguish the level of depth or liquidity of the referent market when allowing the objective value of any market-informed fair value.

${ }^{36}$ This is more of an ill-defined area of fair value. No firm basis for assessing the liquidity or depth of a market is provided and, at least until recent times, any market value has been preferred to a non-market alternative, without reference to the quality of the referent market's formation.
} 
2007d). The intention of standard setters is that fair values will produce accounting standards and information that will enable users to: "identify what cash flows are possible or realistic" (King, 2006; IASB, 2006b). Fair value accounting is implicitly predicated on the view that markets are substantially efficient although, in contrast to certain arguments positing a conceptual challenge to fair value, value-relevance, I extend the predication of fair value to allow that fair value accounting can exist in the context of somewhat inefficient markets. Fair value may be advanced as a normative proposition; enhancing the efficiency of markets (Miller, 1999). ${ }^{37}$ The principal argument for fair value is its decision-usefulness/relevance (Bies, 2004; IASB, 2006b). Standard empirical analyses of accounting valuation relevance are based on an assumption of securities prices as reflections of value. This general circumstance would suggest the fair value case for its own relevance is similarly circular to the case for historical cost and its reliability, described previously. Contra-Zimmerman and Watts (1986), fair value advocacy does not presuppose its own descriptive characteristic. In this sense, fair value can allow a general level of efficiency that can be enhanced by fair value accounting, supporting fair value as a normative proposition, whilst allowing that, at a conceptual level, it has incremental value in an informational role (Miller, 1999).

\subsubsection{The case for Fair Value accounting}

The principal case for fair value accounting is that it has greater relevance for accounting information users (IASB, 2006b). A significant volume of empirical evidence has amassed, establishing, for the most part, that fair value financial accounts more accurately correspond with market prices of equities than historical cost does. Such research supporting fair value includes, inter alia, Caroll, et al (2002) and Venkatachalam (1996). The evidence is not universally supportive of fair value relevance but, intuitively, it is not difficult to infer the greater relevance of fair values (current values) compared with historical, transaction-date values. It is possible to make the qualification to the case for fair

\footnotetext{
${ }^{37}$ This is a point I return to later in this chapter on the discussion of Hitz' (2007) challenge to the conceptual foundations of fair value.
} 
value that where it fails in reflecting market values there may be a case for certain elements of re-specification. One such case might include a more extensive internally generated intangible asset recognition than is available under current accounting rules (Aboody and Lev, 1988). Recognition of revalued, formerly impaired intangibles, up to the maximum level of the pre-impairment level, captures minimal recognition of internally generated intangibles. The only inprinciple reason to object to such recognition lies in the putative lack of reliable measurement of internally generated intangibles. This reliability objection is inherently an historical cost conception as it is the cost, and the ability to separate expensed cost from capitalized cost that cannot be measured reliably where such a distinction would not impact a fair valuation of intangibles. As with many reliability arguments, the default position from uncertainty of measurement seems to be non-recognition. Inferentially, the strong opposition that has arisen in response to the ascendancy of fair value supports its relevance (Edwards, 1989).

The FASB has expressed the desire that the principles underlying financial accounting should be identified and emphasized (FASB, 2005). It is held by the standards' setter that comparability feeds into relevance and reliability. Prima facie comparability favours fair value over historical cost in a systemic sense, where historical cost operates with temporally heterogeneous values against the temporal homogeneity (current value) of fair value. Threats to fair value comparability pertain principally to the specification of its subjective operation on, especially, level three model valuations. The FASB (2007a) concepts statement No. 2 Qualitative Characteristics of Accounting Information, specifies comparability of accounting information, allowing investors to identify similarities and differences between two sets of economic events.

The FASB (2005) identify relevance as consisting in predictive value, feedback value (accountability) and timeliness. Reliability entails verifiability, neutrality and representational faithfulness. ${ }^{38}$ Financial accounting information

\footnotetext{
${ }^{38}$ Reliablity has now been subsumed by representational faithfulness, with reliability relegated to a secondary, or enhancing, characteristic.
} 
should be useful to decision-makers in assessing cash flows and it should provide information on resources and claims on these (FASB, 2005). The FASB (2006; 2006b) concluded that, in general agreement with accounting information users, the fair value option provides relevant information. This would seem to significantly undermine the argument of historical cost, conservatism proponents, such as Holthausen and Watts (2001), that information on equity valuation is a minor concern for standard setters.

Fair value finds general support amongst the major standards' setters, the IASB and FASB (Chorafas, 2006). Part of the ascendance of fair value is in the need to find a standard global accounting measurement base (Camfferman and Zeff, 2007). If this has not established an independent impetus for fair value it has created equality between it and the incumbent, historical cost (European Parliament, 2007). Evidence of the growing support in standards for fair value is based largely on its closer proximity to economic reality, even allowing for model-valuation errors, than the fiction of amortised cost (Woods, 2004).

\subsubsection{The purposive approach}

The case has been made that there are limited implications for the valuerelevance accounting literature unless standards setters infer such relevance (Holthausen and Watts, 2001). This argument is a 'back-door' challenge to the central basis to empirical research involving correlation analysis, that is, stock price regressions on fair values, compared with historical costs, as evidence for fair value relevance. The real target here is fair valuation. The argument is made that such analyses assume the priority of the investor as GPFR user (Holthausen and Watts, 2001). The relevance of value-relevance research is contrasted with the FASB SFAC No. 1, paragraph 41, which states that the direct valuation of equity is not the only purpose of financial accounting. Developments in FASB (and IASB) standards, Discussion Papers, and observer notes generally do not support the view of Holthausen and Watts (2001). ${ }^{39}$ The inferred irrelevance of value-relevance to standards' setters is not a secure conclusion. The FASB

\footnotetext{
${ }^{39}$ This issue has been discussed at greater length previously.
} 
position may be more accurately interpreted as (written), "equity valuation is not the exclusive relevance criterion for accounting information."

The argument that the value-relevance research provides no independent support for fair valuations as an influence on standards setters, strives to undermine the central argument for fair value, its value-relevance, but it fails to do this in two key regards. The case has been made that the primacy of the investor as GPFR user is an intentional objective that major standards setters have been gravitating towards since the early 1970s. Where Holthausen and Watts (2001) argue that this assumption is unsubstantiated, the weight of evidence supports it. Secondly, as Barth, Beaver, and Landsman (2001) demonstrate in a reply to the Holthausen and Watts (2001) view, value-relevance has been the guiding intuition of US accounting standards since the creation of the 1933 Securities Act. The heredity of US accounting regulation is briefly described by Barth, et al (2001), revealing its development as a direct response to the turmoil pursuant to the 1929 stock market crash. Inference is drawn to the standards setters' priority of objective equity market pricing. They also note the number of FASB research supplements that are adaptations of the value-relevance literature, supporting the relevance of this literature. Further, they observe that SFAC No. 5 states that value relevance is distinct from decision relevance. This operates to qualify the targeted information required by standards setters. Value relevance/decision relevance is now, arguably, the paramount focus of both the IASB and the FASB, with their progressive trend towards fair value accounting standards. To use one brief qualification to the importance of value-relevance, dating to 1978, as definitive evidence for the nullity of the enormous body of empirical value-relevance research seems a desperate ploy of academics who simply do not like its fair value implication.

\subsubsection{Industry support for fair value}

A number of industry groups argue that fair value accounting information is useful to accounting information users. Association of Investment Management and Research (AIMR, 2004) believe that investors need to know the current price 
of an asset, not its acquisition price. They argue another advantage of fair value accounting is that it better reflects the growing volatility of markets. I have previously made the case that this increased volatility is a structural feature of modern (post-1980) financial markets, and thus, a long-term effect (Wray, 2007). It is further argued that fair value entails enhanced comparability over historical cost (AIMR, 2004). This point is illustrated by the case of two companies, owning similar pieces of land, with similar current market values, acquired at different times. Under historical cost, provided only that their respective acquisition dates entail a significant differential transaction price, these will be recorded at substantially different prices (Shortridge, et al, 2006). Against this, fair value opponents contend managerial valuation may reflect such similarly valuable assets, valued materially differently on the basis of ostensible differences. It is not clear that this objection describes an inherent feature of fair value. In general then, the issue of cross sectional comparability favours fair value. Fair value imposes a need to misrepresent objective reality, establishing a basis for liability, whereas a similar result can obtain under faithful historical cost accounting. That is, allowing that model-valuation assumptions are disclosed, the reporting entity must make an overt misstatement whereas historical cost permits that same entity to simply not execute the transaction that would deliver the undesired outcome. Rather, it seems to relate a caution regarding external valuation and valuation liability.

The pro-fair value view is iterated by the Certified Financial Analysts Institute (CFA, 2007). They argue that fair value is the only useful information for decision-making. They cite their on-line survey of two thousand investors which found $79 \%$ of respondents preferred fair value accounts as the basis for decisionmaking (Herz and MacDonald, 2008). CFA rejects the value of historical cost valuations, stating that they do not reflect the economic effects of a company's operations. Furthermore, arbitrary depreciation schedules inherent to historical cost accounting do not reliably describe reality (CFA, 2007). Assets may continue to generate cash flows long after having been written-down, such that managerial compensation is calculated in the write-down period on excessively expensed 
accounting records and, upon full write-down, on understatements of cost pertinent to those periods. Through both periods key financial ratios, such as return on investment will be corrupted by the capricious depreciation schedules used. This does not require managerial manipulation although it may; it merely requires an error in judgment where useful life, particularly of unique assets, can only be estimated. This will be especially pertinent where realized depreciation is substantially a function of use. It is argued that all financial decisions are based on fair values and that this establishes their objective worth as the accounting measurement base (CFA, 2007).

Official support for fair value is reflected in the previously described positions of the IASB and FASB and also, with some qualification, by the US Federal Reserve (Federal Reserve, 2005). They grant that fair value accounting information is relevant to users in the valuation of assets and liabilities. However, the Federal Reserve has articulated reservations about the recognition of unrealized changes in the fair value of all financial assets and liabilities. This issue has been addressed previously with the qualification to the singular comprehensive bottom line. Federal Reserve research shows variability in the fair value of bank loans and questions the reliability of subjective inputs into valuation models. It notes that small changes in pricing model assumptions can have significant implications for fair valuations. I address this problem later, following Stephen Ryan's (2008) position, indicating greater disclosure of these modelvaluation subjective inputs.

\subsubsection{Academic/empirical support for fair value}

A significant body of value-relevance literature and research has been developed in support of fair value relevance. Earlier the discussion addressed whether value-relevance was a central concern of standards setters. Here the discussion turns to consider the evidence for the value-relevance of fair value accounting. Although there is contrary evidence, the preponderance of evidence supports fair value relevance to investors. Much of the value-relevance research focuses on proofs of the correspondence of fair values with market prices. The 
preponderance of this research is US based and focuses on the financial sector and, more particularly, financial assets. This is a logistical constraint, imposed by the current application of fair value standards and the level of development of the accounting academy in the US relative to other jurisdictions.

The evidence for fair value relevance, although generally supportive of the proposition, is mixed. The 1995 study by Petroni and Wahlen supports the value relevance of fair values for listed securities but where market prices are unavailable, fair values are too unreliable to be relevant. SFAS No. 107 has been the subject of extensive research. Findings typically follow Petroni's and Wahlen's (1995) conclusion, that fair values for securities with market prices are value-relevant but for non-market securities the correlation between share prices and fair values is less clear (Nelson, 1996; Eccher, Ramesh and Thiagarajan, 1996; Barth, et al, 1996). This evidence is, in turn, equivocal. Arguably, it indicates a positive value to detailing the valuation basis employed in arriving at a fair value for non-market assets and liabilities (Wahlen, Boatsman, and Herz, 2000). ${ }^{40}$ Alternatively, the case has been made that firm-specificity of value is not reflected in fair value (Eccher, et al, 1996). Given an assumption of the inclusion of the basis of fair value calculation in the accounts, this interpretation is abductively inferior to that proposed by Wahlen, Boatsman and Herz (2000). This position is supported by Cotter and Richardson (2002), who find greater fair value/security price correlation with external appraisals of non-market assets. The generally greater relevance of fair values is further supported by Barth and Clinch (1998), who find that fair value revaluations of financial, tangible and intangible assets are reflected in stock prices.

This issue makes the research conducted by Aboody, Barth and Kasnik (2001) of particular interest to the valuation relevance debate. It is additive in substantive terms where much of the value-relevance literature generated in the US is, at best, a modest empirical increment to existing knowledge. It is

\footnotetext{
${ }^{40}$ This is similar to Ryan's (2008) proposal and is not as fair value is currently specified in standards.
} 
distinguished by its contemplation of the implications of fair valuations in terms of relevance and decision-usefulness as they affect fixed assets. Secondly, it supports the predictive value of fair value revaluations of those fixed assets. A significant positive relation between revaluations of fixed assets and future changes in cash-flows and operating incomes is noted in a study of UK firms by Aboody, et al (2001). They control for variation in stock prices that is unrelated to fixed asset revaluation by regressing stock prices on the revaluation balance, earnings and book value. Three years' data from revaluation are used to assess the impact of revaluations. This research and its conclusions are supportive of the predictive value of fair valuations, making this amongst the most significant of the value relevance research.

The findings of Aboody, et al (2001) have been challenged on the grounds of research execution issues by Sloan (2001). He argues that the research methodology was flawed as it had to rely on observable current values without controlling for management errors and biases. Further, the case is made that the Aoody, et al (2001) conclusion is overdetermined as operating performance is influenced by many factors. Amongst the research design flaws Sloan (2001) observes is the use of only three years' of cash flows and operating income data from the revaluation date. The impact of increased debt assumption on the basis of asset revaluations, [maintaining a constant debt-to-equity ratio], is not considered.

The objections raised by Sloan (2001) are largely insubstantial. It is not obvious that three years' cash flow and operating profit data, post-fixed asset revaluation is inadequate as Sloan contends. This relates to his observation that many factors impact on operating performance and the ability to control for these diminishes progressively with time from the operative event. It is unlikely that Aboody, et al (2001) would advance the case that a revaluation of fixed assets functionally guarantees the company's outperformance in terms of its operating and financial metric throughout its indefinite lifespan. If we accept this challenge 
of Sloan's we have to allow that nothing else may affect company performance, however far such extraneous events are from the revaluation date.

The second substantive claim Sloan makes is that revaluations allow the company to assume more debt and thus facilitate increased cash flows and operating earnings. In the first instance, this argument assumes that all debt will yield net positive returns. Clearly Sloan's argument assumes that investors in fixed interest instruments are systematically foregoing risk-adjusted returns. Setting this concern aside, some incremental information value may exist in net profit as one of the tested metrics but it is doubtful this speculative proposition of Sloan's is, in any event, well-conceived. The argument turns on the lack of an explicit control for total debt over the study period. An implicit assumption underlying this observation is that the banking industry lends on the basis of accounting numbers and that a loan would not be extended against an asset worth a given amount if its historical cost was much less. This seems to assume the banking industry systematically eschews risk-adjusted profit opportunities. This is unlikely.

Another issue Sloan (2001) raises is that the Aboody, et al (2001) study relies on observable current values, without controlling for management errors in these. This indicates some value to repeating the study, in expanding the sample, and, possibly, in assessing the veracity of management-estimate history in relation to the sample companies. The latter suggestion is, at best, theoretical and, for practical purposes, logistically too demanding and too uncertain of delivering a sound conclusion. In any event, extending and repeating the research would seem to offer a reasonable control against systematic sample bias in the revaluing companies. It is not clear that Sloan is arguing for more here than that Aboody, et al's (2001) probabilistic conclusion, is not certain. If this is his argument it is reasonable to grant his concern, without sharing the view of its substantive nature. 


\subsubsection{A response to the manipulation risks of fair value}

Managerial manipulation is raised as an inherent risk of fair value measurement, principally due to third level fair valuation methods (Beatty and Weber, 2006; Flegm, 2004). The case is made that marking-to-model involves too great a level of subjective judgment on the part of managers. There is no doubt that this has been a problem in the past. Against this risk Chorafas (2006) argues that volitional manipulation of this kind may be controlled by increased managerial accountability. He cites the risk of imprisonment, describing the case of Daewoo Group in South Korea, owing more than $\$ 80$ billion. The result of this situation was a prison sentence for the former head of Daewoo, Kim Woo-choong (Chorafas, 2006). Further, Enron directors agreed to pay \$13 million personally to settle claims against them involving accounting manipulation. Enron's insurers paid out $\$ 155$ million in relation to this matter (Chorafas, 2006). The implication is that such personal accountability of management and boards may mitigate valuation manipulation risk. Arguably, increased penalties specified under the Sarbanes-Oxley Act will further enhance this risk control. What might be suggested here is that the sufficiency of the management risk is determinative of the risk mitigation achieved. This argues for the removal of arbitrary maximum financial penalties and prison sentences, making them functions of the magnitude of the manipulation and the losses caused. Incremental to this posited risk control, the disintegration of Arthur Andersen might reasonably be expected to reconfigure the agency risk/reward equation.

The Sarbanes-Oxley Reform Act, passed by President Bush in 2002, adjusted the risk-reward ratio for CEOs and CFOs. The CEO or CFO became liable to certify filed financials and where these are later found to be noncompliant, a requirement was imposed that the certifying officer refund any bonus or equity-based compensation received in the year following the non-compliant document (Squires, et al, 2003). Maximum penalties included fines of up to $\$ 5$ million and up to twenty years imprisonment for volitional non-compliance (Squires, et al, 2003). The effectiveness of these measures has been constrained by practical difficulties establishing the "willing and knowing" in non- 
compliance, as a pre-condition for punitive measures. Moreover, Sarbanes-Oxley has had its efficacy in managerial manipulation constrained as it relates to publicly traded companies that are registered in the US. A number of recent highprofile corporate collapses were of companies registered off-shore, including World com, Qwest, and Global Crossing (Squires, et al, 2003; Schuetze, 2006).

It is not clear that the issues raised in recent high-profile corporate collapses relate principally to fair value accounting manipulation. The opportunism inherent in unethical behavior may be more generally linked to the speculative excesses generated by advanced phases of an economic boom (Minsky, 1986; Ryan, 2008). More particularly, in the recent context, competitive pressures for returns in a low interest rate environment may have aggravated the incentive affect of opportunistic behavior (Schwartz, 2008). Deregulation of the telecommunications industry is argued for as a significant influence in the aforementioned collapses (Stiglitz, 2003; Merino, 2007). Tax cuts are also held as aggravating speculation (Stiglitz, 2003). Where Flegm (2004; 2005) ascribes Enron's collapse to fair value subjectivity, Schuetze (2006) observes that the SEC erred in failing to specify external appraisals for model-based valuations. This, then, looks more like an implementation issue rather than an inherent failing of fair value. In addition, Flegm's (2005) complaint of declining ethics cannot reasonably support the inference to causation by fair value. Independently, the suggestion of a decline in business ethics over the past thirty years, if accepted, at least partially exculpates fair value of causality in recent corporate collapses. This suggestion must be qualified by skepticism about Flegm's evidence of declining business ethics. He cites the increased priority afforded investors as the target of GPFR by students after one year's study as evidence of an ethical collapse. This position is incoherent as declining ethics, resulting in business collapses, harms residual interests (equity holders).

Against Flegm's (2004) view that fair value was responsible for the collapse of Enron, Veron, Atret, and Galichon (2006) argue that fair value accounting has reduced the tools available to manage earnings. Arthur Andersen, 
Enron's auditors, were able to take the word of Enron's audit committee regarding model valuations due to rules prevailing at the time (Scheutze, 2006). These rules were not particular to fair value. Notably FAS No. 98 Sale and Leaseback (1988) aroused significant managerial resistance due to the reduced ability to use off balance sheet accounting treatments (Veron, et al, 2006). The fact that the staff of Enron erupted into cheers (Flegm, 2005) upon revelation that they could use fair values may be more instructive of the potential for opportunism that inhered in its (then) too loose specification and insufficient audit practice. The case has been made that tighter specification of audit procedures has a more central role in agency risk control than measurement bases do (Ronen, 2008; Turley, 2008).

\subsection{The misspecification of reliability: Accounting for intangibles}

The historical cost presumption of reliability through verifiability by reference to a past transaction seems to mis-specify objective conditions for reliability. This issue is brought into focus by Aboody and Lev (1998) in their consideration of the growing gap between accounting values and market values. This, they argue, is due to the failure of existing accounting to measure the value of intangible assets. They make the case that SFAS No. 86 introduced the option of capitalizing research and development expenditure and that, of a study of 163 firms taking this option from 1987 to 1995, stock returns were positively associated with intangible capitalization. ${ }^{41}$ Reliability concerns establish the basis for an essentially historical cost basis to resist capitalizing intangibles. Arguably, fair value has the mechanism available for such measurement, in the form of embedded value; the present value of discounted future cash flows. Conversely, historical cost inherently fails to acknowledge a value attributable to internally generated intangibles. The central quality of reliability claimed by historical cost proponents seems to depend on removing the risk of making uncertain positive statements by maintaining silences. In this sense the argument is less obviously

\footnotetext{
${ }^{41}$ It is not clear whether the capitalization option encouraged these firms to invest in $R \& D$, and if this is the reason for their relative outperformance, however, assuming it did not result in nonaccounting variable changes, this serves as independent evidence of the informational value of fair value accounting for intangibles.
} 
for the reliability of accounting information than for its irrelevance. This looks more like ensuring accounts say nothing wrong by saying little worthwhile at all (Booth, 2003).

\subsubsection{Problems for fair value accounting}

The general basis to objections to fair value is that it is unreliable (Hitz, 2007; Wahlen, et al, 2000). This consists in regard to the previously described three levels of fair value specified in the standards of the FASB and IASB. In relation to level one, market values for identical assets, the concern is that the reference market is treated as delivering objective values regardless of its depth and liquidity. This issue affects level two valuations as well, aggravated by the lack of any strictly relevant referent market and the subjectivity inherent in adjusting for differences between the particular asset or liability and its 'similar' referent. The final level, level three model valuations, creates the greatest concern (Hitz, 2007). Model valuations are highly sensitive to minor differences in assumptions, including asset utilization rates, concomitant cash flows, and the discount rate (Bies, 2005). Each assumption is integrally dependent on the accuracy of the others. The reliability risks outlined are valid and they do indicate the need for careful standards' specification (Wahlen, et al, 2000). Arguably, fair valuations could be improved with more explicit legal and contractual sanctions than presently exist. Such liability would optimally extend to managers, directors, valuers, preparers, and auditors. What is not indicated is that historical cost's paucity of useful information offers a superior alternative.

A related area of concern is that of conservatism inherent in the realization basis of historical cost accounting measurement (Landsman, 2006). Where, in traditional accounting, recognition only occurred after realization, in the case of fair value recognition occurs in relation to unrealized changes in the (market) value of assets. The absence of an arms-length transaction is held to undermine the reliability of fair values. These issues interrelate. The essential issue is that we do not have certain knowledge that the values recorded under fair value will be achieved. These concerns have some, if variable merit. What they do tend to do is 
reify the transaction point. There are reasons to resist this implication of historical cost accounting.

The evidence supporting fair value relevance has been challenged on the basis that the fair value/securities' price correlation does not provide evidence of the causal relation. To the extent that fair value merely reports market prices its decision-usefulness is nullified. This proposition is raised by Landsman (2006), although more tentatively than by Hitz (2007) (Discussed later). What we can say here is that evidence of market inefficiencies provides support for improved market efficiency accruing to certain modes of presentation, disrupting the pure information perspective. Such evidence is provided (inter alia) by Coronado, Mitchell, Sharpe, and Nesbitt (2008). They find incremental value relevance of recognition over disclosures of pension liabilities. The argument here is for a normative pursuit of market efficiency, thus the contradiction Hitz apprehends does not arise. This contradiction is between positive market efficiency theory and fair value. Axiomatically, a theory concerning the particulars of regulation presupposes some qualification to the efficient market hypothesis. Hitz (2007) argues that, to the extent that fair value does potentially include incremental information, at levels two and three of fair value, it conceptually violates its own foundations and is compromised by the unreliability of such information (Landsman, 2006). This position too narrowly defines conceptual fair value as market-consensus value, discounting fair value's conceptual extension to values that the market would grant but for insufficient information.

In relation to fair values derived against prices of securities in deep and liquid markets there does not appear to be any substantive basis to the concern. The absence of an arms-length transaction can be proxied by similar transactions in the referent market between willing, unrelated parties. What opponents of fair value (and more pointedly, banks) want to say here is that firm-specific valuation is discounted by fair value. This is, assuming perfect managerial rationality, possibly marginally true. The price delivered by the market is one the firm does not accept, admitting a managerial valuation of the asset that is not less than the 
market price. ${ }^{42}$ In this sense fair value provides a minimum value of assets and liabilities to the firm. If this is problematic for its excessive conservatism it is not clear how historical cost improves the situation. Presumably, transaction prices are not less than (for purchases) or not greater than (for sales) the valuation management places on an asset or liability at the transaction date.

In terms of illiquid markets and second level fair valuation, adjustments are possible and they are regularly made. The case that these are uniquely problematic overstates the difficulties involved. If we allow that employee stock options, subject to escrow of the securities underlying those options or a bonding/vesting period for the underlying securities, a strong-case of instruments distinct from those traded on any potential referent market is established, and we deduce that these are valued at issue, then no case arises to frustrate valuation. These derivatives are necessarily ascribed a value. They form part of compensation. To argue that they are impossible to value by both issuer and employee reductio ad absurdum is to say the company is offering employees some money and other stuff that is good. This is strained. Both parties hold a firm view of the value of the consideration.

In the case of illiquid markets, it is unclear why a range of value proxies would not suffice, founded on disclosed assumptions underlying discount cash flow valuations. Any suggestion that this is problematic presupposes a disruption of the company's going-concern basis. It essentially asserts a liquidation basis to accounting values similar to that proposed by Chambers, without first justifying this liquidation assumption. The intuition here is that representational faithfulness is compromised where reliability is an assumed function of 'worst case scenario' anticipation. That is, the assumption that at any given point, we need to know the current value an (illiquid) market will offer is not secure. The problem is that the

\footnotetext{
${ }^{42}$ Assuming the firm continues to hold an asset or liability, against a given market price, the firm can be assumed to value the asset or liability at an amount not less than (or greater than) the referent market price. It prefers to hold the asset with information about this price known to it. It may be that the market price, as opposed to the asset or liability, produces indifference on the part of the holder, but this describes only the lowest firm-specific valuation of an asset, that it might continues to hold at higher prices, or a liability that it might only discharge at lower values.
} 
marginality of the illiquid market referent is exacerbated to the point where its referent value relates only to forced sales.

The level three model-based valuations of fair value are understandably the most contentious of fair value bases. The subjectivity of appraisal and estimates in model valuations is argued by historical cost proponents to create the basis for valuation manipulation. The model must use as much market-based information as possible. A range of alternative methods are allowed in mark-tomodel fair valuations. Minor changes in assumptions underpinning models may have significant valuation implications. This concern is legitimate but it is principally an issue of fair value operationalisation and specification. The problems at this level are not insuperable and their solution links with the extended disclosure and accountability function anticipated in relation to prospective information. Fair valuations of the mark-to-model kind inherently contain prospective information. At each future period from the modeled valuation, that valuation will gain substantive support or stand in need of revision. If this, in tandem with bolstered liability for culpable misstatement is insufficient as a basis to assert the incremental information value of modeling value of firmspecific, non-vendibles it is, at the minimum, unclear how amortised cost could secure superior information for investors, especially in light of fuller disclosure surrounding model assumptions and a proposal to quantify primitive variables (Ryan, 2008). The objection to fair value of the subjectivity of model-based valuations loses its force provided that primitive variable quantification is disclosed. This provision reduces preparer ability to make unwarranted assumptions, enabling scrutiny of those assumptions, augmented by comparison between entities' assumptions.

Another concern about (SFAS 159) is the relevance of fair value consists in the referent values (that is, market values) used in testing the valuation basis (Wahlen, et al, 2000). This argument is essentially a challenge to market efficiency (Kothari, 2001; Lee, 2001). This turns around the idea that fair value relevance assumes the objective character of market values. The position takes the 
form that where fair values are stronger positive correlates of market values, it is not certain that market values are descriptive of an underlying objective value. This argument is approximately that if market values are just 'fictions' decisionusefulness will not obtain from an accounting measurement base that merely apes (or even contributes to the formation of) those market prices. Fair value financial reporting will do no more than tell the user what is already known to the market and what is 'known' is uncertain as an objective identity.

Fair value referents have been further challenged as being relevant only to traders, not (buy-and-hold) investors (Bush, 2005). This issue is one I have discussed in the preceding chapter, in the consideration given to the question of whether GPFR should focus on current or potential shareholders. In a slightly different sense to the one advanced by Bush it is possible to infer grounds for some doubt about the relevance of fair values. As discussed, Bush's argument is tenuous. Fair value may, however, be flawed in extrapolating from the marginal investor, including traders, to investors in general. This is an implication drawn from the potentially small fraction of a company's equity securities that are regularly traded. In contrast to Bush I would not want to advance so tenuous an argument as the view that fair values prioritise traders as the target of GPFR. However, the referent value objectivity of marginal investors may be doubtful as an input into investors' decisions, at least to the degree of precision implied by market values. Against this, it is unclear how historical cost obviates this 'precision excess' where it relies on values that are definitionally marginalist in that they are derived from completed transactions.

The related concern of no arms-length transaction in recognition without realization seems to only exist as a problem where there is reason to doubt realizability. Possibly the issue that best illustrates this concern is the fair valuation of liabilities impaired on the basis of the reporting entity's increased firm-specific risk, that is, risk of firm non-performance or default risk. As fair value currently stands, an objection is raised to the asymmetric treatment it entails in asset and liability valuation (Chorafas, 2006). Where fair values are used for 
assets, cost amortised to impairment is used for liabilities. The asymmetry bypasses the counter-intuitive balance sheet improvement that obtains from, for example, the reduced fair valuation of an entity's outstanding liabilities, due to the market's estimation of the entity's increased risk of default.

This ostensible asymmetry is less obviously problematic for fair value than critics would suggest. The reason we might resist problematization of this issue, and still reject reporting financial statement improvements on the basis of increased company default risk, is that the company has an ultimate liability to repay the face value of its bonds. It can only avoid paying full value by its bankruptcy or repurchase of its outstanding bonds. Assuming the company was situated to do the latter we would not expect the discount to be substantial and, even if it was, it would reduce significantly in the event that the company bid for its outstanding bonds. There appears to be a need to realize any benefit recorded in the limited case where the company's ultimate liability is to the full nominal value of its debt instruments. Conceptually, fair value as a measure of economic substance survives this challenge.

On the asset side of the balance sheet blockage has some parallels with the corporate bond (liability) situation, although standard setters specify that blockage is not to be discounted. The distinction, and reason to hold the two situations distinct, is that where a company must fundamentally alter the supply/demand equilibrium to realize a gain on its non-performance risk-increased, discounted debt instruments, unless the going-concern assumption is disrupted, no such necessity arises in relation to its assets. It only needs to realize block holdings in other companies, under normal conditions at a discount, where its own viability is doubtful. Conversely, realizing balance sheet gains on its own discounted debt, that are not due to a shift in the market interest rate, without supporting realization, would lead to the inference that the company believes in the possibility/probability of its own bankruptcy and relief from the obligation. Rather than improving the balance sheet this would assure little or no residual (equity) value whatsoever. For these reasons the ostensible asymmetry opponents 
of fair value protest of can be obviated by the specification of minimum conditions of realizability. In the described circumstance the discount for company-risk impaired debt or the value decrement concomitant with the realization of block holdings in other companies both indicate realization as a precondition for recognition of a price differential form, in the first case, nominal (issue price) value, and in the second, market value. As fair value targets underlying economic reality, and that reality is redefined where realization would alter the supply/demand dynamics of the market, nothing incoherent obtains from the ostensible asymmetrical treatment of assets and liabilities that cannot be reconciled by reference to the generative axioms of fair value.

The major standard setters have by-passed this issue by imposing the pragmatic constraint on subjectivity implicit in specifying such instruments (ESOs) be recorded at the value they would have when they vest (IASB, 2006e). Simply, this eliminates any calculus for difference. Similarly, with blockage, no calculation is allowed to discount the holding as a relation to its size. IASB IAS39, paragraphs 48A, AG71, and AG 75 explicitly state the fair value is of a single instrument (IASB, 2006e). Where the standard setters fair value position on blockage does nothing more demanding than assert the going concern assumption, the standard setters' position on, for example, ESOs, is less clearly consistent with economic substance. Plainly, the market would not deliver the same price for conditional and unconditional instruments. This indicates that fair value coherence as a reflection of the substantive economic character of the event (ESO issue), supports accounting accrual of the ultimate instruments value, sensibly as a probablistic inference to the instrument's realization, and thus cost to the issuing entity.

\subsubsection{Empirical evidence rejecting fair value relevance: bubbles and the comprehensive income implication of fair value's balance sheet approach to income}

Although the preponderance of value relevance research supports the view that fair value is value-relevant, the evidence is not unequivocal. Comprehensive 
income, specified under SFAS 130, shows no stronger correlation with returns than net income (Dhaliwal, Subramyanyam, and Trezvant, 1999). In general net income is a better indicator of market value and cash flows. The only incremental information value relates to the changing value of the marketable securities component of accounting reports. This evidence is supported by the findings of Cahan, Courtenay, Gronewoller, and Upton (2000). In regressions of firms' equity values on reported fair values Landsman found that correlation results were mixed (O'Brien, 2005). The case has been made that the link between fixed asset revaluations and future firm performance is overdetermined (Sloan, 2001). Fair value relates to comprehensive income in that it substantially extends the focus on, and priority of, the balance sheet. The evidence of Wang, Buijink and Eken (2006) is more equivocal, finding some incremental relevance to asset revaluations and currency translations. Arguably, Aboody, et al's (2001) research, positively correlating fixed asset revaluations to subsequent performance, further supports the value relevance of comprehensive income.

Intuitively, comprehensive income could be expected to have a variable relation to value due to the variable qualitative characteristics of components of it. Nonetheless, elements of comprehensive income can be assessed for their quality, importantly tied to recurrence, potentially elevating the value relevance of the total information provided by comprehensive income GPFR. What empirical research of this issue generally does is take net profit and comprehensive income, as presented, against each other. This reflects a preoccupation with individual numbers, the bottom line, where, the assumption of modest levels of aggregate investor rationality offers conceptual support for the view that investors will distinguish between elements of a company's performance they expect to be repeated versus those which are one-off. For this reason, the repeated empirical research findings of less, the same or variable incremental relevance of comprehensive income over net income, yields unremarkable results. The 'noise' of non-recurrent items will not have a standard influence. What may be indicated here is empirical research based on an adjustment made to comprehensive income, for the recurrence of its components. Under any circumstances 
comprehensive income affords more information for analysis. This valuerelevance challenge to fair value presupposes investor (and analyst) analysis based on bottom-line numbers. If such an assumption is safe this is a decisive argument against fair value. In such a case GPFR regulation becomes a nullity. Company management may just as well offer their opinion about the company's fortunes as the singular content of financial reporting, possibly augmented with a number (bottom line, out of 100 , for example) for timorous souls who take confidence from numerical representations of opinions.

The evidence of Dhaliwal, et al (1999) is of particular relevance to the fair value issue because it bases its value relevance assessment on comprehensive income on available-for-sale securities (AFS), net losses associated with minimum pension liability adjustments, and foreign currency translation adjustments. What this research does is reveal limitations to comprehensive income more than fair value (Cooper, 2007). Pension liabilities and foreign currency translation need not importantly inform the market of a company's operating performance. The solution proposed to this by the project manager responsible for developing IAS 39, Paul Pacter, was that there should be three bottom lines: net income, income including abnormals, and comprehensive income (Wood, 2004). It is important that the qualities of contributions to reported accounting numbers (operating performance) be known by their source. Nothing inherent to fair value precludes multiple bottom lines.

Against the view of the pro-cyclicality of fair value comprehensive income the case has been made for multiple bottom lines, to describe the qualitative nature of particular components of a company's economic performance (Pacter, cited in Wood, 2004). This allows that earnings quality as a function of recurrence can be isolated and is important to investors. This response addresses the concerns expressed by Mulford (2007). This issue for fair value is also tacitly challenged by the research conclusions of Dhaliwal, et al (1999). If we accept their finding, that comprehensive income has less relevance than net income, we must also accept that fair value does not create pro-cyclical 
aggravation of inflated or depressed market prices. On a separate point Enria, Cappiello, Dierick, Grittini, Haralambous, Maddaloni and Molitor (2004) make the case that fair value provides earlier signals of financial fragility, countering its affect of increasing market volatility and its pro-cyclicality. This latter point is one we need to qualify by the context provided by Dhaliwal, et al's (1999) research findings. We cannot have this one both ways. If fair value comprehensive income has no, or only muted, pro-cyclical implications, then its stabilization of the cycle (countercyclical) implications must be similarly limited (Jameson, 2005; Jameson, 2005b).

The view, then, that comprehensive income under fair value is not relevant in the sense of corresponding more closely with market values, may be allowed without unseating the utility of fair value comprehensive income (Skinner, 1999). He makes the case that comprehensive income performs a role in terms of assessing contracting issues.

Where Dhaliwal, et al (1999) argue that net surpluses provide better indications of future cash flows and income, Skinner (1999) holds that this result is expected (or at least unremarkable). He queries why it might be expected that unrealized gains and losses on the measured variables might be expected to have implications for stock prices. We can sharpen Skinner's point by expanding the function of comprehensive income to stewardship in toto. It is worth noting that nothing of this localized debate offers a challenge to the use of fair values over historical cost so much as it challenges the ubiquitous utility of the balance sheet view of income that has been a concomitant of fair value. As Pacter has argued, the problem comes in the obsession with a single bottom line (Wood, 2004). There is nothing inherent to fair value accounting to preclude the three bottom lines proposed by Pacter (Wood, 2004).

The issue of fair value as a balance sheet approach to income has raised concerns that it supports market bubbles (Penman, 2006; Boyer, 2007; Bondi, 2005). This view holds that mixing present profit with unrealized gains and losses 
obscures the value creation process. In doing this it adds an accounting accelerator to an existing, pro-cyclical financial accelerator, aggravating market cyclicality (Boyer, 2007). Moreover, fair value creates the impression that a firm is an aggregation of substitutable assets. This conflicts with modern theories of the firm and its value creation which shows that managers activities and the strategic complementarities between firm-specific assets are the key to value creation (Bondi, 2005). It has been argued that conceptually fair value improves service to investors but that implementation risks exist. Moreover, market values can be derived from historical cost accounts (Penman, 2006).

A more rigorous investigation of procyclicality and volatility than the tentative, more general discussion of Boyer (2007), is that of Plantin, Sapra and Shin (1997). They find evidence that, in relation to long-term, senior, illiquid assets, such as comprise an important part of bank assets, marking-to-market (fair value) increases inefficiencies. The market for bank loans is small relative to total loan books and is susceptible to supply shocks, such that prices fall sharply in response to increased supply and only recover gradually (JWGBA, 1999). The case is made that such volatility is artificial. ${ }^{43}$ Banks generally hold loans to maturity and price fluctuations over the holding period are more indicative of supply dynamics than risk pricing. Similarly, banks are better situated to extract cash flows from assets, thus the market systematically undervalues such assets relative to their entity-specific value. Naturally, in the context of the current debate, challenges to fair value's ability to capture economic substance must be established on the basis of historical cost's superiority. It is not sufficient to prove fair value's imperfection. Managers' incentives indicate the sale of long-term loan assets to avoid recognition of short-term fair value losses. The authors argue that this creates endogenously elevated volatility as short-horizon managers sell pre-

\footnotetext{
${ }^{43}$ Against the view of increased volatility in financial reports Alkon (2006) finds little evidence that fair value increases financial report volatility, due to countervalence (hedges). In terms of realized (market price) volatility, the evidence does not support reported volatility's translation in market values. This view that fair value's propensity to aggravate volatility is exaggerated is supported by Serafeim (2007). The view of Hodder, Hopkins and Wahlen (2006) is that increased volatility is indicative of real volatility.
} 
emptorarily. The fair value assumption of frictionless markets is unsafe (ECB, 2004). A response to this concern is provided in the following discussion.

\subsubsection{The Decision-Usefulness of Fair Value Accounting: The challenge of Hitz and response to this challenge}

This thesis attempts to establish a conceptual basis to financial accounting. The central importance of accounting valuation, along with the difficulty standards setters have had in the inference from their identified concepts to measurement specification, supports the intuition that this is the optimal testing ground for a general theory of accounting. The discussion will approach its treatment of this issue by means of a reply to Hitz (2007). This is a clear and comprehensive exposition of the counter-thesis. In simple terms, Hitz (2007) makes the case that the proposition of fair value accounting is conceptually challenged. I present the view that this conclusion is unsafe and that Hitz relies on extremist interpretations of fair value accounting as a concomitant of market efficiency. If we only relax our assumptions about market efficiency, as any normative theory of accounting inherently does, his arguments are nullities.

Fair value accounting measurement has gained increasing acceptance amongst regulators to the point where it is now the conceptual preference of the SEC, the FASB, and the IASB (Hitz, 2007). The move to fair value has been progressive since the mid-1980s. This transition entails a shift from historical cost accounting based on transactions to event-based fair valuation (Hitz, 2007). The conceptual foundation for fair value accounting is its decision-usefulness and relevance, inferred from an assumption of the efficient market hypothesis. Importantly, the majority of empirical research, which is supportive of the conceptual confidence in fair value, relates to highly liquid markets, with a focus on the financial sector (Hitz, 2007). ${ }^{44}$ The motivation for fair value rests on decision-usefulness as opposed to stewardship and contracting objectives (Hitz, 2007).

\footnotetext{
${ }^{44}$ This is the reason why Aboody, Barth, and Kasnik (2001) used UK companies to assess the implications of fair value revaluations of fixed assets. The standards and samples using such an approach were unavailable in the US.
} 
"Fair value was introduced to provide information to investors to assess amounts and timing of future cash flows from an investment in a firm's shares and debt securities."

(Hitz, 2007)

This position, as a basis to infer the utility of fair value, generalizes the assumption of market efficiency to all levels of fair value (Hitz, 2007). Fair value has secured growing prominence in international accounting standards, with the fair value option available for all securities, subsequent to the 2003 revision of IAS 39. IAS 16 introduced full fair value for actively traded intangibles (Hitz, 2007).

The case is made that the position taken by standard setters "cannot be unequivocally supported by theoretical reasoning" (Hitz, 2007, p.325). [It is not obvious that any practical application could be operationalised so as to avoid at least some conceptually purist reservations]. One concern raised by Hitz is that fair value assumes an exit price in idealized market conditions of voluntary action of rational agents, operating with identical, complete information. Entity-specific competitive advantages, including private skills and value-in-use, are excluded (SFAS 157, paragraph C32; SFAC No. 7, paragraph 24; JWG, 2000, paragraph 4.5; IASB (2006), paragraphs 42-45; Hitz, 2007). The three-level valuation hierarchy, with preference for level one (market values in deep and liquid markets), provides last resort recourse (level three) to model-valuations. These are internally assessed on a present value approach (SFAC No. 7; SFAS 157: IAS 36; Hitz, 2007). Hitz argues the range of available methods and models that may be used under the fair value standards precludes the coherence of fair value.

The measurement perspective holds that "accounting should measure and report the...value of a firm...decision-useful information is information on the contribution of assets and liabilities to enterprise value [indicating value-in-use]" 
(Hitz, 2007). In practice, value and income are not well-defined and so they are proxied by information aiding the determination of the present value of future cash flows. The information perspective supports accounting information that improves decisions. It views accounting information as one source in a broader information set. The form of presentation does not influence its ability to influence decisions, supporting a view of perfected market efficiency. Conceptually, the newness of information capable of altering investors' expectations regarding the value of the firm is important or, less demandingly, cost effective information aggregation establishes a basis to assert satisfaction of the information perspective (Hitz, 2007). Absent the information newness factor the aggregation conduit assumes either, a), market efficiency imperfection or b), that aggregation is not individual-investor cost effective.

Financial reporting is an institution created by the deficiencies of realworld markets, including asymmetric information and transaction costs (Hitz, 2007). The present value of future cash flows, fair value basis, assumes investor indifference to the timing of those cash flows. Value-in-use is the benchmark measurement attribute yet fair value will, generally, not correspond with value-inuse (Hitz, 2007). Fair value ignores management skill, or firm-specific human capital thus fair value systematically undervalues the firm. ${ }^{45}$ Hitz's (2007) presumption appears to be that all firms possess superior management. By definition (of superior), this is impossible. From an information perspective, fair value only aggregates market (publicly available information) so it cannot revise the expectations of market participants. It, therefore, has no incremental information content or value. Conceptually, this observation applies to synthetic, model-based valuations as well (Hitz, 2007).

It is noted that model valuations fail in terms of reliability yet they may contain incremental information, but only so far as they stand outside of the conceptual basis for fair value (Hitz, 2007). By implication, internally modeled

\footnotetext{
${ }^{45}$ Fair value also ignores the sub-optimal utilization of assets by the firm, where those assets have uncertain external referents. This, at the least, raises a question about the systematic undervaluation inherent in fair value.
} 
valuations cannot be market-consensus expectations. For this reason investors need to assess the trade-off between increased relevance of private information impounded into model valuations against the increased risk of intentional bias in those valuations. This disrupts the fair value paradigmatic information aggregation assumption, impairing the decision-usefulness of model-based fair values (Hitz, 2007).

In assessing financial statement fair value applications against decisionusefulness from the information and measurement perspectives, Hitz finds limited support for fair value. The information perspective of fair value balance sheets isolates aggregation, discounting the mode of presentation. Fair value does eliminate hidden reserves, moving fair value closer to market value than does historical cost. It fails to account for internally generated goodwill. Fair value income increases volatility, although volatility may not necessarily increase due to off-setting changes on aggregation. It may also be argued that increased volatility is actual and thus, should be reflected in financial statements. From the measurement perspective, empirical evidence supports the closer proximity of fair value income to economic income (versus historical cost) and its greater predictive value, although Hitz describes economic income as ambiguous, stating that over time fair value income will equal historical cost income.

In general terms Hitz (2007) finds the conceptual basis for fair value tenuous. He raises concerns that the income concept needs to be clarified. The reliability of fair values is doubtful as it relies on idealized market conditions yet proxies such assumptions under real-world conditions, with sub-optimal market values, where they are the applicable reference for an asset or liability. He allows that liquid market information is decision-useful but that model valuations are less strong. Conversely, the incremental information value possible in model valuations depends on violating the conceptual basis to fair value, by impounding private information (VIU) into these models. 


\subsubsection{The counter-argument: the conceptual case for fair value}

Before considering fair value it is useful to consider whether the case for current value as an assumption or stipulation is warranted. The assumption of current values over historic values consists in two central elements. One is that current value accounting reflects the most recent information on aggregated market participant assumptions and expectations. Any accounting measurement system that does not form around a current valuation basis excludes the full range of possible information. The case that current valuation excludes historical information appears to presuppose the investor, otherwise isolated from financial information, makes investment decisions on the basis of single annual reports. This assumption discounts the competitive market for company-specific financial information that poses an imminent threat to accounting. Accounting as a discipline cannot pretend the absence of such competition. Moreover, the 'selfcontainment' proposition discounts previous annual reports. As this information augmentation exists, these assumptions implicit in the case for historical cost are rejected.

The second reason we might prefer current values is that they are (analytically) temporally homogeneous where historical cost values are temporally determined by the time of their transaction. Beyond relevance to current decisions, it is reasonable to assume this feature supports comparability. Against this position, historical cost proponents argue that such values can be extracted from historical cost accounting information. In this sense it is redundant to argue for current value superiority in terms of relevance or comparability as these qualities are implicitly granted of current value by historical cost proponents. What we do need to do is secure a current valuation base against claims that it unduly compromises reliability. The historical cost position is only slightly better than an argument for a more abstruse accounting information presentation such as arguing that this information should be written in code or that hardcopies should only be produced in small, faded print. The argument appears to tacitly accept that fair value is relevant but that agency risk entails that management subjectivity outweighs management information accessibility. 
Subject to certain specifications, I make the case for fair value formulated to address this concern. The objective is to combine management's superior information access with constraints on management bias.

The arguments Hitz (2007) raises contesting fair value decision-usefulness from measurement and information perspectives depends on a certain questionable characterization of fair value. His challenge attends no decisionusefulness increment in aggregation or confirmation of preceding market and model valuations; an account function. He also challenges fair value assumptions of idealized market conditions, irrespective of the referent market valuation base, while assuming market efficiency as a constraint on the incremental information value of fair value of level one valuations. It is open to stipulate (on the basis of sufficient empirical evidence) a degree of market inefficiency as an operating assumption of normative accounting theory (financial reporting regulation), as Hitz does, that may be mitigated by instantiating fair value standards. All we need to do to validate this proposition is to establish the relative closeness of fair value to economic concepts of income and value when juxtaposed with historical cost. The completion of this proposition is to establish an implied process-view of accounting standards' perfection, that is, fair value's momentum justifies its instantiation as an improvement on extant accounting practice. Finally, Hitz argues that value-in-use is explicitly conceptually precluded from fair value. In contrast I argue that value-in-use is implicit in fair value's present value-basis assessment of non-generic (where generic is level one) assets and liabilities, and that it is in these lower level items that firm specificity can be located. That is, by deduction, where the firm's present and future cash flows support a differential valuation to the aggregate value of level one items the difference must be firmspecific and a particular relation between model-valued assets and other economic income generating factors controlled by the entity. If human capital forms some part of the future cash flow assumption then it must either be controlled or constructively controlled by the company, due to the human agent's rational selfinterest. Any deficits in this proposition may be addressed by Crowther's (1992) 
view that single financial reports are not discrete datum in the real-world context, but are better viewed as individual chapters in a larger text.

The case that market values are to be preferred, without reference to the quality of the market formation appears to create some disjuncture between conceptual fair value and fair value-as-implemented. The motivational force behind fair value, its conceptual claim to relevance, enabling informed, rational decisions, is predicated on its reflection of economic substance. The pragmatic motivation of standard setters that I infer from the inconsistency of their treatments is that they are reluctant to step back from any kind of market price, regardless of such a price's separation from one that would be delivered in a deep and liquid market, between willing and knowledgeable economic agents. The inferred reason for this is that market depth and liquidity become areas requiring some quantification, that is, an absolute cut-off point is needed. This concern importantly impacts the issues raised by Boyer (2007) and Plantin, et al (1997). Economic substance is not going to be reflected in market values driven by shortterm supply dynamics in an illiquid market for preponderantly hold-to-maturity entities (Plantin, et al, 1997; JWGBA, 1999). What we can say here is that market values of long-term assets, held long-term, with demonstrable marginality and minority of the (securitization) market, do not necessarily describe the economic (fair) value of the assets to the term holder.

It is not clear that this is problematic for fair value conceptually. The valuation here that seems best indicated is level three. This only requires that we qualify markets as fair value referents, relative to some predeterminate level of depth and liquidity. This position is supported by Ryan (2008) arguing that level three valuations may be preferable to level two, where the level two valuations are derived from illiquid markets. The greater disclosure of model valuation assumptions may improve its information value to investors (Ryan, 2008). ${ }^{46}$

\footnotetext{
${ }^{46}$ Ryan (2008) also notes that neither SFAS-157 nor SOP 94-6 Disclosure of Certain Risks and Uncertainties requires quantitative information about the primitive variables involved in modeling calculus. In relation to the subprime crisis that is the focus of Ryan's discussion, such variables
} 
Where the market itself so far departs from the depth and liquidity preferred of level one fair valuations, its referent value is voided. Loans have a nominal or capital value and a (generally) specified intervening cash flow. The only relevant variables incremental to these known factors are changes in the debtors risk profile. Absent a suitable market referent, level three fair valuation is indicated. Because changing market values confound an assessment of this risk with shortterm supply dynamics, model valuations may be superior.

Notwithstanding this tentative solution, many of the objections to market values are specious. The suggestion of Plantin, et al (1997) that short-horizon sellers, motivated by contracting concerns, would pre-emptively sell, argues only for appropriate control of agency risks, potentially indicating compensation aligned with cash flows. It offers no independent insight into optimal accounting measurement. Their argument, that fair value may be endogenously volatilityenhancing, presupposes fair value is 'helicopter dropped' on an environment otherwise held constant. Plainly if, as Plantin, et al (1997) suggest, strategic concerns would be elevated over fundamental (long-term value creation) concerns, recalibating incentives would be indicated. This does not constitute a basis to reject fair value. Moreover, where short-termism indicated certain agents' opportunistic 'short-selling', term benefits would accrue to rational capital through discounted loan asset acquisition, supported by long-term agent incentivisation. The 'pernicious' action of fair value would then, if anything at all, make 'stupid' money, small money. This would ultimately chase it out of the market, thereby enhancing efficiency.

Arguably, the youth of credit-derivative markets is the principal determinant of market liquidity and concomitant inefficiency (JWGBA, 1999). The assumption of frictionless markets under such conditions is unsafe (ECB, 2004). We can allow that such circumstances may introduce artificial volatility into long-term, illiquid assets. Conversely, market discipline may be conducive to

include assumptions about house price depreciation, discount rates, expected future interest rates, and mortgagor refinancing capability and timing. 
more rapid corrective action in relation to valuation revisions under adverse circumstances. The Savings and Loan crisis was exacerbated by historical cost treatments that muted the deteriorating fundamentals of companies (ECB, 2004). The Savings and Loan Companies, as with banks in general, borrowed (then, as now), short-term and provided fixed long-term loans. This resulted in ongoing net losses when interest rates rose from $7 \%$ to $11 \%$, above the level of loan interest rates. Under historical cost, the losses showed only in the income statement going forward, whereas fair value would have reflected the loan impairment in the balance sheet. Nothing about this undermines level three valuations for such assets but the case may be made that, even if we grant the market's imperfection, it is not an argument for historical cost. If the concerns raised by opponents of fair value tell us anything substantial at all, they seem to make a case in favour of the "willingness" of parties to a transaction, in the IASB definition of fair value and the "normal business conditions" of the FASB definition (Blanchard, 2007; Ryan, 2008). The problematisation of fair value by Hitz (2007), Boyer (2007) and Platin, et al (1997), relates to an assumption of a fair value preference for any market, irrespective of how well formed it is, as though illiquid markets were the next best proxy for deep and liquid markets, of the underlying economic value of assets and liabilities. Where the FASB (IASB, 2007e) describe fair value as:

"an estimate of the price an entity would have realized if it had sold an asset or paid if it had been relieved of a liability on the reporting date in an arm-length exchange motivated by normal business considerations."

The IASB (2007e) describes fair value as:

"the amount for which an asset could be exchanged or a liability settled between knowledgeable, willing parties in an arms-length transaction” (Blanchard, 2000).

What is not indicated is a carte blanc rejection of fair value. Conceptually fair value maintains its robustness against the special cases fashioned as charges against it. Such arguments point to necessary considerations underlying the 
progressive operationalisation of fair value measurement. The case may be made that standards need to specify depth and liquidity sufficient to apply level one fair values.

The distinction that is able to be drawn is between market values and fair values. Where this has been the source of much of the contention surrounding fair value, it operates to secure fair value against the allegations that it fails to reflect the underlying economic substance of events. This point is made clear by the testimony of Dorchester to the FASB (2004), in which, while lauding initiatives towards current values, he stated a preference for market values over fair value (FASB, 2004). Dorchester complained of the ambiguity of fair value and the uncertainty as to whom it was fair (FASB, 2004). This creates no particular difficulties for the proposed theory. The owner (shareholder) is the party in singular contemplation here.

This brings us to the next explicit concern raised by Hitz (2007), that fair value assumes market efficiency. The conceptual commitment to a purest view of market efficiency is not inherent to fair value. It is in evidence in the view expressed by Dorchester, outlined above. What fair value implies is a reasonable basis to infer we cannot systematically improve the objective character of a market-based valuation basis in relation to values derived from deep and liquid markets. This is a significantly more modest claim on the efficiency of markets than Hitz (2007) supposes. What he seems to object to are particular specifications prevalent in accounting standards that are (pragmatically) reluctant to step back from any market values. His basic assertion that market efficiency is generalized to markets per se, from deep and liquid markets, although somewhat true, provides no conceptual challenge to fair value. Only so long as the implementation of fair value is consistent with the underlying economic reality it describes, preferring market referents where the reference market satisfies minimum liquidity conditions, then it is conceptually coherent. For this reason, this conceptual challenge by Hitz (2007) is rejected. 
The view described above challenges Hitz' objection to fair value on the grounds that it assumes idealized market conditions, irrespective of market formation. It also undermines Hitz's assumption that no incremental information obtains from fair value financial reporting. We might point to cost-effective information aggregation and confirmatory value of fair value information. Notably, this fits well with the described view of decision-useful accounting information, in which stewardship is an element, principally useful for assessing the veracity of prospective information. Ultimately, the stewardship function is not an essentially punitive operation. The ability to seek redress is almost invariably a minority component of the account function. It is in the continued employment of individual agents and an attendant concern for a company's prospectivity that accountability is importantly implicated.

It is not as certain as Hitz (2007) would have us believe that fair value functionally eliminates any recognition of value-in-use. This, Hitz (2007) argues, systematically undervalues the firm. This objection to fair value is an interesting contrast to Plantin, et al (1997) and Boyer's (2007) concern that during expansive economic conditions, fair value is procyclical. Unfortunately, having rejected this concern, it is not available to enlist it as a counter-weight to Hitz's systematic undervaluation problematisation of fair value. Such an approach would, in any event make the reliability and relevance of fair value something of a lottery. Firmspecific value is reflected in elements of fair value, satisfying the information perspective. It is only Hitz's assertion of a market consensus valuation as conceptual fair value that precludes such firm-specific valuations under fair value. This is the ideal fair value, not an axiomatic property of it. The net present value of future cash flows necessarily incorporates elements of firm-specific value. For this reason it is only the sufficiently generic, marketable assets and liabilities that conceptually presuppose market values as fair values. In this case the value-added of fair value GPFR is cost-effective aggregation and (ex post) confirmation of values, including model valuations. 
Other objections Hitz raises to fair value accounting measurement include: the fact that internal modeling cannot be market-consensus expectations, it is therefore unreliable, that, although it does eliminate hidden reserves, it fails to account for internally generated goodwill. In relation to reliability, as has been drawn out in the preceding discussion, this is not the prioritized qualitative characteristic of fair value. Fair value aims at relevance, targeting decisionusefulness, subject to minimum satisfaction of reliability. This does presuppose certain minimum conditions of reliability and, more than the abnegation of reliability as a qualitative characteristic, advances a different set of mechanisms for its achievement. Previously, the view was presented that market-consensus expectations are not a necessary condition of fair value must be qualified. In relation to level one fair valuations, reliability is definitionally inherent in the consensus of the market. For levels two and three, reliability is aimed at by disclosure of model valuation bases, by confirmation (and/or revision and bases for this) in subsequent reports, supported by a textural view of the broader information set that views a company financial report as a datum, as a rational investor necessarily must. It is envisaged that rational capital will realign managers' incentives to longer, multiple-period horizons.

The failure of fair value to account for internally generated goodwill under IFRS 3 does not constitute a fundamental conceptual challenge to it as an accounting measurement base. One of the objections to fair value is that the impairment basis operating under it captures some value attributable to internally generated goodwill. Simply, goodwill impairments may be reversed up to the full pre-impairment value of the goodwill, reflecting some of the value of internally generated goodwill. In contrast, under historical cost, goodwill is amortized on a scheduler basis of (typically) up to twenty years, without the option of reversal. This is not, however, the central issue. More importantly, the expensing of internally generated goodwill is predicated on reliability grounds. Conceptually, fair value is not inconsistent with the recognition of internally generated goodwill. To the extent that this goodwill is reflected in enhanced cash flows, the underlying economic reality of the goodwill, its fair value, may be recognized as 
an asset in proportion to the value increment it entails. Fair value has the mechanism to measure goodwill, the present value of expected cash flows. It is only the narrow, somewhat empirically established interpretation of fair value, which precludes such valuation. Contra-Hitz, I would make the case that this reflects the extent to which fair value deviates from its conceptual basis, rather than a basis to reject it conceptually.

\subsubsection{Summary}

The case made by Hitz (2007) for the conceptual incoherence of fair value takes an excessively narrow view of the assumptions underlying fair value. Market efficiency is not centrally implicated in fair value as an accounting measurement base. Level one fair valuations grant that current market prices are 'best guess' proxies for value but historical cost entails the reification of realized, historic, temporally heterogeneous fair values. Equally, fair valuation does not preclude entity-specific valuations. Such values are inherent in the present value assumptions in lower level fair valuations. Hitz (2007) takes fair value's articulation in standards as a complete, conceptually committed expression of the measurement basis. I make the case that standard setters have been concerned to overgeneralise market pricing for pragmatic reasons, including the appearance of a consistent, coherent and unqualified confidence in the objective character of markets. If we allow that conceptually, fair value is wholly about reflecting the underlying economic value of an entity and its income generating capacity, the substantive concerns of Hitz (2007), Plantin, et al (1997), and Boyer (2007), are addressed and nullified. Where aggregate fair values do not reflect the full economic value of an entity's cash flows nothing about exclusion from the balance sheet of the entity indicates other than that the entity does not control the excess value-generating capacity. 


\section{Chapter Five}

\subsection{Discussion and Conclusion}

The preceding discussion has examined developments in and on accounting theory as a basis for the consideration of the development of a coherent theory of accounting. I have considered the contribution of the academy to accounting theory development. This has consisted, in broad terms, in three distinct periods. Until the mid-1950s accounting was essentially an empiricallybased description of existing practice. Subsequent to this, from the mid-1950s until approximately 1970, normative accounting theory rose to the fore in the accounting academy. From 1970 positive accounting theory has predominated. This has been in substantial part, defined by an implicitly ethnographic, prediction-predicated study of accountants and management choices. Only in the intermediate period was the academy centrally concerned with the development of a normative theory of accounting.

The generally limited (or negative) contribution of the academy to a conceptual framework has been aggravated since the 1960s (and 1970s) by the fairly persistent flirtation of academia with stakeholder theory, and latterly, critical theory. These sub-paradigms have demanded recognition, particularly in relation to stakeholder theory, that has confounded the ability or inclination of the academy to advance a general theory of accounting. This has occurred over the period of positivism's incumbency. The predominant paradigm definitionally precludes its own engagement with the development of a normative theory of accounting. These factors have generally precluded a positive contribution by the academy to a general theory of accounting and its operationalisation.

Although not immune to trends in academic accounting, regulators have made substantial progress in the development of a conceptual framework. Work on this project began in the depression era of the 1930s as a direct response to the social and economic turmoil aggravated by the collapse of asset markets. The progress was at best sporadic between 1933 and 1966, with substantial progress in evidence only from 1966. This enervated, more strident development in 
accounting regulation predicates was reflected in a number of reports culminating in the Wheat and Trueblood Committee reports. Wheat established the FASB and Trueblood identified the principles that were to form the basis for the FASB's conceptual framework. From this period, accounting Conceptual Frameworks and regulation have developed in what I have described as a 'quiet' move towards coherence.

The nature of development of the conceptual framework to the current period has centred around its progressive focus on the investor. Decision-useful information, relevant to investors in their allocation of risk capital is the general achievement of major standard setters' conceptual frameworks. To this end current value variant, fair value, has surfaced as the principal measurement base challenge to historical cost.

In developing a framework for a general theory of accounting, chapter three makes the case that current conceptual frameworks are (a somewhat qualified) success. The innovations proposed in this discussion include the elimination of equivocation over the centrality of investor as GPFR user. In particular, creditors are no more than marginal claimants, otherwise protected by contract and their priority over equity holders, securing the intuition articulated by standard setters that information sufficient for risk capital providers will satisfy creditor needs. Similar arguments apply to debt capital providers, with the incidental advantage that this eliminates coherent theory-frustrating arguments from debt providers, motivated by their plural imperatives as issuers and managers. Defining the user is fundamental to a coherent normative theory of accounting.

The determination of investor-as-user is generated from an examination of the elements of the broad socio-economic environment. I consider the development of the corporation in the (prevailing) mixed economic system. Beyond this I describe the broader evolution of society. It is in the context of the 
existing elements of contemporary society that I make the case for the singularity of investor as user.

The theory operates from the achieved conclusion of the investor as user to identify the optimal mix of objective functions and qualitative characteristics required to satisfy investor needs. The analysis supports the view that standard setters have acted correctly in preferring decision-usefulness and in the subsumption of stewardship by it. A further element of standard setters' achievement of conceptual framework coherence is the deflation of reliability as a definitional entailment of transactions-based accounting measurement. This is reflected in the substitution of representational faithfulness as a primary qualitative characteristic, of which reliability is an element. Comparability has also gained greater prominence. These conceptual elements aggregate to favour a current valuation basis to accounting measurement.

Auxiliary to the conceptual propositions, it is envisaged that fair value implementation requires certain conditions to secure it from reliability risks. This implicates fair value in a systematic elevation of risk of opportunistic agent behavior. This does not undermine fair value on the basis of execution risks. The increased prospect of opportunistic behavior inheres in fair value's greater prospectivity for relevance. Simply, historical cost accounting can be faithfully applied, without satisfying representational faithfulness, obviating the manifestation of preparer opportunism. This issue turns on the perverse implications historical cost's recognition-basis has. Simply by holding poorlyperforming assets, preparers avoid the need to present significant value destruction or increase up to the point of sale of the relevant assets. The position adopted here is that certain phases of economic cycles establish predispositional conditions for opportunism and, given the argued for rejection of fair value's procyclicality, nothing inherent in fair value will do anything more than describe the modes of opportunism. Incremental to historical cost, positive misstatements are required under fair value to achieve the obfuscation readily available under historical cost. The central concern is that agent liability and accountability lack 
sufficient motivational force. This is the basis for proposing fair value which is supported by augmented liability and penalties, extending to valuers/appraisers, preparers, auditors and managers (including directors).

The theory assesses the current accounting valuation debate against the implications of the proposed general theory of accounting. I find the case for fair value is supported by the theory. The inference to fair value from the theory does not presuppose fair value-as-operationalised in existing standards is perfected current value. Independent of the outlined theoretical precepts, fair value's momentum recommends it over rival, potentially superior, current valuation methodologies. In this sense pragmatism balances a purist theoretical position. It is not envisaged that prevailing fair value is other than progressive in the evolution of accounting. Arguments thus, that certain refinements may enhance it are granted but only with an intentional conviction in relation to a conceptually coherent fair value. What we seem to experience is objections to the incoherence of elements of implemented fair value which has necessarily had to evolve and adapt to survive political pressures for compromise.

The proposed theory implies fair value as a relation between current value and its correspondence to underlying economic value. The theory does not operate on the assumption of the current implementation of fair value in the standards developed by major standards setters. This is not a conceptually based exposition of fair value but it is confused, in itself, mixed attribute, accounting valuation base. I explicitly reject the characterization of fair value as systematically undervaluing firm-specific value. From the same base the case made by Hitz, that fair value adds no information increment to otherwise readily available market information, is rejected. In terms of reliability, the conceptual case for fair value is strangely undemanding. In the first case, fair value accents relevance and, thus, indicates a minimum possession of reliability. This standard seems likely to be satisfied by disclosure of assumptions central to valuation models, and by confirmation, or revision and explanation, of past level two and three valuations. For these reasons Hitz's challenge is rejected. 
Arguments challenging fair value on the basis that it is inherently procyclical are also rejected. This argument is linked to the case that fair value increases reported volatility and may increase real volatility. The view that GPFR should reflect elevated market volatility seems justifiable. Moreover, evidence exists that fears of the excessive reflection of real volatility by fair value in GPFR are challenged empirically by (inter alia) Alkon (2006) and Dhaliwal, et al (1999). The case is made that offsetting fair values potentially increase financial statement stability and, that markets discount certain elements of income inherent to fair value comprehensive income. Given the trend of economies and markets to long-term growth, the procyclicality of fair value is an argument for systematic net market overvaluation. This entails that competing objections to fair value accounting measurement are that, in terms of Hitz' and Plantin, et al's (1997) position, fair value systematically undervalues companies and, in the case of Boyer (2007), it systematically overvalues companies and markets. In both cases the bases for challenging fair value are rejected.

Fair value, in the form preferred by this discussion, satisfies the theoretical criteria established here as the basis for a general theory of accounting. It provides information useful for investors to make rational economic decisions, concerning whether they should buy, sell, or hold equities in a company. The information is incremental to market information but it is conceptually sufficiently reliable to underwrite its relevance to investors. Fair value information can increase market efficiency in the allocation of scarce, economic resources by means of cost effective aggregation, by confirmation, and by reducing market inefficiencies. Fair value does not require perfected market efficiency. More pointedly, the fair value prescription specifically targets efficiency enhancement. The more persistent objections to fair value typically relate to its specification rather than an effective challenge to its conceptual foundations. Collectively, these reasons secure fair value against conceptual, fundamental objections but indicate certain overdue enforcement and accountability enhancements, including extending the liability of agents for culpable errors or misstatements. 


\subsection{Conclusion}

Financial information markets have become increasingly competitive with the proliferation of myriad sources of such information, facilitated by the growth in communications technology and financial asset markets. These factors have created the means and motivation for a competitive market. In this environment accounting does not have any sacrosanct claim to a non-negotiable share of this market. It cannot simply hide behind its governmental mandate. Accounting must compete for its claim as a unique provider of useful financial information. The inference is available that accounting as an arcane pseudo-science has presumed an ability to hide behind its mandated role. To a considerable extent the intuition behind this assertion finds support in the debate surrounding accounting regulation. At its best a highly politicized debate, subject to a sub-optimal trajectory by the partisan arguments of vested interests, accounting risks marginalizing itself. Short-termism characterizes the debate. This is reflected in arguments for 'obcurantist', ritualistic accounting treatments such as historical cost that frustrate clear insight into the underlying economic substance of a company's operations. The preparer community's ability to capture accounting regulation risks making its capture a pyrrhic victory If this interpretation is allowed, positive accounting theory's study of accounting choice will be nothing more than a narrow aspect of accounting history which, as a consolation will become all of accounting that is available to study. It is in this context that the preceding normative accounting theory is proposed. 


\section{Glossary}

AAA American Accounting Association

AIA American Institute of Accountants

AICPA American Institute of Certified Public Accountants

APB Accounting Principles Board

ASOBAT A Statement of Basic Accounting Principles

CAP Committee on Accounting Principles

CFA Certified Financial Analysts

COCOA Continuously Contemporary Accounting

EMH Efficient Market Hypothesis

FASB Financial Accounting Standards Board

FEI Financial Executives International

GASB Governmental Accounting Standards Board

GPEAFR General Purpose External Accounting and Financial Reporting

GPFR General Purpose Financial Reporting

IASC International Accounting Standards Committee

IASB International Accounting Standards Board

IAS International Accounting Standards

ICAEW Institute of Chartered Accountants of England and Wales

ICAS Institute of Chartered Accountants of Scotland

PAT Positive Accounting Theory

SFAC Statement of Financial Accounting Concepts

SFAS (FAS) Statement of Financial Accounting Standards

SEC Securities Exchange Commission 


\section{References}

AAA (American Accounting Association). (1966). Committee to Prepare a Statement of Basic Accounting Theory. A Statement of Basic Accounting Theory. Sarasota: Florida: FL: AAA.

Abdel-Khalik, AR, and Ajinka, BB. (1979). Empirical research in Accounting. Sarasota, Florida: American Accounting Association.

Aboody, D, ME Barth, and R. Kasnik. (2001). Revaluations of fixed assets and future firm performance: evidence from the United Kingdom. Journal of Accounting and Economics, 26, 1: 149-178.

Aboody, D, and Lev, B. (1998). The value relevance of intangibles: the case of software capitalisation. Journal of Accounting Research, 36: (Supplement) 161191.

Accounting Principles Board (APB). (1970). Statement No. 4. Basic Concepts and Accounting Principles Underlying Financial Statements of Business Enterprizes. New York: NY: AICPA.

Aivazian, VA, and JL, Callen. (1983). Core theory and uniformity in accounting: rationalizing the accounting rulemaker. Journal of Accounting and Public Policy, 2, 4: 225-237.

Albrecht, WS, and RW Sack. (2000). Accounting Education: Charting the Course Through a Perilous Future. American Accounting Association Accounting Education Series, vol. 16

Alexander, D, and Archer, S. (2000). On the myth of "Anglo-Saxon" financial accounting. International Journal of Accounting, 35(4): 539-557.

Alexander, D, and Britton, A. (2004). Financial Reporting (Seventh Edition). London: Thomson Publishing.

Alexander, D, Britton, A, and Jorissen, A. (2007). International Financial Reporting and Analysis (Third Edition). London: Thomson Publishing.

Alfredson, K, Leo, K, Picker, R, Pacter, P, Radford, Jn and V Wise. (2007). Applying international financial reporting standards (enhanced edition). Milton: John Wiley \& Sons Australia Limited.

Alkon, A. (2006). Result of FAS 133 on market volatility in the financial services sector. MURJ-Massachusetts Institute of Technology Undergraduate Research Journal. Spring. Vol. 13. Spring. pp. 44-47

American Accounting Association (AAA). (1966). A Statement of Basic Accounting Theory. Evanston, IL: AAA. 
American Institute of Certified Public Accountants. (AICPA). ( April 13, 1962). Statement by the Accounting Principles Board. New York: AICPA.

American Institute of Certified Public Accountants (AICPA). (2008). An AICPA Backgrounder. New York: NY: AICPA.

Anderson, RH, and Epstein, MJ. (1996). The Usefulness of Corporate Annual Reports. Greenwich, CT. London: Jai Press Inc.

Anson, M, and Lamoureux, C. (2006). Preliminary Views on an Improved Conceptual Framework for Financial Reporting: The Objective of Financial Reporting and Qualitative Characteristics of Decision-Useful Financial Reporting Information. International Corporate Governance Network (ICGN). Accessed on 06/08/2008, at:

http://www.icgn.org/organisation/documents/aap/fasb_iasb_letter_nov2006.pdf

Arai, K. (1970). Accounting Postulates. In, Theory Formulations. (Ed.) E. Stone. Gainsville, Florida: Accounting Department, College of Business Administration.

Armstrong, M. (1977). Politics of establishing accounting standards. Journal of Accountancy. 143(2). Pp. 76-79.

Arrington, CE, and Francis, JR. (1989). Letting the chat out of the bag: deconstruction, privilege and accounting research. Accounting, Organizations and Society, 14(1/2): 1-28.

ASSC. (1975). (Accounting Standards Steering Committee). The Corporate Report-a Discussion Paper. London: ASSC.

Association of British Insurers (ABI, 2006). Preliminary Views on an Improved Conceptual Framework for Financial Reporting- ABI response to IASB Discussion Paper. Accessed on 06/08/2008, at: http://www.abi.org.uk?Public/Consultation/other/IASB_Nov06.061106094819.pd $\underline{f}$

Association of Investment Management research. (2004). Fair Value. Accessed 18/03/2008 at, http://retail.about.com/cs/sup_accounting/a/bl-aimr020304.htm

Attmore, R. (2006). Current Issues in Service Efforts and Accomplishments Reporting. AGA Performance Management Conference (October 31) New York: Governmental Accounting Standards Board (GASB).

Bank for International Settlements. (BIS). (2008). Fair Value Measurement and Modeling: An Assessment of the Challenges and Lessons Learned. Basel: Bank for International Settlements. 
Barth, ME. (1994). Fair value accounting: evidence from investment securities and the market valuation of banks. The Accounting Review, 69, January, 1-25

Barth, ME. (2000). Valuation-based accounting research: implications for financial reporting and opportunities for future research. Accounting and Finance, 40(1), 7-32.

Barth, ME, Beaver. WH, andWR. Landsman. (1996). Value-relevance of banks' fair value disclosures under SFAS 107. The Accounting Review, 71(4): 513-537.

Barth, ME, WH. Beaver, and WR Landsman. (2001). The relevance of the valuerelevant literature for financial accounting standard-setting:another view. Journal of Accounting and Economics, 31(1-3), 79-104.

Barth, ME, and G. Clinch. (1998). Revalued financial, tangible, and intangible assets: Associations with share prices and non-market-based value estimates. Journal of Accounting Research, 36 (Supplement): 199-233.

Barth, ME, Clinch, G, and Shibano, T. (2001). Market effects of recognition and disclosure. Journal of Accounting Research, 41(4), September: 581-609.

Bartlett, SA, and Chandler, RA. (1997). The Corporate Report and the private shareholder: Lee and Tweedie twenty years on. British Accounting Review, 29(3): 245-261.

Beatty, A, and J. Weber. (2006). Accounting discretion in fair value estimates: an examination of SFAS goodwill impairments. Journal of Accounting Research, 44(2), (May): 257-288.

Beaver, WH.(1981). Financial Reporting: An Accounting Revolution. Englewood Cliffs, New Jersey: Prentice-Hall, Inc.

Beaver, WH, and Demski, JS. (1974). The nature of accounting objectives: A summary and synthesis. Journal of Accounting Research, 12, (supplement): 170187.

Belkaoui, A. (1981). Accounting Theory. New York. Harcourt Brace Jovanovich, Inc.

Belkaoui, A. (1989). The Coming Crisis in Accounting. New York, NY. Westport, CT. London: Quorum Books.

Benita, C. (2003). Accountability lost: the rise and fall of double-entry. Omega (Oxford), 31: 4, August, 303-310.

Benston, CJ, Bromwich, M, Litan, RE, and Wagonhofer, A. (2006). Worldwide Financial Reporting: The Development and future of Accounting Standards. Oxford: Oxford University Press. 
Benston, CJ, Bromwich, M, and Wagenhofer, A. (2006). Principles-versus rulesbased accounting standards: the FASBs standard setting strategy. Abacus, 42(2), June: $165-188$.

Bernanke, BS, and Mishkin, FS. (1997). Inflation targeting: A New Framework for Monetary policy? NBER Working paper No. 5893, Cambridge; MA: NBER.

Bernanke, BS. (2004). Remarks by Governor Ben. S. Bernanke. Federal Reserve Board. The Great Moderation. February 20, 2004. At, the Meetings of the Eastern Economic Association.

Berry, RH, and Waring, A. (1995). A user perspective on 'Making Corporate Reports Valuable'. British Accounting Review, 27(2): 139-152.

Berton, H, and Schiff, JB. (1990). The Wall Street Journal on Accounting. Homewood: Dow-Jones-Irwin.

Bierman, H. (1979). The Feasibility and Desirability of Accounting Standards. In, Essays in honour of William A. Paton Pioneer Accounting Theorist. (Eds) SA. Zeff, J. Demski, and N. Dopuch. Ann Arbor, Michigan: University of Michigan Press.

Bies, SS. (2005). Fair Value Accounting. United States Federal Reserve: New York. Accessed 18/01/2008 at, http://www.federalreserve.gov/pubs/bulletin/2005/winter2005_fair.pdf

Blanchard, R. (2000). Fair Value Accounting. Accessed on 03/07/2008, at: http://www.actuary.org/ppt/naic/blanchard 1200.ppt

Blough, CG. (1970). Developing Accounting Principles for Financial Reporting. In, Theory Formulations. (Ed.) WE. Stone. Gainsville, Florida: Accounting Department, College of Business Administration.

Booth, B. (2003). The Conceptual framework as a coherent system for the development of accounting standards. Abacus, 39(3): 310-324.

Bordo, M, Mizach, B, and Schwartz, AJ. (1995). Real versus pseudo-international systemic risk: some lessons from history. Working paper No. 5371. Cambridge, MA: NBER, Inc.

Borio, C, English, W, and Filardo, A. (2003). A Tale of Two Perspectives: Old or New Challenges for Monetary Policy. BIS Working Paper No. 127. Basel: Bank For International Settlements: Monetary and Economics Department.

Boyer, R. (2007). Assessing the impact of fair value upon financial crises. Socioeconomic Review, 5(4), October: 779-807. 
Bradbury, M. (2008). Discussion of Whittington. Abacus. 44(2): 169-180.

Bradbury, M, and van Zijl, T. (2005). The New Zealand Financial Reporting Framework. Milton, Queensland: John Wiley and Sons (Australia).

Bratten, WW. (2004). Rules, principles, and the accounting crises in the US. European Business Organization Law Review. 5(1): 7-36.

Brief, RP. (1988). Edward Stamp. The United Kingdom View of the Conceptual Framework in Accounting. New York. London: Garland Publishing, Inc.

Bromwich, M. (1992). Financial Reporting, Information, and Capital Markets: London. Pitman Publishing.

Bromwich, M, and Hopwood, A. (1983). Some issues in accounting standard setting: an introductory essay. In, Accounting standards setting An International Perspective. (Eds) M. Bromwich, and A. Hopwood. London: Pitman Publishing.

Brousseau, V, and Dretkin, C. (2001). Monetary policy and fears of financial Instability. ECB Working Paper No. 89. Accessed on 07/08/2008, at: http://www.ecb.eu/pub/pdf/scpwps/ecbwp089.pdf

Brown, MT. (2005). Corporate Integrity. Rethinking Organizational Ethics and Leadership. Cambridge: Cambridge University Press.

Buckley, JW, Kircher, P, and Matthews, RL. (1968). Methodology in Accounting Theory. Accounting Review, 43(2): 274-283.

Burton, JC. (1978). The FASB's Conceptual Framework project reviewed: a report on the Forth Seaview Symposium. Financial Analysts Journal, Jan-Feb: $69-74$.

Bush, T. (2005). Divided by common language. Where economics meets the law: US versus non-US financial reporting models. ICAEWs Dialogue in Corporate Governance. London: Institute of Chartered Accountants of England and Wales (ICAEW).

Busto, del, G. (2006). The Use of a Sector Neutral Framework for the Making of Australian Accounting Standards. Commonwealth Treasury. http://www.frc.gov.au/reports/other/sector_neutral_submissions/PWC.pdf+simpki $\underline{\text { ns+Application }}$

Cahan, SF, Courtney, SM, Gronewoller, PL, and Upton, D. (2000). Value relevance of mandated Comprehensive Income disclosures. Journal of Business Finance and Accounting. 27(9/10): 1233-1265.

Cain, LP, and Hughes, J. (2006). American Economic History (7th Edition). Toronto: Addison Wesley. 
Cairns, D. (2006). The Use of Fair Value in IFRS. Accounting in Europe, 3(1), 522.

Campbell, SD. (2005). Stockmarket volatility and the Great Moderation. Finance and Economics Discussion Series Divisions of research and statistics and Monetary Affairs. Federal Reserve Board: Washington: Washington DC.

CAS Task Force. (2007). Task Force on Fair Value Liabilities-White Paper. Accessed on 05/07/2008, at:

http://www.casact.org/research/tffvl/tffv1001.pdf

Camfferman, K, and Zeff, SA. (2006). Financial Reporting and Global Capital Markets. A History of the International Accounting Standards Committee, 19732000. Oxford: Oxford University Press.

Cannon, AM. (1962). Discussion notes on the basic postulates of accounting. Journal of Accountancy. February: 42-53. 114(3).pp. 43-49.

Carcello, JV. (2007). Financial Accounting Regulations and Organizations. In, Accountants' Handbook (Eleventh Edition). Vol. 1. (Eds.) Carmichael, DR, Whittington, OR, and Graham, L. Hoboken: NJ: John Wiley \& Sons, Ltd.

Carroll, TJ, Linsmeier, T, and KR Petroni. (2002). The Reliability of Fair Value vs Historic Cost information: Evidence from Closed-End Mutual Funds. http://www.stern.nyu.edc/journals/Linsmeier.pdf

Certified Financial Analysts (CFA, 2007). A Comprehensive Business Reporting Model: Financial Reporting For Investors. New York: CFA Institute Centre Publications.

Certified Financial Analysts (CFA). (2006). Fair Value Reporting. CFA Institute Center. Accessed 15/03/2008 at, http://www.cfainstitute.org/center/positions/reporting/fair_value_reporting.html

Chambers, RJ. (1955).

Chambers, RJ. (1976). Continuously Contemporary Accounting: misunderstandings and misrepresentations. Abacus. 12(2): 137-151.

Chambers, RJ. (1982). Why Bother With Postulates. In, Accountancy in Transition. (Ed.) RP, Brief. New York. London: Garland Publishing, Inc.

Checcetti, SG, Flore-Laganes, A, and Klause, S. (2007). Assessing the Sources of Changes in the Volatility of real growth. NBER Working papers 11946. New York: NY: National Bureau of Economic Research, Inc. 
Chorafas, DN. (2006). IFRS, FV and Corporate Governance. The Impact on Budgets, balance sheets and management accounts. Oxford. Burlington: CIMA Publishing.

Chua, WF. (1986). Radical developments in accounting thought. Accounting Review, LXI: 601-632.

Churchill, NC. (1977). Toward a Social Theory of Accounting. In, Studies in Accounting. (Eds.) Baxter, WT, and Davidson, S. London: ICAEW.

Clarke, F, and Dean, G. (1993). Law and Accounting-The Separate Legal Entity Principle and Consolidation Accounting. Australian Law Review, 21(4): 246-249.

Clark, GL, Hebb, T, and Wojick, D. (2007). Institutional investors and the language of finance: The global metrics of market performance. In, Global Accounting Standards. (Eds) JM Godfrey, and K. Chalmers. Cheltenham. Northampton, MA: Edward Elgar Publishing, Inc.

Clarke, F, and Craig, R. (1991). Juridical perceptions of accounting data in wage fixation. British Journal of Industrial Relations, 29(3): 463-483.

Clayton, P, and Blake, J. (1984). Inflation Accounting. London. New York: Longman.

Colantani, CS. (1971). Logic and Sanctions in Accounting: Critique. In, Accounting in Perspective. (Eds) RR Stirling, and WE. Bentz. Cincinnati, Ohio. Chicago, IL: South-Western Publishing Company.

Colson, RH. (2005). The Reign of Confusion. Research in Accounting Regulation, 18(5): 321-329.

Cooper, DJ, and Sherer, MJ. (1984). The Value of Corporate Accounting Reports: Arguments for a Political Economy. Accounting Organizations and Society, 9(3/4): 207-232.

Cooper, S. (2007). Performance measurement for equity analysis and valuation. Accounting in Europe, 4(1), 1-49.

Cordery, CJ, and RF Baskerville. (2005). Hegemony, Stakeholder Salience and the Construction of Accountancy in the Charity Sector. Working Paper Series. No. 25. School of Accounting and Commercial law. Victoria University. Wellington. http://www.accounting-research.org.nz

Coronado, J, Mitchell, OS, Shartpe, SA, and Nesbitt, SB. (2008). Footnotes Aren't Enough: The Impact of Pension Accounting on Stock Values. NBER Working Paper No. 13726. Accessed on 23/09/2008, at:

http://papers.nber.org/papers/w13725 
Cotter, J, and Richardson, S. (2002). Reliability of asset revaluations: the importance of appraiser independence. Review of Accounting Studies. 7(4): 435457.

Coy, D, Fischer, M, and Gordon, T. (2001). Public accountability: a new paradigm for college and university annual reports. Critical Perspectives on Accounting, 12(1): 1-31.

Crockett, A. (2002). Towards global financial reporting standards: a critical pillar in the international financial architecture. Bank for International Settlements. Basel.

Crockett, A. (2003). Central Banking Under Test? In, , pp. 1-6. Monetary Stability, Financial Stability and the Business Cycle: five views. Basel. BIS: Monetary and economics Department. Pp.1-6.

Crowther, D. (2002). A Social Critique of Corporate Reporting. Aldershot: Ashgate Publishing Ltd.

Cudd, A. (2007). Contractarianism. Stanford Encyclopedia of Philosophy. Accessed on 18/08/2008, at:

http://plato.stanford.edu/entries/contracarianism/

Cunningham, C. (2004). Fair value accounting: fair value for whom? Financial Executive. Accessed on 01/09/2008, at: http://www.thefreelibrary.com/fair+valueaccounting+fair+for+whom

Czerawski, M, Sherman, K, and D. Mead. (n.d.) Governmental Accounting Standards Board, Project pages, Economic Condition Reporting-Phase III. Accessed 23/04/2008 at, http://www.gasb.org/project_pages/economic_condition_reporting.html.

Dalassio, AN, Seiler, ME, and Jones, RC. (1999). International Accounting Standards. In, Volume one: Financial Accounting and General Topics. (Eds.) Carmichael, DR, Lilien, SB, and Mellan, M. Chichester: John Wiley and Sons, Inc.

Dan-Cohen, M. (1986). Rights, Persons and Organizations. Berkeley; California: University of California Press.

Dannish Institute of State Authorized Public Accountants. (2006).

Dean, GD, and FL Clarke. (2003). An Evolving Conceptual Framework. Abacus, 39(3), 279-297.

Debelle, G. (2004). Household debt and the macroeconomy. Working paper No. 153. Bank for International Settlements. Basel. 
Deegan, C (2004). Financial Accounting Theory. North Ryde. Australia. McGraw-Hill.

Degen, RA. (1987). The American Monetary system. A concise Survey of its Evolution since 1896. Massachusetts. Toronto: Lexington Books.

Deloitte. (2008). IASB Agenda: Fair Value Measurements. IAS Plus. Accessed on 04/07/2008, at:

http://www.iasplus.com/agenda/fairvalue.htm

Deloitte. (n.d.) IAS Plus International Reporting Standards in Europe. Accessed on 29/09/2008, at: http://www.iasplus.com/restruct/euro.htm

Deloitte. (n.d.) Financial Reporting-Are Investors needs being met? Financial Reporting Update. Accessed 03/06/2008 at, http://www.deloitte.com/dtt/article/0,1002,sid\%253D2895\%253D106013

Deloitte. (u.d. (a)). International Accounting Standards. IAS 39, Financial Instruments Recognition. Accessed on 04/07/2008, at:

http://www.iasplus.com/standard/ias39.htm

Demski, JS. (1973). The General Impossibility of Normative Accounting Standards. The Accounting Review, 48 (4): 718-723.

Descamps, R, and Gevers, L. (1978). Leximin and utilitarian rules: a joint Characterization. Journal of Economic Theory, 17(2): 143-163.

Dhaliwal, D, Subramanyam, KR, and Trezvant, R. (1999). Is Comprehensive Income superior to net income as a measure of firm performance. Journal of Accounting and Finance, 26(1-3), 64-104.

Donaldson, T. and Preston, LE. (1995). "The Stakeholder Theory of the Corporation: Concepts, Evidence and Implications. Academy of Management Review, 20(1): 65-91.

Dye, RA, and Sunder, S. (2001). Why not allow the FASB and IASB standards to compete in the United States? Accounting Horizons, 15(3): 257-271.

Dymski, G, and Pollin, R. (1992). Hyman Minsky as Hedgehog: The Power of the Wall Street Paradigm. In, Financial Conditions and Economic Performance. Essays in Honour of the Late Hyman P. Minsky. (Eds.) Farazzi, S and Papadimitriou. London. Armonk: ME Sharpe Inc.

Dynan, KE, Elmendorf, DW, and Sichel, DE. (2005). Can Financial innovation Explain the reduced volatility of Economic activity? Federal reserve Bank Working Paper 2005-54. Washington: DC: Board of governors of the Federal reserve. 
Dynan, KE, Johnson, K, and Pence, K. (2003). Recent changes to a measure of US household debt service. Federal Reserve Board's Division of Research and Statistics. Accessed on 25/01/2008 at:

http://www.federalreserve.gov/pubs/bulletin/2003/1003lead.pdf

Dynan, KE, Kohn, DL. (2007). The Rise in Household Indebtedness: Causes and Consequences. Finance and Economics Discussion Paper 2007-37. Federal reserve Board. Accessed on 23/01/2008 at:

http://www.federalreserve.gov/pubs/feds/200737/index.htm

Eastman, H. (2007). Fair Value Measurement. Where are we in the project? IASB. Accessed 26/03/2008 at, http://www.iasb.org/Current+Projects/IASB+Projects/Fair+Value+ Measurement/

Eastman, H. (2008). Fair Value Measurement. London. IASB. Accessed 18/03/2008 at, http://www.iasb.org/Current+Projects/IASB+Projects/Fair+Value+Measurement

Eccher, EA, Ramesh, K, and SR Thiagarajan. (1996). Fair value disclosures by bank holding companies. Journal of Accounting and Economics, 22(1-3): 79-117.

Edwards, JR. (1989). A History of Financial Accounting. New York: Routledge.

Elad, C. (2004). Fair value accounting in the agricultural sector: some implications for international accounting harmonization. European Accounting Review, 13(4), 621-641.

Elbannan, M, and McKinley, W. (2006). A theory of corporate decision to resist FASB standards: an organization theory perspective. Accounting, Organizations and Society, 31(7), October: 601-622.

Elliott, RK. (2001). Oral testimony RK Elliot. Past Chairman AICPA. Before the House Committee on Financial Services. (June).

Enria, A, Cappiello, L, Dierick, F, Grittini, S, Haralambous, A, Maddaloni, A, and Molitor, P. Fair value accounting and financial stability. ECB Occasional Paper. No. 13.

Enthoven, AJH. (1973). Accounting and Economic Development Policy. Amsterdam. London: North-Holland Publishing Co.

Epstein, MJ, and Pava, ML. (1993). The Shareholder's use of Corporate Annual Reports. London. Jai Press Inc.

Ewer, SR. (2007). Transparency and understandability, but for whom? The CPA Journal. New York State Society of Certified Public Accountants. Accessed 01/02/2008 at, http://www.nysscpa.org/cpajournal/2007/207/infocus/p16.htm 
FASB. (1976). Discussion Memorandum, Conceptual Framework for Financial Accounting and Reporting: Elements of Financial Statements and Measurements. FASB: New York.

FASB. (2002). Concepts statement No.5. Proposal. Principles-based approach to US Standards Setting. Norwalk. FASB.

FASB (2004). Minutes from fair value measurement team to Board members. Accessed on 09/09/2008, at: http://wwww.fasb.org/board_meeting_minutes/0921-04_fvm_roundtable_am_rev.pdf

FASB. (2005). FASB-Revisiting the Concepts. (May). Accessed 18/03/2008 at, http://www.fasb.org/project/communications_paper.pdf

FASB. (2006). FASB Project Updates Fair Value Measurements Updated. August, 2006. Accessed 18/03/2008 at, http://www.fasb.org/project/fv measurement.shtml

FASB. (2006a). User Advisory Council Minutes of the Meeting. Accessed 03/06/2008 at, http://www.fasb.org/user_advisory_council/uac_04_11_06.pdf

FASB. (2006b). Project Updates. Fair Value Option. Accessed on 13/08/2008, at: http://www.fasb.org/fv_option.shtml

FASB. (2006c). Summary of Statement 157. FASB. Accessed 20/03/2008, at: http://72.3.243.42/st/summary/stsum157.shtml

FASB. (2007). Conceptual framework-Joint Project of the IASB and FASB. Accessed $18 / 03 / 2008$

at, http://www.fasb.org/project/conceptual framework.shtml

FASB. (2007a). Fair Value Measurements. Accessed 18/03/2008 at http://www.fasb.org/Current+Projects/IASB+Projects/Fair+Value+Measurements $\underline{. h t m}$

FASB. (2007b). FASB Summary of Statement No. 107. Fair Value Measurements. Accessed 18/03/2008 at, http://www.fasb.org/st/summary/stsum157.shtml

FASB. (2008). FASB Press Release. (29 May). Accessed 10/06/2008 at, http://www.fasb.org/draft/index.shtml

FASB. (2008a). Preliminary views Conceptual framework for Financial Reporting: The Reporting Entity. (May, 29). FASB. Financial Accounting Series No. 1580-100. Norwalk. Connecticut

Faulkner-MacDonagh, C and Muhlesisen, M. (2004). Are US Households Living Beyond Their Means? Consumer Spending, household wealth, and real estate 
prices in the United States. International Monetary fund. Accessed on 23/02/2008 at: http://www.imf.org/external/pubs/ft/fanss/2004/03/pdf/faulkner.pdf

Fearnley, S, and Hines, T. (2003). The regulatory framework for financial reporting and auditing in the United Kingdom: the present position and pending changes. International Journal of Accounting, 38(2): 215-233.

Fergusson, RW. (2003). Should financial stability be an Explicit Central bank Objective? BIS Working Papers No. 18. Monetary Stability, Financial Stability and the Business Cycle: five views. Basel: BIS. Monetary and Economic Department.

Fields, TD, Lys, TZ, and Vincent, L. (2001). Empirical research on accounting choice. Journal of Accounting and Economics, 31(1-3): 255-307.

Financial Reporting Council. (2005). No. 46 Update on Current projects. Financial Reporting Council. ASB. Accessed 23/03/2008 at, http://www.frrp.org.uk/asb/publications/it33_p266.html

Fink, R. (2006). Will Fair Value Fly. CFO Asia.com. Accessed 18/03/2008 at, http://www,cfoasia.com/archives/200610-11.htm

Flegm, E. (2000). Letters. A historical look at standards. Journal of Accountancy, October. Accessed 19/05/2008 at, http://www.aicpa.org/pubs/jofa/oct2000/letters.htm.

Flegm, EH. (2004). Accounting: how to meet the challenges of relevance and regulation. Studies in the Development of Accounting Thought. Volume 17. Amsterdam: Elsevier Ltd.

Flegm, E. (2005). On Solving the problem. Not being part of it. The CPA Journal. NY: NYSSCPA. Accessed on 02/02/2008 at: http://www.nysscpa.org/cpajournal/2005/205/perspectives/p12.htm

Fogarty, TJ. (1992). Financial accounting standard setting as an institutionalized action field: constraints, opportunities and dilemmas. Journal of Accounting and Public Policy. 11(4): 331-355.

Fogarty, TJ, Hussein, ME, and Ketz, JE. (1994). Political aspects of accounting standard setting. Accounting, Auditing and Accountability Journal, 7(4): 24-46.

Fogel, RW. (1970). Railroads and American Economic Growth: Essays in Econometric History. Baltimore: The Johns Hopkins University Press.

Foley, B, and Maunders, K. (1977). Accounting Information Disclosure and Collective Bargaining. Basingstoke. London: Macmillan Press Ltd. 
Foreningen af Statsautoriserede Revisoner (FSR, 2006). Discussion Paper. Preliminary Views on an Improved Conceptual Framework for Financial Reporting: The Objective of Financial Reporting and Qualitative Characteristics of Decision-Useful Financial Reporting Information. Copenhagen: Institute of State Authorized Public Accountants of Denmark.

Freeman, R. (1984) Strategic Management: A Stakeholder Approach. Marshall, MA: Pitman.

Freeman, RE, Hicks, AC, and Parner, B. (2004). Stakeholder Theory and "the corporate objective revisited". Organization Science, 15(3), June-May: 364-369.

Friedman, BM. (1992). Risks in Our High_Debt Economy: Depression or Recession? In, Conversations with Hyman Minsky: Financial conditions and Economic Performance. (Eds) Farazzi, S and Papadimmitriou. Armonck. London: ME Sharpe, Inc.

Friedman, BM. (1999). The Future of Monetary policy: The Central bank as an army without a signal Corps? Working Paper no. 7420. Cambridge, MA: NBER, Inc

Friedman, M. (1985). Social Responsibility of Business. In, Business and SocietyEconomic, Moral and Political Foundations. (Ed.) TG. Marx. Englewood Cliffs, New Jersey: Prentice-Hall Inc.

Funnell, W. (1996). The narrative and its place in the new accounting history: the rise of the counternarrative. Accounting, Auditing and Accountability Journal, 11(2): 142-162.

Gaa, JC. (1986). User primacy in corporate financial reporting: a social contract approach. The Accounting Review, LXI(3): 399-425.

Gambling, T. (1974). Positive Accounting Problems and Solutions. London: Macmillan Press.

GASB. (1994). Summaries/Status . Summary of Concept Statement No. 2 Service Efforts and Accomplishments Reporting. (April). Accessed 24/05/2008 at, http://www.gasb.org/st/concepts/gconsumm2.html

GASB. (u.d.) Performance Reporting for Government-about Performance Reporting. Accessed 06/06/2008 at, http://www.seagov.org/aboutping/history.shtml

GASB. (2002). White Paper: Governmental Accounting and Financial Reporting is-and should be-Different. Accessed 01/04/2008 at, http://www.gasb.org/white paper executive summary.html 
Gassen, J. (2008). Are stewardship and valuation-usefulness compatible or alternative objectives of financial accounting? Humbolt University of Berlin: Berlin: Center for Applied Statistics and Economics.

Gerboth, DL. (1973). Research, intuition, and politics in accounting inquiry. The Accounting Review, XLVII(3): 475-482.

Giroux, G. (1999). A Short History of Accounting and Business. Accessed on 18/08/2008, at:

http://acct.tamu.edu/history.html

Gjesdal, F. (1981). Accounting for Stewardship. Journal of Accounting Research, 19(1): 208-231.

Gonedes, NJ. (1975). Information-production and capital market equilibrium. Journal of Finance, 30(3): 841-864.

Gonedes, NJ, and N. Dopuch. (1974). Capital market equilibrium, information production, and selecting accounting techniques: theoretical framework and review of empirical work. Journal of Accounting Research, 12(1): 26-62.

Grady, P. (1965). Inventory of Generally Accepted Accounting Principles for Business Enterprizes. Accounting Research Study No. 7. Sarasota: FL: AAA.

Gray, R, Owen, D, and Maunders, K. (1988). Corporate social reporting: emerging trends in accountability and the social contract. Accounting, Auditing, and Accountability Journal. 1(1): 6-20.

Gray, R, Owen, K, and Maunders, K. (1987). Corporate Social reporting: Accounting and Accountability. Hemel Hempstead: Prentice Hall.

Gray, R, Owen, K, and Maunders, K. (1991). Accountancy, corporate social reporting and the external social audits. Advances in Public Interest Accounting. 4(1): $1-21$.

Greenspan, A. (2005). Risk Transfer and Financial Stability. Remarks by Chairman Alan Greenspan. Federal Reserve Board. Accessed on 14/01/2008 at: http://www.federalreserve.gov/Boarddocs/Speeches/2005/20020505/default.htm

Greenspan and Kennedy. (2007). Sources and Uses of equity extracted From Homes. Finance division Discussion series. Divisions of Research and statistics and Monetary affairs. Federal reserve Board. Washington, DC. Accessed on 12/ 12/2007, at: http://www.federalreserve.gov/pubs/feds/200720/200720/pap.pdf

Grixti, I. (2005). SEC July 9 Roundtable on Fair Value Accounting Standards. Accessed on 07/08/2008, at: http://www.sec.gov/comments/4-560/4560-2.pdf 
Hagopian, K. (2006). Expensing employee stock options is improper accounting. California Management review, 48(4): 136-156.

Hague, IP, K, Jones, A. Milburn, and M. Walsh. (2006). New developments in the framework for financial reporting: the role of national standard setters and the Canadian contribution to research on measurement on initial recognition and a framework for disclosure of financial information. Journal of International Financial Management and Accounting, 17 (3). Pp. 256-270.

Hawkins, DF. (1973). Financial Accounting, The Standards Board and Economic Development. Accessed 04/04/2008 at, http://newman.baruch.cuny.edu/digital/saxe/saxe_1973/hawkins_73.htm

Healey, PM, and Palepu, IKG. (2001). Information Asymmetry, corporate disclosure and capital markets: A review of the empirical disclosure literature. Journal of Accounting and Economics, 31(1-3):405-440.

Henderson, S, and Peirson, G. (1983). Financial Accounting Theory. Its Nature and Development. Melbourne: Langman Cheshire.

Henderson, S, Pierson, G, and Harris, K. (2004). Financial Accounting Theory. Frenches Forest, NSW: Pearson-Prentice Hall.

Hendriksen, ES. (1970). Accounting Theory (revised Edition). Homewood: IL: Irwin.

Hendriksen, ES. (1982). Accounting Theory (4th Edition). Homewood, IL: Richard D Irwin.

Hendriksen, ES, and MF. Van Breda. (1992). Accounting Theory (5 $5^{\text {th }}$ edition). Honeywood, IL: Irwin.

Herz, RH. (2003). Commentary A Year of Challenge and Change for the FASB. Accounting Horizons, 17(3), September: 247-255.

Herz, RH. (2006). US Government Accountability Office, Washington, DC. Accessed 12/12/2008 at, http://www.gao.govgovand/cl_fasb061108.pdf

Herz, RH, and MacDonald. (2008). Some facts about Fair Value. Understanding the issues. Norwalk, CT: FASB.

Higson, A. (2003). Corporate Financial Reporting. Theory and Practice. London: Sage Publications.

Hitz, J. (2007). The decision usefulness of fair value accounting-a theoretical perspective. European Accounting Review, 16(2). 323-362. 
Hodder, LD, Hopkins, PE, and JM Wahlen. (2006). Risk-relevance of fair value income measures for commercial banks. The Accounting Review, 81(2): 337-375.

Holthausen, RW, and RL Watts. (2001). The relevance of the value-relevant literature for financial accounting. Journal of Accounting and Economics, 31(1-3), $3-75$.

Hopkins, PE, Nelson, KK, and M. Venkatachalam, et al. (2005). Response to the FASBs Exposure Draft on Fair Value Measurements. Accounting Horizons, 19(3) (September). 187-196.

Hopwood, A. (1984). Accounting and the pursuit of efficiency in, Hopwood, A, and Tompkins, C. (Eds.) Issues in Public Sector Accounting. Oxford. Phillip Allen.

Hopwood, AG. (1989). International Pressures for Accounting Change: An Introduction. In, AG Hopwood (Ed.) International Pressures for Accounting change. Hemel Hampstead. Prentice-Hall Publishing (International Inc.)

Horngren, CT. (1973). The marketing of accounting standards. Journal of Accountancy, 63(4): 61-66.

Hughes, M, Gordon, C, and Read, A. (2007). Addressing Accounting's 'Fifth Column': The Complicity of the Standard Setting Boards in Off-Balance Sheet financing. Oxford. Oxford University Business and Economics Conference.

Hylton, DP. (1962). Current Needs in Accounting Theory. The Accounting Review, 37(1): 22-27.

IASB (1989). Framework for the Preparation and Presentation of Financial Statements. London. IASB.

IASB. (2005). Information for Observers. Conceptual Framework-IASB Meeting. London. Accessed 20/03/2008 at, http://www.iasb.org.uk

IASB. (2005). Information for Observers. Agenda Paper 3. Conceptual Framework. London:IASB

IASB. (2005). Observer Notes. Proposal to replace reliability with representational faithfulness. Accessed 21/03/2008 at, http://www.iasb.org.uk

IASB. (2006). Conceptual Framework Project. London. Accessed 25/03/2008 at, http://www.iasb.org/NR/rdonlyres/EC02CB15-77EO-4A6D-BDCB

IASB. (2006a). Preliminary Views on an Improved Conceptual Framework: The Objective of Financial Reporting Information. Discussion Paper. London: The International Accounting Standards Board. 
IASB.(2006b). Measurement bases for Financial Reporting. Accessed on 26/08/2008, at:

http://www.iasplus.com/uk/0604measurementpaper.pdf

IASB. (2007). Information for Observers. Conceptual Framework-Objective of Financial Reporting and Qualitative Characteristics of Decision-Useful Financial Reporting Information-Redeliberations (Agenda Paper Nine). http://www.iasb.org

IASB. (2007a). Information for Observers. Conceptual Framework (Agenda Paper 9a). London:IASB. http://www.iasb.org

IASB. (2007b). Conceptual Framework. Meeting. Accessed 18/03/2008 at, http://www.iasb.org?Current+Projects?Conceptual+Framework?Meeting

IASB. (2007c). Fair Value Measurement. Accessed 18/03/2008 at, http://www.iasb.org/Current+Projects/Fair+Value+Measurement/Meeting

IASB (2007d). Update. London. Accessed 04/05/2008 at http://wwwiasb.org/NR/rlodyres/3C5BIDC8-67AC-422F-B556199EA424/0/Upd0740.pdf

IASB. (2007e). Fair Value Measurements. Discussion Paper. Invitation to Comment. London: IASB.

IASB. (2008). Information for Observers-Conceptual framework. United Kingdom Shareholders Comment letter. (May 12). Accessed 10?06/2008 at, http://www.iasb.org/NR/rdolyres/98ECF91C-648C-421F-AB9B-6COCB18

IASB. (2008a). Changes and Challenges. IASB. London. Accessed on 04/07/2008, at:

http://www.iasb.org/NR/rdonlyres/1FF5073B-B795-4EB5-ADJA

IASB. (2008b). Conceptual Framework for Financial Reporting: The objective of Financial Reporting and Qualitative Characteristics and constraints of DecisionUseful financial Reporting. Exposure Draft. Financial Accounting Series. London: IASB.

Ijiri, Y. (1971). Logic and Sanctions in Accounting. In, Accounting in Perspective. (Eds) RR. Stirling, and WE. Bentz. Cincinnati, Ohio, Chicago, IL: South-Western Publishing Company.

Ijiri, Y. (1975). Theory of Accounting Measurement. Studies in Accounting Research No. 10. Sarasota: FL: AAA.

Ijiri, Y. (1983). Accountability-based conceptual framework (Guest Editorial). Journal of Accounting and Public Policy, 2: 75-81. 
Inanga, EL, and Schneider, WMB. (2005). The failure of accounting research to improve accounting practice: a problem of theory and lack of communication. Critical Perspectives on Accounting, 16(3): 227-248.

Iqbal, MZ, Melcher, TU, and AA, Elmallah. (1997). International Accounting-A Global Perspective. South-Western College Publishing.

Issing, O. (2003). Monetary and financial stability: is there a trade-off? In, BIS Papers no. 18. pp. 16-23. Monetary stability, financial stability and the business cycle: Five views. Monetary and Economic department. Basel: Bank for International Settlements.

Jameson, J. (2005a). FASB and IASB vs JR Hicks. Research in Accounting Regulation, 18(5): 331-334.

Jameson, J. (2005b). How FASB and IASB should Apply Hicksian Theory to Calculate Income. Journal in Accounting Regulation, 18(5): 335-349.

Jenkins, EL. (1994). Improving Business Reporting-A Customer Focus. AICPA Special Report. "The Jenkins Report". Meeting the Information Needs of Investors and Creditors. AICPA.

Jensen, MC. (2001). Value maximization, stakeholder theory, and the corporate objective function. Journal of Applied Corporate Finance, 14(3): 8-21.

Jensen, MC, and Meckling, WH. (1978). Can the corporation Survive? Financial Analysts Journal. 34(1), Jan-Feb: 31-37.

Jermakowicz, EA, Prather-kinsey, and I. Wulf. (2007). The Relevance of Accounting Income Reported by DAX-30 German companies. Journal of International Financial Management and Accounting. 18(3): 151-191.

Johnson, LT. (2004). The Project to Revisit the Conceptual Framework. Accessed on $26 / 07 / 2008$, at, http://www.fasb.org/articles\&reports/project_revisit_cf_tfr_dec2004.pdf

Johnson, LT. (2005). Relevance and Reliability. The FASB Report. (February 28). Norwalk: FASB.

JWGBA. (Joint Working Group of Banking Associations) (1999). Accounting for Financial Instruments of Banks. Accessed on 28/08/2008, at: http://www.aba.com/aba/pdf/GR_tax

Kam, V. (1986). Accounting Theory (2nd Edition). Singapore: John Wiley \& Sons.

Kindleberger, C, and Laffarge, JP. (1992). Financial Crises: theory, history and policy. New York: NY: Cambridge University Press. 
King, AM. (2006). Fair Value for Financial Reporting. Meeting the New FASB Requirements. Hoboken: John Wiley and Sons, Inc.

Kinney, WR. (2001). Accounting scholarship: what is uniquely ours? Accounting Review, 76(2). April. 275-284.

Kirkman, PRA. (1985). Inflation Accounting in Major English-Speaking Countries. In, Research Studies in Accounting. (Ed.) Carsberg, BV. London: Prentice-Hall.

Kothari, SP. (2001). Capital markets research in accounting. Journal of Accounting and Economics, 31(1), 105-231.

Kregel (1992). Theory of Economic Growth. London: Macmillan.

Landsman, WR. (2006). Fair value accounting for financial instruments. (August). BIS Working Paper No. 209. Basel: Bank for International Settlements.

Landsman, WR. (2006). Fair Value and Value Relevance: What Do We Know? Better Markets Conference. December 18-19. London. ICAEW.

Lansing, KJ. (2005). FRBSF Economic letter Spendthrift Nation. Federal Reserve Bank of San Francisco. Accessed on 23/03/2008 at:

http://www.frbsf.org/publications/economics/letter/2005/el2005-03.html

Laughlin, RC. (1977). Accounting Objectives and the Corporate Report. Journal of Business Finance and Accounting, 4(1).: 115-129

Laughlin, R. (1987). Accounting in organizational contexts: a case for critical theory. Accounting, Organizations and Society, 12(5): 479-502.

Laughlin, R. (2008). A Conceptual Framework for Public Benefit Entities: Taking Stock of the issues. Paper for Presentation at the BAA Conference, 1-3 April 2008, Paramount Imperial Hotel, Blackpool.

Laughlin, R, and Puxty, A. (1981). The decision-usefulness criterion: wrong cart wrong horse. AUTA Review, 13: 42-87.

Laughlin, R. (1987). Accounting systems in organizational contexts: a case for critical theory. Accounting, Organizations and Society, 12(5): 479-502.

Lee, CMC. (2001). Market efficiency and accounting research: a discussion of capital market research in accounting by SP Kothari. Journal of Accounting and Economics, 31(1-3), 233-253.

Lee, TA. (2006). Financial Reporting and Corporate Governance. Chichester: John Wiley and Sons, Ltd. 
Lee, TA, and Tweedie, DP. (1990). Shareholder Use and Understanding of Financial Information. London: Garland Publishing, Inc.

Lennard, A. (2007). Stewardship and the Objectives of Financial Statements: a comment on IASB's Preliminary Views on an Improved Conceptual Framework for the Decision-Usefulness of Financial Information. Accounting in Europe, 4(1): 57-66.

Lev, B. (1988). Toward a theory of equitable and efficient accounting policy. The Accounting Review, LXIII(1): 1-22.

Lev, B, and Zarowin, P. (1999). The Boundaries of Financial Reporting and how to extend them. Journal of Accounting Research, 37(2), Autumn: 333-385.

Levitt, A. (2007). On the increasing problems of US accounting. Wall Street Journal. Accessed 09/03/2008 at, http://online.wsj.com/article/SB117341014938031922.html?mod=todays_us_opin ion

Lewis, R, and Pendrill, D. (2004). Advanced Financial Accounting (7th edition). Harlow: Prentice-Hall.

Liam, Li. (u.d.). Investment Management Association. Accessed 23/04/2008 at, http://www.investmetuk.org

Littleton, AC. (1953). Structure of Accounting Theory. American Accounting Association (AAA) Monograph No. 5, Sarasota, Florida: AAA.

Loftus, JA. (2003). The CF and accounting standards: the persistence of discrepancies. Abacus. 39(3): 289-309.

Luscombe, N. (1995). Jenkins on the Jenkins Report. Improving Business Reporting. CA Magazine. April. 128(3): 15-18.

McNeal, K. (1977) What's Wrong with Accounting? In, Studies in Accounting. (Eds) WT Baxter and S. Davidson. London: ICAEW.

Mack, J, and C, Ryan. (2004). An Empirical Investigation of Users of General Purpose Financial reports of Australian Government Departments. Working Paper No. 2004-009. Brisbane. Queensland University of Technology.

Mack, J, and C, Ryan. (2006). Reflections on the theoretical underpinnings of the General Purpose Financial Reports of Australian Government Departments. Accounting, Auditing, and Accountability, 19(4): 592-612.

Macve, R. (1981). A Conceptual Framework for Financial Accounting and Reporting. London: ICAEW. 
Maines, L, Bartow, E, Fairfield, P, Hirst, DE, et al.(2003). Evaluating ConceptsBased vs Rules-Based Approaches to Standard Setting. Accounting Horizons, 17(1): 73-89.

Marcoux, A. (2008). Business Ethics. Stanford Encyclopedia of Philosophy. Accessed on 18/08/2008, at: http://plato.stanford.edu/entries/ethics-business/

Mattessich, R. (1955). Towards a General and Axiomatic Foundation of Accountancy. New York: McGraw-Hill.

Mattesich, R. (1995). Critique of accounting. An Examination of the Foundations and Normative Structure of an Applied Discipline. London. Westport, Connecticut. Quorum Books.

Mattli, W, and Buthe, T. (2005). Accountability in Accounting? The Politics of Private Rule-Making in the Public Interest. Governance, 18(3), July: 399-429

May, RG, and Sundem, GL. (1976). Research for accounting policy: an overview. The Accounting Review, LI(4): 747-763.

Merino, B. (2007). Review of the Roaring Nineties by J. Stiglitz. Research in Accounting Regulation, 19: 319-321.

Miller, PB. (1999). Accounting Regulation and Organizations. In, Accountants' Handbook (Ninth Edition). Volume one: Financial Accounting and General Topics. (Eds.) Carmichael, DR, Lilien, SB, and Mellan, M. Chichester: John Wiley and Sons, Inc.

Miller, PB, and Redding, RJ. (1988). The FASB, the People, the Process and the Politics. ( $2^{\text {nd }}$ Edition). Homewood, Il: Richard D. Irwin, Inc.

Miller, RI, and Young, MR. (1997). Fordham Law Review (65). Accessed 21/05/2008 at, http://www.groups.haas.berkeley.edu?accounting/conferences\&programs/may200 3/Miller\%Article\%20Abstract.rtf

Millstein, IM, Bajpas, SGN, Berglof, E, and Claessens, S. (2008). Enforcement and Corporate Governance: Three Views. Global Corporate Governance Forum. Accessed on 29/09/2008, at: http://www.ifc.org/ifcext/cgf.nsf

Minsky, H. (1986). Stabilizing an Unstable Economy. New Haven: CT: Yale University Press.

Mitchell, RK, Agle, RR, and Wood, DJ. (1997). Toward a theory of stakeholder identification and salience: Defining the principle of who and what counts. Academy of Management Review, 22(4): 853-886. 
Mobley, SC. (1970). The challenge of socio-economic accounting. Accounting Review. October. 45(4): 762-768.

Moonitz, M. (1961). The Basic Postulates of Accounting. Accounting Research Study No. 1. New York: AICPA.

Most, KS. (1982). Accounting theory (2nd Edition). Columbus. OH: Grid Publishing.

Mulford, CW. (2007). All isn't fair in fair-value accounting. Financial Week, April 4. Accessed on 03/07/2008, at:

http://www.cashflowanalytics.com/news.php?articleID=1507

Mumford, MJ. (1994). Edward Stamp-A Crusader for Standards. In, Twentieth Century Accounting Thinkers. (Ed). Edwards, JR. London. New York: Routledge.

Mussa, M. (2003). Remarks on achieving Monetary and Financial Stability. BIS Working Papers No. 18. pp. 24-27. Monetary Stability, Financial Stability and the Business Cycle: five views. Basel; BIS. Monetary and economic Department.

Nakov, A, and Pescatori, A. (2007). Oil and the Great Moderation. Research Paper No. WP-0735. Madrid: Banco de Espana.

Nelson, KK. (1996). Fair value accounting for commercial banks: An empirical analysis of SFAS No. 107. The Accounting Review, 71(2): 161-182.

Nelson, M, Elliott, J, and Tarpley, R. (2002). Evidence from Auditors about Auditors and Managers' and Auditors' earnings-management decisions. The Accounting Review, 77, (supplement): 175-202.

Newman, B, and Mellan, M. (1967). Accounting Theory-A CPA Review. New York. London. Sydney: John Wiley and Sons, Inc.

Newman, R1. (1989). Accounting Information for decision-makers. Cheshire. Melbourne: Langman Publishing.

Nobes, C, and Parker, R. (2004). Comparative International Accounting (Eighth Edition). Harlow: United Kingdom: Prentice-Hall Financial Times.

Nolke, A, and Perry, J. (2007). The Power of Transnational Corporate Governance: Financialisation and the IASB. Business and Politics. 9(3): 4.

O'Brien, J. (2005). Relevance and reliability of fair values: A discussion of issues raised in "Fair Value Accounting for Financial Instruments: Some Implications for Bank Regulation." Board of Governors of the Federal Reserve System. United States Federal Reserve: New York. 
OECD. (1986). Harmonization of Accounting Standards Achievements and Prospects. Paris. OECD.

Ordelheide, D. (2004). The Politics of Accounting: A Framework. In, The economics and Politics of Accounting. (Eds) Leuz, C, Pfaff, D, and A. Hopwood. Oxford: Oxford University Press.

Owen, DL, Swift, TA, and Hunt, K. (2001). Questioning the role of stakeholder engagement in social and ethical accounting, auditing, and reporting, Accounting Forum, 25(3): 264-82.

Padoa-Schioppa, T and Saccomi, F. (1994). Managing a Market-led Global financial System. In, Managing the World economy: Fifty years after Bretton Woods. (eds.) Kenen, PB. Institute for International Economics. Washington.

Parker, LD. (1982). Corporate annual reporting: a mass communication perspective. Journal of Accounting and Business Research, 12(48): 279-286.

Parker, LD. (1999). Historiography for the new millennium: adventures in accounting and management. Accounting History, 11(2): 11-42.

Paton, WA, and Littleton, AC. (1940). An Introduction to Corporate Accounting Standards. Chicago: IL: AAA.

Paton, WA. (1973). Accounting Theory. Houston: Texas. Scholars Book Company.

Peasnell, KV. (1982). The function of the conceptual framework for corporate financial reporting. Accounting and Business Research, 12(48): 243-256.

Penman, S. (2006). Financial Reporting Quality: Is fair value a Plus or a Minus? Columbia University Graduate School of Business. Paper prepared for the Better Markets Conference. December 18-19. Institute of Chartered Accountants of England and Wales (ICAEW). Accessed on 04/07/2008, at:

http://www.icaew.co.uk/index.cfm

Performance Reporting Group. (2002). Performance Reporting for GovernmentAbout PRG. Accessed 02/05/2008 at, http://wwwseagov.org/aboutpmg/history/shtml

Petroni, K, and Wahlen, JM. (1995). Fair Values of equity and debt securities and share prices of property liability insurance companies. Journal of Risk and Insurance. 62(4): 719-737.

Plantin, G, Sapra, H, and Shin, HS. (1997). Marking-to-Market: Panacea or Pandora's Box? Accessed on 28/08/2008, at:

http://ssrn.co/abstract $=1186362$ 
Pratt, MC. (2002). The Regulatory Framework of Accounting. Accessed 24/04/2008 at, http://www.staff.ucsm.ac.uk/mpratt/The\%20Regulatory\%20Framework\%20of\%A ccounting.ppt

PriceWaterhouseCoopers. (2008). Point of View: Fair Value Accounting: PriceWaterhouseCoopers (US). April, 2008. Accessed on 04/07/2008, at: http://www.pwc.com/extweb/pwcpublications.nsf

Ramana, K, and Watts, R. (2007). Evidence of the Effects of Unverifiable Fair Value Accounting- HBS Working Knowledge. September, 17. Accessed on 04/07/2008, at:

http://www.hbswk.hbs.edu/item/5767.htm

Rappeport, A, Leone, M. (2007). CFO.com. SEC Used Budget to Strong-arm FASB.

http://www.cfo.com/article.cfm/8959118/1/C_2984313

Ratliff, PA. (2005). Reporting employee stock option expenses: is the debate over? The CPA Journal. 75(11): 38-43. New York: NY: New York Society of CPAs.

Rayman, RA. (2006). Accounting Standards True or False. London. New York: Routledge, Taylor, and Francis Group.

Renman, E. (1968). Strategic Management. New York, NY: John Wiley and Sons.

Riahi-Belkaoui. (1995). The Cultural Shaping of Accounting. Westport, CT. London: Quorum Books.

Riahi-Belkaoui, A. (2002). International Accounting and Economic Development. Westport, Connecticut. London.: Quorum Books.

Richardson, AJ. (1987). Accounting as a legitimating institution. Accounting, Organizations and Society, 12(4): 341-355.

Roberts, RW, and Mahoney, L. (2004). Stakeholder conceptions of the corporation: their meaning and influence in accounting research. Business Ethics Quarterly. 14(3): 399-431.

Roberts, C, Weetman, P, and Gordon, P. (2005). International Financial Reporting (3rd Edition). London: Prentice-Hall.

Ronen, J. (2008). To fair value or not to fair value: a broader perspective. Abacus, 44(2): 181-208. 
Rutteman. (1989). International Pressures for the Harmonization of Accounting. In, International Pressures for Accounting Change. AG Hopwood (Ed.). Hemel Hampstead. Prentice-Hall Publishing (International Inc.).

Ryan, RJ. (1980). Scientific Method in Topics in Management Accounting. (Eds). Arnold, J, Carsberg, R, and Scarpens, R. Oxford: Philip Allen Publishers.

Ryan, SC. (2008). Accounting in and for the Subprime Crisis. New York: NY: Stern Business School. New York University.

Salvary, SC. (1979). Tracing the Development of a Conceptual Framework of Accounting. A Western European and Northern American Linkage: A Partial Examination. Working Paper No. 40 (Aug). The Academy of Accounting Historians. Virginia Commonwealth University.

Samuels, J, Rickwood, C, and Piper, A. (1989). Advanced Financial Accounting. Maidenhead, England: McGraw-Hill Book Company (UK) Ltd.

Schipper, K, and Vincent, L. (2003). Earnings quality. Accounting Horizons, 3(4): 91-102.

Schon, DA. (1971). Beyond the Stable State. London: Temple Smith.

Schroeder, RG, Clark, M and McCullers, LD. (1991). Source and Methodology of Accounting Principles. Introduction. In, Accounting Theory Text and Readings. New York: NY: John Wiley \& Sons, Inc.

Schroeder, R, and Schauer, DA. (2008). SFAS-R: the controversy and its economic consequences. Managerial Auditing Journal, 23(3): 295-306.

Schuetze, WP. (2004). Mark-to-Market Accounting. 'True North' in Financial Reporting. (Ed.) WP. Wolnizer. London. New York: Routledge, Taylor and Francis Group.

Schuetze, WP. (2006). In defense of fair value. The CPA Journal. New York: New York Society of Certified Public Accountants.

Schwartz, AJ. (2008). Anna Schwartz blames the Fed for sub-prime crisis. Telegraph. (19, January). Accessed on 12/2/2008 at: http://www.telegraph.co.uk/money/main.jhtmlxml=/money/2008/01/13/ccschwart z113.xml

Serafeim, G. (2007). Relevance vs Reliability. Evidence from Embedded Value Accounting. http://ssrn.com/abstracts-1088010

Shillinglaw, G. (1979). Cost Accounting Principles for External Reporting-A Conceptual Framework. In, Essays in honour of William A. Paton Pioneer Accounting Theorist. Ann Arbor, Michigan: University of Michigan Press. 
Shortridge, R, Schroeder, A, and Wagoner, E. (2006). Analyzing the Changing Environment. New York: NYSSCPA. (CPA Journal).

Simpkins, K. (2006). The IASB/FASB Conceptual Framework Projects Preliminary Views on an Improved Conceptual Framework for Financial Reporting: Application in Not For Profit Entities in the Private and Public Sectors. Working Paper to Australia, Canada, New Zealand and UK Accounting Standards' Boards.

Skinner, DJ. (1999). How well does net income measure firm performance: a discussion of two studies. Journal of Accounting and Economics, 26(1-3): 105111.

Sloan, RG. (2001). Evaluating the reliability of current value estimates. Journal of Accounting and Finance, 26(1):193-200.

Smith, M. (1996). Qualitative Characteristics in Accounting Disclosures: a desirability trade-off. Managerial Auditing Journal, 11(3): 11-16.

Smnett, WM, and Grasino, C. (2005). What do users of private company financial statements want? Financial Executive Research Foundation. Accessed 03/06/2008 at, http://www.nfib.com/object/10-29293.html

Solomons, D. (1979). The Politicization of Accounting in, Essays in Honour of William A. Paton Pioneer Accounting Theorist. (Eds) SA, Zeff, Demski, J, and Dopuch, N. Ann Arbor, Michigan: University of Michigan Press.

Solomons, D. (1989). Guidelines for Financial Reporting Standards. London: ICAEW.

Sprouse, RT. (1978). The importance of earnings in the Conceptual Framework. Journal of Accountancy. 78(1): 64-71.

Sprouse, RT, and Moonitz, M. (1962). A Tentative Set of Broad Accounting Principles for Business Enterprises. Accounting Research, No. 3, New York: AICPA.

Squires, SE, Smith, CJ, McDougall, L, and Yeack, WR. (2003). Inside Arthur Andersen, shifting Values, Unexpected consequences. New Jersey: Financial Times Prentice-Hall.

Stamp, E. (1970). Accounting Principles and the City Code-The case for Reform. Altrinchain: Butterworths and Co., Ltd.

Stamp, E. (1980). Corporate Reporting: Its Future Evolution. Toronto: Canadian Institute of Chartered Accountants. 
Stamp, E. (1984). Accounting History and the Development of a Profession. (Ed.) RP. Brief. New York. London: Garland Publishing Company.

Stanley, CH. (1968). Objectivity in Accounting. Ann Arbor, Michigan: Bureau of Business Research, University of Michigan.

Stanton, PA. (1997). Users' rights to publicized accounting information: nature, justification and implications. Accounting, Auditing and Accountability. 10(5), 684-701.

Staubus, GJ. (1959). The residual equity point of view in accounting. Accounting Review, vol. XXXIV (1): 3-13.

Staubus, GJ. (1961). A Theory of Accounting to Investors. Berkeley. Los Angeles: University of California Press.

Staubus, GJ. (1999). The Decision-Usefulness Theory of Accounting. A Limited History. New York; London: Garland Publishing Company.

Staunton, J. (2003). A Statement of Accounting Concepts for level I of the Conceptual framework. Abacus, 39(3).

Steadman, ME, and Green, RF. (1997). An extension of stakeholder theory research: developing surrogates for net original capital. Managerial Auditing Journal, 12(3): 142-147.

Sterling, RR. (1970). On theory construction and verification. Accounting Review, (3): 444-457.

Sterling, RR. (1979). Towards a Science of Accounting. Houston, Texas: Scholars Book Company.

Sterling, RR. (2003). Guest Editorial. A Patch on GAAP. Abacus, 39(3): i-vi.

Stigler, GJ. (1971). The theory of economic regulation. Bell Journal of Economics and Management Science 2(1): 3-21.

Stiglitz, J. (2003). The Roaring Nineties: A New History of the World's Most Prosperous Decade. New York: Penguin.

Stittle, J. (2003). Annual Reports: Delivering your Corporate Message to Stakeholders. Hampshire: Gower Publishing Company.

Stock, JH, and Watson, MW. (2003). Has the business cycle changed? Evidence and expectations. Prepared for the Federal Reserve Bank of Kansas City Symposium, Monetary Policy and Uncertainty". Jackson Hole: Wyoming. August 28-30. 
Stolowy, H, and Lebas, MJ. (2006). Financial Accounting and Reporting. A Global Perspective (2nd Edition). London: Thomson.

Storey, RK. (2007). The Framework of Financial Accounting Concepts and Standards. Chapter 2 (1-120). In, Accountants' Handbook. (eds.) Carmichael, DR, Whittington, OR, and Graham, L. Hoboken: NJ: John Wiley \& Sons, Ltd.

Storey, RK, and Storey, S. (1998). Special Report: The Framework of Financial Accounting Concepts and Standards. Norwalk, CT: FASB.

Street, DL. (2006). The G4's role in the evolution of the international accounting standard setting process and partnership with the IASB. Journal of International Accounting, Auditing, and Taxation. 15(1): 109-126.

Street, DL. (2007). The US Role in the Globalization of Accounting Standards. In, Globalization of Accounting Standards. (Eds.) Godfrey, JM, and Chalmers, K. Cheltenham. Northampton: MA: Edward Elgar Publishing, Inc.

Summers, PM. (2005). What Caused the Great Moderation? Some Cross-Country Evidence. Accessed on 07/08/2008, at: http://www.kansascityfed.org/Publicat/PDF/3q05summ.pdf

Sunder, S. (2007). Uniform Financial Reporting Standards. Reconsidering Topdown Push. (April). CPA Journal Online. Accessed 26/05/2008 at, http://www.nysscpa.org/cpajournal/2007/407/perspectives/p6.htm

Sunder, GL. (2007). A Note on the Information Perspective and the Conceptual Framework. In, Essays in Accounting Theory in Honour of Joel S Demski. (Eds) Antle, R, Gjesdal, F, and PJ Liang. Springer.

Sutcliffe, P. (2007). IFAC IPSASB Meeting, Accra, Ghana. Accessed 25/05/2008 at, http://www.ifac.org/PublicSector/Meeting-FileDL.php?FID=2931

Tan, P. (2007). Singapore Management University. Accessed 12/12/2007 at, http://www.smu.sg/research/Knowledgehub/jan2007/smukh_00.asp

Tinker, AM. (1980). Towards a political economy of accounting: an empirical illustration of the Cambridge controversies. Accounting Organizations and Society, 5(1): 147-160.

Tinker, A, Merino, B, and Neimark, M. (1982). The normative origins of positive theories: ideology and accounting thought. Accounting, Organizations and Society, 7(2): 167-200.

Toppe-Shortridge, R, A. Schroeder, and E, Wagoner. (2006). Fair value accounting. Analysing the changing environment. The CPA Journal. http://www.nysscpa.org/cpajournal/2006/406/essentials/p37.html 
Tricker, RI. (1996). Pocket Director. London: The Economist Books.

Trueblood Report, (Trueblood, R, 1973). The Trueblood Committee Report. Objectives of Financial Statements. Report of the study group on the objectives of financial statements. AICPA: New York:NY.

Turley, S. (2008). Discussion of Ronen. Abacus. 44(2): 209-216.

Tweedie, D. (2004). New World Order. CFO.com. CFO Europe Magazine (March). Accessed on 01/12/2007, at: http://www.cfo.com/article.cfm/3011965/1/c-3046607?f=related

Tweedie, D, and Whittington, G. (1987). The End of the Current Cost Revolution. In, The Development of Accounting in an International Context. (Eds.) Nobes, $\mathrm{CW}$, and Cooke, T. London: Routledge.

Van Zijl, T, and G. Whittington. (2006). Deprival value and fair value: a reinterpretation and reconciliation. Accounting and Business Research, 36(2): 121-130.

Vatter, WJ. (1964). An Income Approach to Accounting Theory. In, Davidson, et al (Ed). Origins of Fund Theory. Englewood Cliffs, NJ:Prentice-Hall, p. 6-20.

Venkatachalam, M. (1996). Value-relevance of banks' derivative disclosures. Journal of Accounting and Economics, 22(1-3): 327-353.

Vergoosen, RGA. (1994). Accounting Changes and The Use of Financial Statements. Narden: Verhagen b.v.

Veron, N, Atret, M, and Galichon, A. (2006). Smoke and Mirrors, Inc. Accounting for Capitalism. Ithaca: Ohio: Cornell University Press.

Volcker, P. (2001). Statement of Paul. A. Volcker before the Capital Markets Insurance and government sponsored Enterprises Subcommittee of the House of Represenattives. Washington, DC. Accessed on 13/09/2008, at: http://www.iasplus.com/resource/volcker.pdf

Wahlen, JM, Boatsman, JR, and Herz, RH. (2000). American Accounting Association's Financial Accounting Standards Committee: Response to the FASB Preliminary Views: Reporting Financial Instruments and Certain Related Assets and Liabilities at Fair Value.

Walker, RG. (2003). Objectives of Financial Reporting. Abacus, 39(3), 340-355.

Walker, SP. (2004). The genesis of professional organization in English accountancy. Accounting, Organizations and Society, 29(2): 127-156. 
Wang, Y, Buijink, W, Eken, R. (2006). The value relevance of dirty surplus accounting flows in the Netherlands. International Journal of Accounting. 41(4): $387-405$.

Watkins, AL. (2007). An Accountability View of Accounting. Guidance for Accounting Practice. The CPA Journal. New York: New York Society of Certified Public Accountants.

Watts, RL. (1977). Corporate Financial Statements, A Product of the Market and Political Processes. Australian Journal of Management, 2(1): 53-78.

Watts, RL, and JL, Zimmerman. (1979). The demand for and supply of accounting theories: the market for excuses. The Accounting Review, LIV(2): 273305.

Watts, RL. (2003). Conservatism in accounting part 1: explanations and implications. Accounting Horizons, 17(3): 207-221.

Watts, RL, and JL, Zimmerman. (1979). The demand for and supply of accounting theories: the market for excuses. The Accounting Review, LIV(2) 273305.

Watts, RL, and Zimmerman, JL. (1986). Positive Accounting theory. Englewood Cliffs, NJ: Prentice-Hall Incorporated.

Watts, RL, and Zimmerman, JL. (1990). Positive Accounting Theory: A Ten Year Perspective. The Accounting Review, 65(1), (January): 131-156.

Weinstein, GW. (1987). The Bottom Line Inside Accounting Today. New York. Scarborough, Ontario: NAL Books.

Wells, M. (2003). Forum: The accounting Conceptual Framework-introduction. Abacus. 39(3).

Wheat Report. (1972). Establishing Financial Accounting Standards. New York: NY: AICPA.

White, GI, and McNally, RT. (2006). Fair Value Accounting. The Certified Financial Analysts Institute. October, 31. Accessed on 03/ 07/2008, at: http://www.cfainstitute.org/centre/topics/comment/2006/pdf/fasb_fair_value_final .pdf

Whittington, G. (1985). Financial accounting theory: an overview. British Accounting Review, 85. (2): 4-41.

Whittington, G. (1987). Positive Accounting: a review article. Accounting and Business Research, 17(68), 327-336. 
Whittington, G. (2007a). Profitability, Accounting Theory, and Methodology. London. New York: Routledge.

Whittington, G. (2007b). Fair Value and the FASB/IASB Conceptual Framework Project: An Alternative View. Accessed on 23/08/2008, at: http://www.eiasm.org/User/Files/Fair_Value_and_the_IASB_Septclean.doc

Whittington, G. (2008). Fair Value and the IASB/FASB Conceptual Framework Project: an alternative view. Abacus. 44(2), May: 139-168.

Whittred, G, Zimmer, I, Taylor, S, and Wells, P. (2004). Financial Accounting Incentive Effects and Economic Consequences (6th Edition). Southbank: Thomson.

Williams, PF. (1989). The logic of Positive Accounting Research. Accounting, Organizations and Society, 14(5-6): 455-468.

Williams, P. (2007). Stewardship relaunched. Accessed on 06/08/2008, at: http://www.accountancyage.com/financialdirector/analysis/2193950/stewardship_relaunched

Willis, JL. (2003). Implications of Structural changes in the US Economy for Pricing Behavior and Inflation Dynamics. Federal Reserve Bank of Kansas. Economic Review. First Quarter: 5-27.

Wilton, RL, and Tabb, BJ. (1978). An Investigation into private shareholder usage of financial statements in New Zealand. Accounting Education, (May): 93-101.

Wok, HI, Francis, JR, and MG. Tearney. (1992). Accounting Theory A Conceptual and Institutional Approach (3rd Edition). Cincinati: Ohio: SouthWestern Publishing Company.

Wolk, HI, Dodd, JL, and Rozycki, JJ. (2008). Accounting theory. Conceptual Issues in a Political and Economic Environment (7th Edition). Thousand Oaks, CA: Sage Publications.

Wood, J. (2004). CFO Europe Magazine. Accounting-A fairwell to history. (29 November). Accessed 12/12/2007 at, http://www.cfo.com/article.cfm/3258520/1/C_2984368?f=search?

Woods, M. (2004). Fair Value Accounting. Accessed on 12/06/2008, at: http://www.accaglobal.com/members/publications/accounting_business/archive_b y_topic/i_a_s/2004/2253115

Wray, LR. (1992). Minsky's Financial Instability Hypothesis and the Endogeneity of Money. In, Financial Conditions and Macro-economic Performance. ME Sharpe, Inc. Armonk and London. p 
Wray, LR. (2007). Lessons from the Subprime Meltdown. Economic Working Paper Article wp_522. The Levy Economics Institute.

Yamaguchi, Y. (2003). Asset price "Bubbles" and Monetary Policy. BIS Papers No. 18. pp. 28-30. Monetary Stability, Financial Stability and the Business Cycle: five views. Basel. BIS. Monetary and Economic Policy Department.

Young, JJ. (2006). Making up users. Accounting, Organizations and Society, 31(6): 579-600.

Zeff, SA. (1971). Forging Accounting principles in Five Countries. Champargi, IL: Stripes Publishing Co.

Zeff, SA. (1974). Comments on Accounting Principles-How they developed. In, Institutional Issues in Public Accounting. (Ed.) Sterling, R. New York: NY: Scholars Books.

Zeff, SA. (1979). Chronology. Significant Developments in the Establishment of Accounting Principles in the United States 1926-1978. Pp. 208-221. In, The Evolution of Corporate Financial Reporting. (Eds.) TA. Lee and RH Parker. Melborne: Thomas Nelson and Sons, Ltd.

Zeff, SA. (1982). Introduction. In, The accounting principles and Postulates Controversy of the 1960s. (Ed. ) Brief, RP. London: Garland Publishing Co.

Zeff, SA. (1991). The Rise of Economic Consequences. In, Accounting Theory Text and Readings. (Eds.) Schroeder, RG, Clark, M, and McCullers, LD. New York: NY: John Wiley \& Sons, Inc.

Zeff, SA. (2002). "Political" lobbying on proposed standards: A challenge to the IASB. Accounting Horizons, 16(1): 43-54. 


\section{Appendix One: A brief chronology of major developments in conceptual frameworks}

1929 Economist Canning proposes the 'True income approach' to accounting, advancing an economic income concept of profit. This proposal was informed by the work of Professor Irving Fisher and is perhaps the earliest precursor to fair value as it is presently conceived.

1933 Securities Act, Administered by the Federal trade Commission (FTC) in response to the general market breakdown beginning with the stockmarket crash in 1929.

1934 Securities Exchange Act: establishes the Securities Exchange Commission (SEC) as the United States Securities Markets' Regulator. This body was empowered with ultimate responsibility for control over the quality of financial reporting.

1936 The American Accounting Association (AAA) produces A Tentative Statement of Accounting Principles Underlying Corporate Financial Statements. This statement used a deductive approach to the development of accounting principles.

1940 WA Paton and WC Littleton produce a monograph elaborating on the AAA's 1936 statement.

1949 AIA Committee on Accounting Procedures (CAP) proposes a comprehensive statement of generally accepted accounting practices (GAAP) but later abandons the project as unfeasible.

1955 RJ Chambers "Blueprint for a Theory of Accounting may have been the origin of decision-usefulness. Subsequent to this Chambers expounded his theory of optimal accounting valuation, Continuously Contemporary Accounting 
(COCOA), which advanced the case for presenting accounting reports based on exit values.

1956-1960 A succession of proposals is made to establish the postulates underlying accounting. In 1958 the CAP is superceded by the Accounting Principles Board (APB). In 1958 a report to the council of the AICPA argued that the basic assumptions of accounting must be drawn from the political and economic environment. This view significantly informs the proposal herein.

1961 Accounting Research Study No. 1, The Basic Postulates of Accounting. AICPA. This study, authored by Maurice Moonitz, proposed extending the use of current values in accounting. It also established (asserted) the need for a coherent theory of accounting.

1962 Accounting research Study No. 3, A Tentative Set of Broad Accounting principles for Business Enterprises, co-authored by Moonitz and RT Sprouse, builds on the 1961 study. This study detailed elements in the general environment that it held would have to be accommodated by a general theory of accounting. These included the private ownership of most productive resources, the primacy of the market as a means of distributing goods and services, and the existence of free labour.

1966 AAA monograph A Statement of Basic Accounting Theory is published. (ASOBAT).

1970 APB issues statement No. 4:

'Basic Concepts and Accounting Principles Underlying Financial Statements of Business Enterprises.”

This was the culmination of a five year study. 
1971 American Institute of Certified Public Accountants (AICPA) commissioned two major studies. These were chaired respectively by Francis Wheat and Robert Trueblood.

1972 The Wheat Commission recommended the establishment of the Financial Accounting Standards Board (FASB) under the auspices of the Financial Accounting Foundation (FAF), with technical guidance by FASAC (Financial Accounting Standards Advisory Council). The proposal included a recommendation for seven fulltime staff and a budget of $\$ 2.5-\$ 3$ million for the FASB. The proposed FASB was a response to the perceived inadequacy of the APB, particularly in relation to its failure to develop a conceptual framework. Wheat also identified an underlying need for an exposition of assumptions as accounting theory postulates.

1973 The Trueblood Commission Report issues Objectives of Financial Statements. The commission identified a preference for forward-looking financial accounting information. This clearly favoured decision-usefulness over stewardship. Notably, the Commission had in contemplation a diverse range of users. It also emphasized the economic substance of events and proposed a narrower focus on investors and creditors as key users. This possibly established the basis for the 'primary user' device in standards. Further, the Trueblood Report tacitly softens the qualitative characteristic, reliability, by allowing that information influenced by judgment naturally has some bias. Trueblood takes the view that the concern for accounting reports is that there is no systematic bias, favouring any group over any other.

1973 AICPA declares that the FASB has replaced the APB, ushering the era of professional standard setting. SEC (ASR No. 150) declares that the standards and practices of the FASB have substantial authoritative support. The APB rejected the 1961 and 1962 Moonitz and Sprouse and Moonitz studies because they were too far from GAAP. A primary motivation behind the establishment of the APB 
was that GAAP was widely perceived as unsatisfactory. The timorous nature of the APB is centrally implicated in its demise.

1973 The FASB commences a Conceptual framework project. A Report by a study group of the AICPA publishes Objectives of Financial Statements, highlighting the importance of the decision-usefulness of GPFR.

1974-1985 The FASB Conceptual Framework Project. In 1978 the Seaview Symposium (FASB) re-affirms the primacy of objectivity (reliability) over predictive value (relevance). It was felt unreliable information should be presented outside of financial statements.

1975 The Corporate Report is produced in the UK (ICAEW) as a response to the Trueblood Report. It identifies GPFR users as those with a reasonable right to information (Macve, p. 66), but indicates that although there are many users, they have similar information needs. This anticipates the view articulated in subsequent standards that information satisfying equity investors will meet the needs of other users. The public's right to information is emphasized. The report identifies numerous qualitative characteristics, some of which it allows, may be mutually exclusive.

Mid 1970s-early 1980s Historical cost weathers an inflation 'storm', leading to growing calls and research into a departure from the traditional accounting valuation basis. Globally, inflation recedes from about 1983, and the pressure for inflation-adjusted accounting declines. This heralded a growing interest in current cost accounting, although the default status of Historical cost remained intact.

1976 The FASB issues a discussion memorandum as a response to the Trueblood Report.

Conceptual framework for financial Accounting and reporting

1977 AAA issues Statement of Theory and Theory Acceptance 
This explicitly identified the importance of present and potential investors as users of financial accounting information. It was seen as a significant step towards the development of a conceptual framework.

1978 SFAC 1, GPFR targets, "investors and creditors and other users", by inference from the explicit reference to investors and creditors, prioritizing them. [para. 34. FASB. 1978]. However, it does identify 34 user groups. Further, the statement refers to financial reporting's aim to aid, "rational investment, credit and other similar decisions". Specifically, SFAC 1 targeted external uses without the power to specify the information required. It is unclear what 'similar' decision the Board has in contemplation. The inference is available here that the FASB is dissembling here and has no other decisions in contemplation. If we were to assume 'labour supply decisions' or 'goods/services supply decisions', as examples of similar decisions, it remains doubtful that the cost of supplying such greater specification of 'similar decisions' would have run foul of the pervasive cost-benefit constraint.

1978-84 FASB produce a Conceptual Framework, SFACs 1-5. Wanting to avoid the appearance of an overreliance on pure theory, the concepts statements drew on many traditions, including: stewardship, capital maintenance, true and fair, and prudence.

1980 Stamp Report (who earlier co-authored the British "Corporate Report") was the Canadian (CICA) response to the Trueblood Report. It reiterated the view of diverse GPFR users, including: shareholders, creditors, analysts, employees, nonexecutive directors, customers, suppliers, unions, industry groups, government, public, regulators, other companies and standards' setters.

1980 SFAC-2, Qualitative Characteristics. The FASB Conceptual Framework is to serve the public interest by providing a structure to financial information that enables the efficient allocation of resources. This development is important in that 
it relates the broadest possible stakeholder perspective to the narrowest possible view of 'users'-the investor.

1980 AAA (American Accounting Association) advance the view of verifiable, perhaps the most intransigent aspect of reliability, as values that are able to be reproduced by experts working independently of each other. This tentatively offers the basis for a departure from the transactions basis to reliability of historical cost.

1988 MacMonnies Report for the Institute of Chartered Accountants of Scotland (ICAS), Making Corporate Reports Valuable, accents decision-usefulness of prospective information.

Late 1980s Fair value gained progressive support in the wake of the Savings and Loan crisis in the United States, as the deficiencies of historic cost were exposed by this event as companies 'cherry picked' assets for realization to support a positive view of their financial position and performance.

1989 Solomons Report prioritises relevance. Minimum levels of the two primary characteristics are required for other to exist, that is, they are positive correlate.

1988-9 The International Accounting Standards Council (IASC) Conceptual Framework.

1989 Framework for the Preparation and Presentation of Financial Statements. Focus is decision-useful information. It describes various users, who are typically investors, suggesting support for fair value measurement.

1990s FASB pushed for full fair value standards, including SFAS 142 'unverifiable fair value'. 
1994 AICPA Jenkins Commission report delivers a focus on efficient capital markets, accenting investors and creditors, prospective information and decisionusefulness. This report continued trends in the direction of financial reporting prescription.

1998 Draft IAS-39 the inclusion of a full fair value option for financial instruments.

2000 IOSCO recommends members allow member countries to use IASs. The IASB JWG (Joint Working Group) proposes all financial instruments should be valued at fair value regardless of the purpose they are held for.

2001 The IASB is established, replacing the IASC. It argues that information that will meet the needs of investors will meet other users' needs. (Framework F-9).

2002 IASB/FASB Norwalk Agreement commits the two key accounting standards' setters to the development of compatible standards.

2005 By this time standards requiring fair value included (IASB): IASs 11, 16, 17, 18, 18, 20, 26, 33, 36, 38, 39, 40, 41 and IFRSs 1,2,3,5.

Standards that required fair value by reference to another standard:

IAS 2, 21, 27, 28, 31, 32. IFRS 4, 7.

IASB proposed replacing reliability with faithful representation.

2005-2008 An increasing emphasis on the priority of the investor, on relevance, and on fair value as a logical derivative of earlier trends in conceptual frameworks. It is notable that one area of significant divergence between the IASB and FASB is in the more singular user definition preferred by the IASB (that is, the investor).

2006 The FASB and IASB formally agree to work together on the development of accounting standards. IASB Qualitative Characteristics include relevance, faithful 
representation, and comparability. Notably, verifiability is relegated to secondary status as an enhancing characteristic and comparability tends to support fair value due to the heterogeneous transaction dates of historical cost accounting.

2006-2008 Continuing work on operation of fair value, i.e. What it applies to, the 3-level hierarchy of valuation options, which market to reference and whether fair values should be based on entry/exit prices.

2007 SFAC- 7; SFAS 157 Establishes a common definition of fair value.

IASB conceptual framework discussion related to users is concerned with whether consideration should be extended beyond current investors to include potential investors.

2008 The range of financial instruments measured at fair value, including those in less liquid markets requiring model-based valuations, is expanded.

2008 The FASB are seeking an improved objective of financial reporting. ED proposes information useful to present and potential investors, lenders and other creditors. IASB have moved further, identifying the investor as GPFR user. This, importantly, eliminates a significant source of dissemblage by banks, as they have (inferentially) used their status as creditors to argue to a position that supports their interests as issuers.

Verifiability is separated from faithful representation and identified as an enhancing characteristic rather than a primary characteristic. This continues a trend with the earlier introduction of 'faithful representation' which added 'completeness' as an element of reliability, (inferentially) diluting the 'verifiability' element of reliability which is strongly related to the historical cost, transaction-based conception of objectivity.

Sources: Zeff, SA. (1979). Chronology. Significant Developments in the Establishment of Accounting Principles in the US 1926-78 in TA. Lee and RH. Parker. The Evolution of Corporate Financial reporting. Melbourne: Thomas Nelson and Sons, Ltd; Samuels, Rickwood and Piper, 1989; IASB, 2008; FASB, 2008; Landsman, 2006; Deloitte, 2008; PriceWaterhouse Coopers, 2008; Smith, 1996; Bank for International Settlements, 2008; Ramana and Watts, 2008; Higson, 2003; AICPA, 2008; CFA 2001; Miller and Redding, 1988; Schroeder, Clark and McCullers, 1991; Henderson, Pierson and Harris, 2004; Chorafas, 2006; White and McNally, 2006; Whittington, 2007; Macve; IASB, 2006; FASB, 2005. 


\section{Appendix Two}

\section{Developments in Accounting Theory, Regulation and Measurement}

\begin{tabular}{|c|c|c|}
\hline Broad trends in Accounting & Trends in user definition & Measurement Trends \\
\hline Theory & & \\
\hline $\begin{array}{l}\text { Until 1956: Accounting theory } \\
\text { was }\end{array}$ & $\begin{array}{l}\text { Pre-1920s: } \\
\text { shareholders/creditors }\end{array}$ & \\
\hline $\begin{array}{l}\text { essentially descriptive of } \\
\text { practice }\end{array}$ & $\begin{array}{l}\text { 1920s-1960: Users extended } \\
\text { to share- } \\
\text { holders, investors, creditors \& } \\
\text { analysts }\end{array}$ & \\
\hline $\begin{array}{l}\text { 1956-1970: Prescriptive } \\
\text { theories } \\
\text { predominated, including those } \\
\text { of } R J\end{array}$ & $\begin{array}{l}\text { 1960s-1990s: User status is } \\
\text { extended }\end{array}$ & \\
\hline $\begin{array}{l}\text { Chambers, Staubus, and } \\
\text { Sterling }\end{array}$ & $\begin{array}{l}\text { to shareholders, investors, } \\
\text { creditors \& }\end{array}$ & Until the mid-1970s: \\
\hline & $\begin{array}{l}\text { employees, suppliers, } \\
\text { customers and }\end{array}$ & $\begin{array}{l}\text { Historical cost accounting } \\
\text { measurement } \\
\text { predominates, substantially } \\
\text { unchallenged. } \\
\text { changes with elevated } \\
\text { levels of inflation. Oil } \\
\text { price/supply shocks, } \\
\text { aggravated by loose } \\
\text { monetary policy created an } \\
\text { environment in which } \\
\text { traditional historic cost } \\
\text { accounting came to be } \\
\text { seen as increasingly } \\
\text { irrelevant }\end{array}$ \\
\hline Post-1970: & Governments & $\begin{array}{l}\text { threatened by elevated } \\
\text { inflation as it }\end{array}$ \\
\hline $\begin{array}{l}\text { Descriptive theories come to } \\
\text { the fore } \\
\text { again }\end{array}$ & $\begin{array}{l}\text { The rise of the malevolent } \\
\text { influence of } \\
\text { stakeholder theory, exerted } \\
\text { an influence }\end{array}$ & $\begin{array}{l}\text { is seen as increasingly } \\
\text { irrelevant } \\
\text { Proposals for general price } \\
\text { level }\end{array}$ \\
\hline Positive Accounting Theory & $\begin{array}{l}\text { progressively expanding the } \\
\text { GPFR user }\end{array}$ & $\begin{array}{l}\text { adjustment accounting } \\
\text { arise }\end{array}$ \\
\hline Agency Theory & & $\begin{array}{l}\text { By mid-1980s inflation } \\
\text { subdued }\end{array}$ \\
\hline $\begin{array}{l}\text { This is the so-called 'new } \\
\text { empiricism' }\end{array}$ & This was reflected in: & $\begin{array}{l}\text { The pressure for price-level } \\
\text { adjustment }\end{array}$ \\
\hline & 1. Trueblood Report (1973) & $\begin{array}{l}\text { subsides. Current cost } \\
\text { accounting }\end{array}$ \\
\hline $\begin{array}{l}\text { Note: In describing prevalent } \\
\text { theoretical }\end{array}$ & 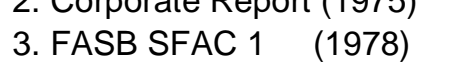 & \\
\hline $\begin{array}{l}\text { trends this is not to say they } \\
\text { were } \\
\text { total. However, we might infer } \\
\text { to an }\end{array}$ & 4. Stamp Report & $\begin{array}{l}\text { Late-1980s:residual interest } \\
\text { in current } \\
\text { cost accounting gains } \\
\text { momentum }\end{array}$ \\
\hline
\end{tabular}




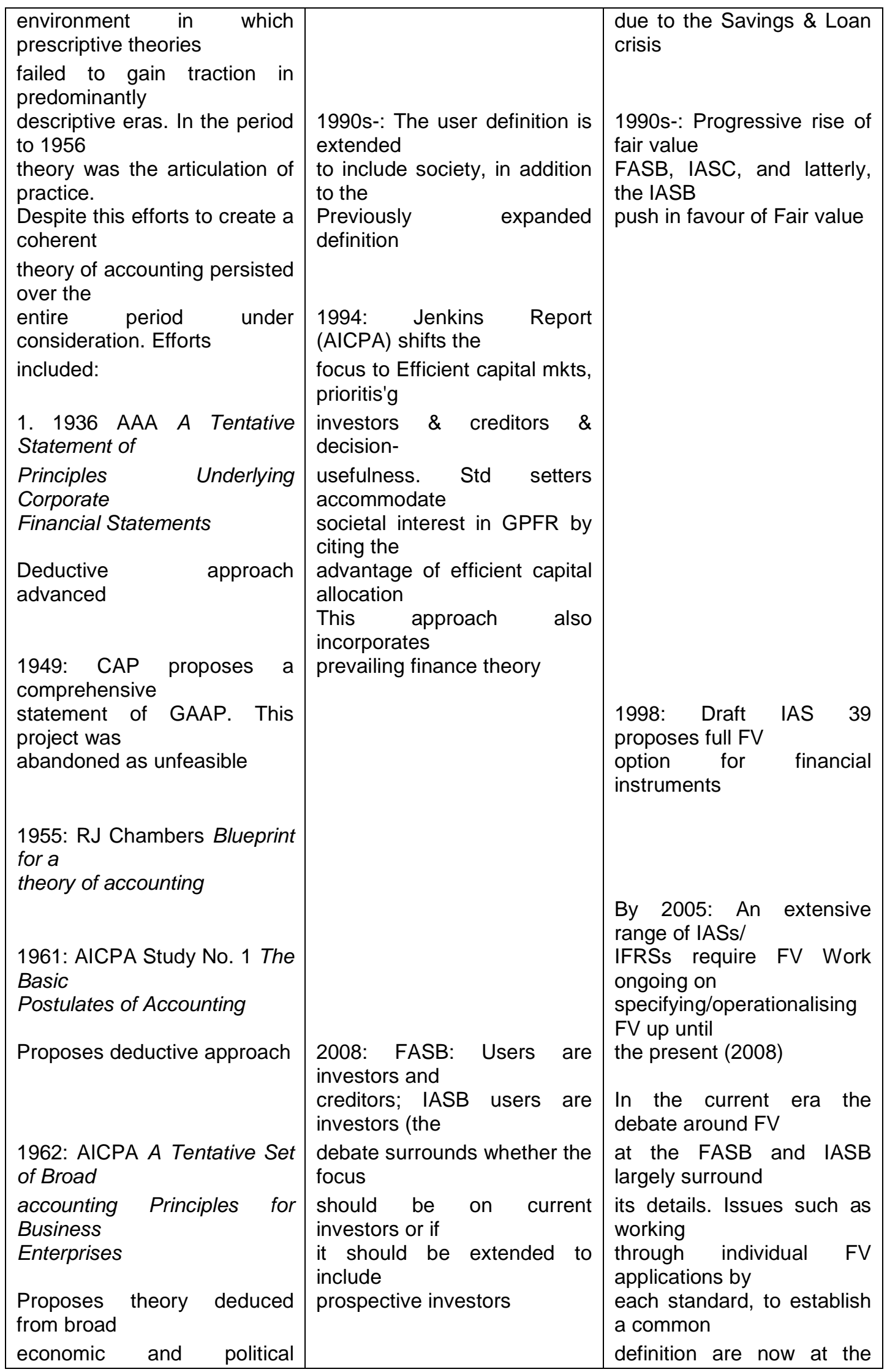


environment.

fore.

1974-85: FASB works to develop a CF

to operationalise a general theory of accounting (normative). 


\section{Appendix Three}

IAS 2 Inventories

IAS 3 Consolidated Financial Instruments

IAS 6 Accounting Responses to Changes in Prices

IAS 11 Construction Contracts

IAS 12 Income Taxes

IAS 15 Information Reflecting the Effects of Changing Prices

IAS 16 Property, Plant and Equipment

IAS 18 Revenue Recognition

IAS 19 Employee Benefits

IAS 20 Accounting for Government Grants and Disclosure of Government assistance

IAS 21 The Effects of Changes in foreign Exchange Rates

IAS 22 Accounting for Business Combinations

IAS 25 Accounting for Investments

IAS 26 Accounting and Reporting by Retirement Benefit Plans

IAS 27 Consolidated and Separate Financial Statements

IAS 28 Investments in Associates

IAS 31 Financial Reporting of Interests in Joint Ventures

IAS 32 Financial instruments: Disclosure and Presentation

IAS 36 Impairment of Assets

IAS 38 Intangible Assets

IAS 39 Financial Instruments: Recognition and Measurement

IAS 40 Investment Property

IAS 41 Agriculture

IFRS 1 First-Time Adoption of IFRS

IFRS 2 Share-based Payment

IFRS 3 Business Combinations

IFRS 4 Insurance Contracts

IFRS 5 Non-current Assets Held for Sale and Discontinued Operations

IFRS 7 Financial Instruments: Disclosure 